\title{
Spectral line survey of the ultracompact HII region Monoceros R2^
}

\author{
D. Ginard ${ }^{1}$, M. González-García ${ }^{2}$, A. Fuente ${ }^{1}$, J. Cernicharo ${ }^{3}$, T. Alonso-Albi ${ }^{1}$, P. Pilleri ${ }^{1,3}$, M. Gerin ${ }^{4}$, \\ S. García-Burillo ${ }^{1}$, V. Ossenkopf ${ }^{5,6}$, J. R. Rizzo ${ }^{3}$, C. Kramer ${ }^{2}$, J. R. Goicoechea ${ }^{3}$, J. Pety ${ }^{7}$, O. Berné ${ }^{8}$, and C. Joblin ${ }^{9,10}$ \\ 1 Observatorio Astronómico Nacional (OAN), Apdo 112, 28800 Alcalá de Henares, Madrid, Spain \\ e-mail: davidginard@gmail.com \\ 2 Instituto de Radio Astronomía Milimétrica (IRAM), Avenida Divina Pastora 7, Local 20, 18012 Granada, Spain \\ 3 Centro de Astrobiología, CSIC-INTA, Crta M-108, km. 4, 28850 Torrejón de Ardoz, Spain \\ ${ }^{4}$ LERMA, Observatoire de Paris, 61 Av. de l'Observatoire, 75014 Paris, France \\ 5 I. Physikalisches Institut der Universität zu Köln, Zülpicher Straße 77, 50937 Köln, Germany \\ ${ }^{6}$ SRON Netherlands Institute for Space Research, PO Box 800, 9700 AV Groningen, The Netherlands \\ 7 Institut de Radioastronomie Millimétrique, 300 rue de la Piscine, 38406 Saint Martin d'Hères, France \\ ${ }^{8}$ Leiden Observatory, Leiden University, PO Box 9513, 2300 RA Leiden, The Netherlands \\ 9 Université de Toulouse, UPS-OMP, IRAP, Toulouse, France \\ 10 CNRS, IRAP, 9 Av. Colonel Roche, BP 44346, 31028 Toulouse Cedex 4, France
}

Received 27 October 2011 / Accepted 15 March 2012

\section{ABSTRACT}

Context. Ultracompact (UC) HII regions constitute one of the earliest phases in the formation of a massive star and are characterized by extreme physical conditions $\left(G_{0}>10^{5}\right.$ Habing field and $\left.n>10^{6} \mathrm{~cm}^{-3}\right)$. The UC HII Mon R2 is the closest example and an excellent target to study the chemistry in these complex regions.

Aims. Our goal is to investigate the chemistry of the molecular gas around UC HII Mon R2 and the variations caused by the different local physical conditions.

Methods. We carried out $3 \mathrm{~mm}$ and $1 \mathrm{~mm}$ spectral surveys using the IRAM 30-m telescope towards three positions that represent different physical environments in Mon R2: (i) the ionization front (IF) at $\left(0^{\prime \prime}, 0^{\prime \prime}\right)$, and two peaks in the molecular cloud; (ii) molecular Peak 1 (hereafter MP1) at the offset $\left(+15^{\prime \prime},-15^{\prime \prime}\right)$; and (iii) molecular Peak 2 (hereafter MP2) at the farther offset $\left(0^{\prime \prime}, 40^{\prime \prime}\right)$. In addition, we carried out extensive modeling to explain the chemical differences between the three observed regions.

Results. We detected more than 30 different species (including isotopologues and deuterated compounds). In particular, we detected $\mathrm{SO}^{+}$and $\mathrm{C}_{4} \mathrm{H}$ confirming that ultraviolet (UV) radiation plays an important role in the molecular chemistry of this region. In agreement with this interpretation, we detected the typical photo-dissociation region (PDR) molecules $\mathrm{CN}, \mathrm{HCN}, \mathrm{HCO}, \mathrm{C}_{2} \mathrm{H}, \mathrm{and}_{\mathrm{c}}-\mathrm{C}_{3} \mathrm{H}_{2}$. There are chemical differences between the observed positions. While the IF and the MP1 have a chemistry similar to that found in high UV field and dense PDRs such as the Orion Bar, the MP2 is similar to lower UV/density PDRs such as the Horsehead nebula. Our chemical modeling supports this interpretation.

In addition to the PDR-like species, we detected complex molecules such as $\mathrm{CH}_{3} \mathrm{CN}, \mathrm{H}_{2} \mathrm{CO}, \mathrm{HC}_{3} \mathrm{~N}, \mathrm{CH}_{3} \mathrm{OH}$, and $\mathrm{CH}_{3} \mathrm{C}_{2} \mathrm{H}$ that are not usually found in PDRs. The sulfur compounds CS, $\mathrm{HCS}^{+}, \mathrm{C}_{2} \mathrm{~S}, \mathrm{H}_{2} \mathrm{CS}, \mathrm{SO}$, and $\mathrm{SO}_{2}$ and the deuterated species DCN and $\mathrm{C}_{2} \mathrm{D}$ were also identified. The origin of these complex species requires further study. The observed deuteration fractionations, $[\mathrm{DCN}] /[\mathrm{HCN}] \sim 0.03$ and $\left[\mathrm{C}_{2} \mathrm{D}\right] /\left[\mathrm{C}_{2} \mathrm{H}\right] \sim 0.05$, are among the highest in warm regions.

Conclusions. Our results show that the high UV/dense PDRs have a different chemistry from the low UV case. Some abundance ratios such as $\left[\mathrm{CO}^{+}\right] /\left[\mathrm{HCO}^{+}\right]$or $[\mathrm{HCO}] /\left[\mathrm{HCO}^{+}\right]$are good diagnostics for differentiating between them. In Mon $\mathrm{R} 2$, we have the two classes of PDRs, a high UV PDR towards the IF and the adjacent molecular bar, and a low-UV PDR, which extends towards the north-west following the border of the cloud.

Key words. surveys - stars: formation - ISM: molecules - line: identification - astrochemistry - ISM: individual objects: Mon R2

\section{Introduction}

During the earliest stages of star formation, the ultraviolet (UV) radiation from the newlyborn star ionizes the most exposed layers of the host molecular cloud, creating a layer of ionized gas (constituted mainly by HII) and a so-called photo-dissociation region (PDR).

Ultracompact HII regions (UC HII) are defined as regions of ionized gas with diameters smaller than $\sim 0.1 \mathrm{pc}$ (see Churchwell 2002 , for a review). They are expected to expand at velocities on

\footnotetext{
* Appendices A and B are available in electronic form at http://www . aanda.org
}

the order of the sound speed $\left(10 \mathrm{~km} \mathrm{~s}^{-1}\right)$ until reaching equilibrium at dimensions of a few pc. In regions with a density of $n \sim 10^{5} \mathrm{~cm}^{-3}$, HII regions should remain UC for $\sim 3000 \mathrm{yr}$ and only a few dozen should exist in the Galaxy. However, observations suggest that many more UC HIIs exist and that their lifetimes should be one to two orders of magnitude longer. Several models have been proposed to explain this "lifetime paradox" but all have shortcomings. The paradox could be resolved if the molecular gas in which an $\mathrm{O}$ star forms is denser and warmer than previously believed, resulting in an initial Stromgren sphere that ismuch smaller than originally estimated. This suggestion is supported by observations indicating that in dense molecular 

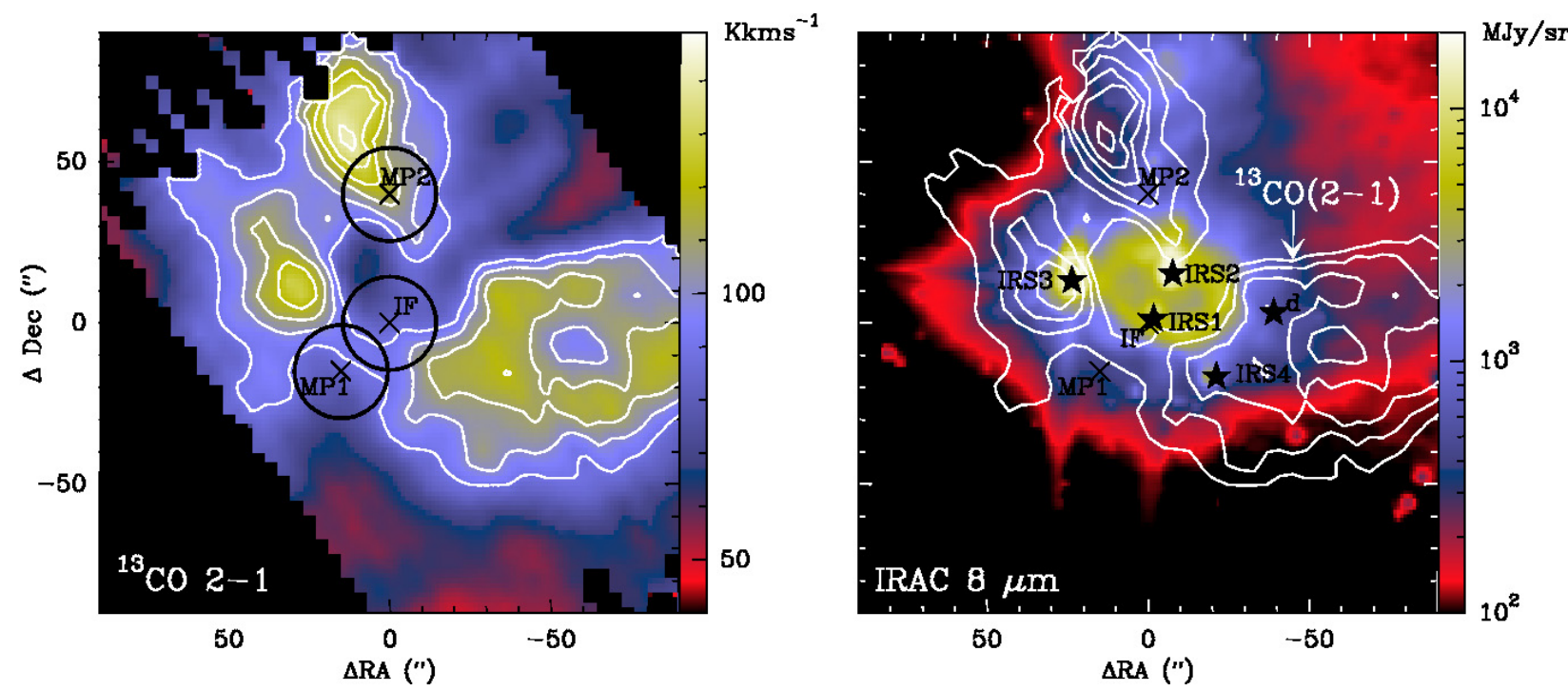

Fig. 1. Left: map of the integrated intensity between -5 and $15 \mathrm{~km} \mathrm{~s}^{-1}$ of the ${ }^{13} \mathrm{CO} 2 \rightarrow 1$ line observed at the IRAM $30 \mathrm{~m}$ telescope (lower contour at $90 \mathrm{~K} \mathrm{~km} \mathrm{~s}^{-1}$ and steps of $10 \mathrm{~K} \mathrm{~km} \mathrm{~s}^{-1}$, from Pilleri et al. 2012). The three observed positions, IF, MP1, MP2, are indicated. The beam of the $30 \mathrm{~m}$ at $3 \mathrm{~mm}$ towards the three observed positions is also drawn. Right: IRAC $8 \mu \mathrm{m}$ map towards Mon2. The extended emission is produced by the PAH bands at $7.7 \mu \mathrm{m}$. This figure shows the existence of an extended PDR in the cloud.

cloud cores densities of $\sim 10^{7} \mathrm{~cm}^{-3}$ and temperatures of $\sim 100 \mathrm{~K}$ are not atypical (Rizzo et al. 2005). The studies of the physics and chemistry of UC HII and of the surrounding PDRs are critical steps to understanding this evolutionary stage of a massive star.

The UC HII are characterized by extreme UV radiation field $\left(G_{0}>10^{5}\right.$ in units of the Habing field) and gas densities often higher than $>10^{6} \mathrm{~cm}^{-3}$. They may represent the best examples of highly UV-irradiated PDRs and can be used as a template for other more complex systems. Highly UV-irradiated PDRs are found in extremely interesting astrophysical environments such as the surface of circumstellar disks and the nuclei of starburst galaxies. Unfortunately, our knowledge of the chemistry and physics of UC HII is still far from complete.

Monoceros R2 (Mon R2) hosts the closest ( $d=830$ pc; Herbst \& Racine 1976) and brightest Galactic UC HII, and the only one that can be spatially resolved in the mm domain with single-dish telescopes. It is therefore the optimal case study to determine the physical and chemical evolution of massive starforming regions. The central, spherical UC HII was created by the interaction of the central infrared source IRS1 (Wood \& Churchwell 1989) with its host molecular cloud. The formation of the B0V star associated with IRS1 created a huge bipolar outflow $\left(\sim 15^{\prime}=3.6 \mathrm{pc}\right.$ long, Massi et al. 1985; Henning et al. 1992; Tafalla et al. 1994). Later CO $3 \rightarrow 2$ mapping of the region showed that this very extended outflow is now inactive. The highest velocity gas is detected towards IRS 3 , suggesting that this young star is associated with a compact $\left(<14^{\prime \prime}\right)$ bipolar outflow (Giannakopoulou et al. 1997).

Further studies at mm-wavelengths (Giannakopoulou et al. 1997; Tafalla et al. 1997; Choi et al. 2000; Rizzo et al. 2003, 2005) showed that the UC HII region is located inside a cavity bound by a dense molecular ridge at the south-east. The peak of this molecular ridge is located at the offset $\left(+10^{\prime \prime},-10^{\prime \prime}\right)$ relative to the peak of the ionized gas, and has a molecular hydrogen column density of $2-6 \times 10^{22} \mathrm{~cm}^{-2}$. The detection and subsequent analysis of the millimeter lines of the cyclic hydrocarbon species c- $\mathrm{C}_{3} \mathrm{H}_{2}$ with the IRAM 30 m telescope revealed gas densities of a few $10^{6} \mathrm{~cm}^{-3}$ (Rizzo et al. 2005) in the PDR surrounding the HII region. Spitzer observations of the $\mathrm{H}_{2}$ rotational lines and the polycyclic aromatic hydrocarbons (PAHs) midinfrared bands have revealed a thin layer $\left(n=4 \times 10^{5} \mathrm{~cm}^{-3}\right.$, $\left.N\left(\mathrm{H}_{2}\right)=1 \times 10^{21} \mathrm{~cm}^{-2}\right)$ of warm gas $\left(T_{\mathrm{k}}=574( \pm 20) \mathrm{K}\right)$ between the ionized gas and the dense molecular gas traced by previous millimeter observations (Berné et al. 2009). They interpreted the differences between the spatial distributions of the emission of the $\mathrm{H}_{2}$ rotational lines and the emission from PAHs around the HII region as the consequence of variations in the local UV field and density in this molecular gas layer.

In this paper, we present a mm molecular survey towards the UC HII region Mon R2. Our goal is to investigate the molecular chemistry in the PDR that surrounds the UC HII region and try to construct a pattern to interpret future observations.

\section{Observations}

Figure 1 displays a summary of the morphology of Mon R2 at both $\mathrm{mm}\left({ }^{13} \mathrm{CO} 2 \rightarrow 1\right)$ and mid-IR wavelengths. As expected, the maximum of the emission at $8 \mu \mathrm{m}$ is found towards the HII region and the infrared star IRS 3. Extended emission is detected around the HII region that is associated with the PAH band at $7.7 \mu \mathrm{m}$. This emission does not distribute uniformly around the HII region. It extends more than one arcminute away from IRS 1 towards the north-west, whereas it declines very rapidly towards the south-east.

We performed a $3 \mathrm{~mm}$ and $1 \mathrm{~mm}$ spectral survey towards three selected positions that are expected to represent different physical and chemical conditions. Our central position (RA = $06^{\mathrm{h}} 07^{\mathrm{m}} 46.2^{\mathrm{s}}$, Dec $\left.=-06^{\circ} 23^{\prime} 08.3^{\prime \prime}(\mathrm{J} 2000)\right)$ corresponds to the position of the ionization front (IF) and that of the ionizing star IRS 1. This offset together with the $\left(+15^{\prime \prime},-15^{\prime \prime}\right)$ offset form a strip across the molecular bar with a sampling of $\approx 1$ beam (see Fig. 1). For simplicity, we refer hereafter to this offset as MP1. The farther offset $\left(0^{\prime \prime},+40^{\prime \prime}\right)$ (hereafter MP2) is within the extended PAH emission towards the north-west.

The observations were carried out with the IRAM $30 \mathrm{~m}$ telescope at Pico Veleta (Spain) during July 2009. To optimize the observing time, we used the dual sideband offered by EMIR. In this way, we can simultaneously observe $8 \mathrm{GHz}$ in the lower sideband and $8 \mathrm{GHz}$ in the upper sideband, separated by a gap 
D. Ginard et al.: Spectral line survey of the ultracompact HII region Mon R2
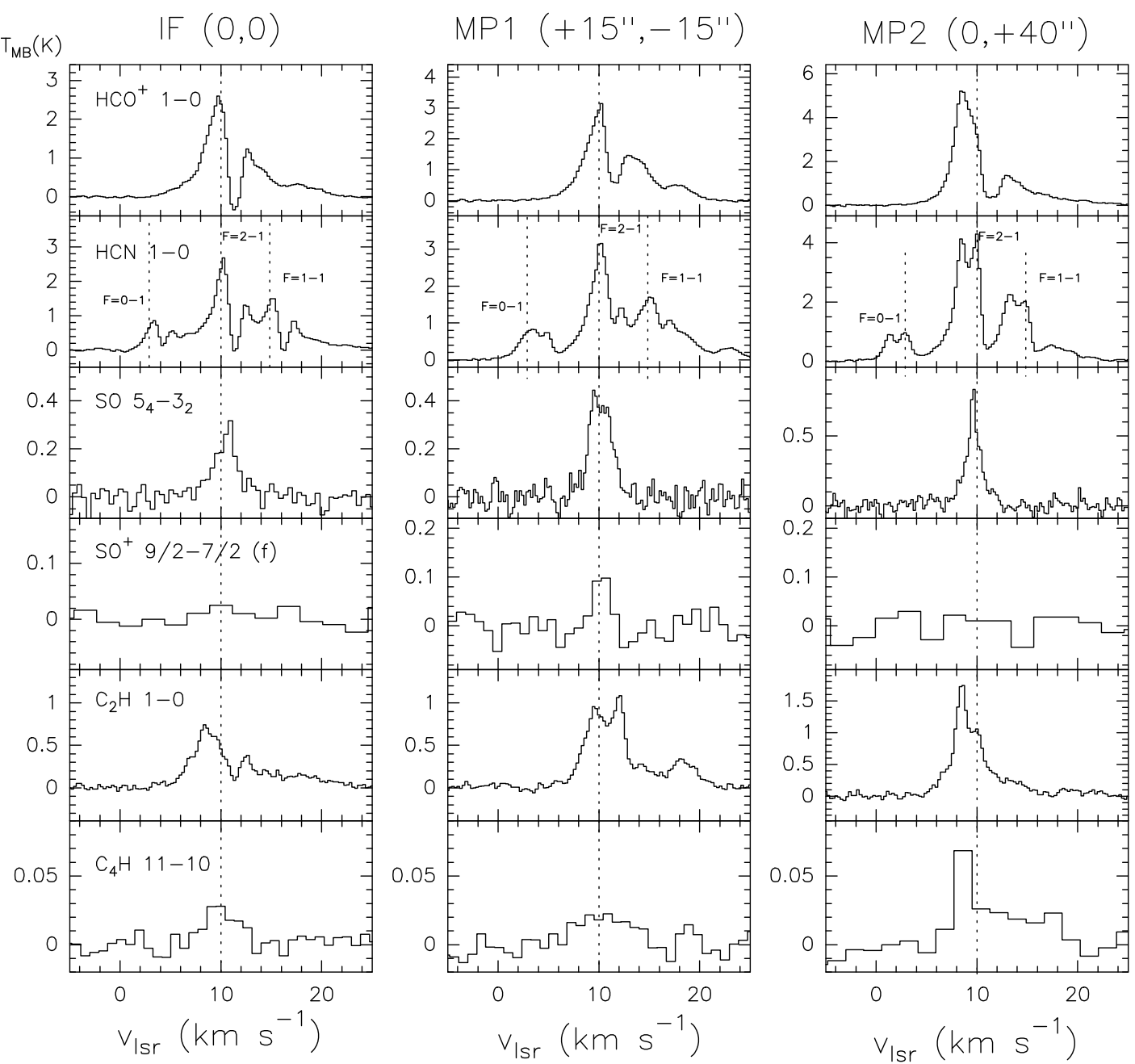

Fig. 2. High resolution spectra observed with the $30 \mathrm{~m}$ telescope towards the positions $\left(0^{\prime \prime}, 0^{\prime \prime}\right),\left(+15^{\prime \prime},-15^{\prime \prime}\right)$ and $\left(0^{\prime \prime},+40^{\prime \prime}\right)$. All the lines were observed with a spectral resolution of $\sim 40 \mathrm{kHz}$. The spectra of the $\mathrm{SO}^{+} 9 / 2 \rightarrow 7 / 2$ and $\mathrm{C}_{4} \mathrm{H} 11 \rightarrow 10$ lines have been rebinned to obtain a higher signal-to-noise ratio.

of $8 \mathrm{GHz}$. The rejection from one band to the other one has been measured by the IRAM staff to be $\approx 13 \mathrm{~dB}$. This observing mode allows us to cover a band of $16 \mathrm{GHz}$ at $3 \mathrm{~mm}$ with only one tuning. Initially, we observed $16 \mathrm{GHz}$ single polarization (from 87.517 to $94.942 \mathrm{GHz}$ and from 103.197 to $110.622 \mathrm{GHz}$ ) using the dual sideband of the $3 \mathrm{~mm}$ receiver. Afterwards, we completed our survey by observing simultaneously the $3 \mathrm{~mm}$ and $1 \mathrm{~mm}$ bands ( $4 \mathrm{GHz}$ at $3 \mathrm{~mm}$ and $4 \mathrm{GHz}$ at $1 \mathrm{~mm}$ ) and integrating the two polarizations. The $3 \mathrm{~mm}$ and $1 \mathrm{~mm}$ EMIR receivers were centered at $85.339 \mathrm{GHz}$ and $217.937 \mathrm{GHz}$, respectively. In the $1 \mathrm{~mm}$ receiver, we need to neglect one of the polarizations owing to the poorer quality of the baselines. Two additional settings were used to observe the $\mathrm{SO}^{+} 9 / 2 \rightarrow 7 / 2(207.800 \mathrm{GHz})$ and SO $5_{4} \rightarrow 3_{2}(206.176 \mathrm{GHz})$ lines. Simultaneously with the observations of these lines at $1 \mathrm{~mm}$, we used the $3 \mathrm{~mm}$ receiver to obtain the high spectral resolution spectra of the $\mathrm{HCO}^{+} 1 \rightarrow 0$, $\mathrm{HCN} 1 \rightarrow 0, \mathrm{C}_{2} \mathrm{H} 1 \rightarrow 0$, and $\mathrm{C}_{4} \mathrm{H} 11 \rightarrow 10$ lines shown in Fig. 2.

The observed spectral ranges, telescope beam efficiencies, half-power beam width (HPBW), and rms of our observations are listed in Table 1 . The observing procedure was position switching with the reference located at an offset $\left(+400^{\prime \prime}\right.$, $\left.-400^{\prime \prime}\right)$. To cover these spectral ranges, we used the WILMA autocorrelator, which provides a spectral resolution of $2 \mathrm{MHz}$
(5.4-6.8 $\mathrm{km} \mathrm{s}^{-1}$ in the $3 \mathrm{~mm}$ band). This spectral resolution does not allow us to resolve the lines at $3 \mathrm{~mm}$ and therefore provides information only on the integrated line intensity. The WILMA spectra and the line integrated intensities are shown in Appendix A. Selected lines were observed simultaneously with the VESPA autocorrelator, providing a spectral resolution of around $40 \mathrm{kHz}$. These high spectral resolution spectra are shown in Fig. 2 and Gaussian fit parameters to the $\mathrm{SO}, \mathrm{SO}_{2}, \mathrm{SO}^{+}$, and $\mathrm{C}_{4} \mathrm{H}$ lines are given in Table 3. All the intensities are in units of main beam brightness temperature $\left(T_{\mathrm{MB}}\right)$.

\section{Results}

\subsection{Line identification}

To identify the lines, we used three different catalogues, the $\mathrm{JPL}^{1}$, the $\mathrm{CDMS}^{2}$ and that of Cernicharo (priv. comm.) The observations were performed with $2 \mathrm{SB}$ receivers with an image band rejection of $\sim 13 \mathrm{~dB}$. Therefore, we have some bright lines from the image band in our spectra (see Figs. A.1A.3). In Appendix A, we show the spectra of our complete $\mathrm{mm}$ survey, and give a list of the detected lines $(\geq 3-\sigma)$, their

\footnotetext{
1 http://spec.jpl.nasa.gov

2 http://www.astro.uni-koeln.de/cdms/catalog
} 
Table 1. Summary of $30 \mathrm{~m}$ observations.

\begin{tabular}{lccccc}
\hline \hline Offset & $\begin{array}{c}\text { Freq } \\
(\mathrm{GHz})\end{array}$ & $\begin{array}{c}\text { HPBW } \\
\left({ }^{\prime \prime}\right)\end{array}$ & $\eta_{\mathrm{MB}}$ & $\begin{array}{c}\mathrm{rms}^{1} \\
(\mathrm{mK})\end{array}$ & $\begin{array}{c}t \\
(\mathrm{~min})\end{array}$ \\
\hline IF & {$[83.746,87.461]$} & 29 & 0.81 & 6 & 55 \\
$\left(0^{\prime \prime}, 0^{\prime \prime}\right)$ & {$[87.517,91.232]$} & 29 & 0.80 & 4 & 46 \\
& {$[91.227,94.942]$} & 29 & 0.80 & 4 & 46 \\
& {$[103.197,106.913]$} & 24 & 0.80 & 3 & 46 \\
& {$[106.907,110.622]$} & 24 & 0.80 & 4 & 46 \\
& {$[204.583,208.294]$} & 12 & 0.63 & 20 & 41 \\
& {$[207.184,210.900]$} & 12 & 0.63 & 13 & 74 \\
MP1 & {$[216.344 .220 .059]$} & 11 & 0.63 & 15 & 28 \\
$\left(15^{\prime \prime},-15^{\prime \prime}\right)$ & {$[83.746,87.461]$} & 29 & 0.81 & 3 & 55 \\
& {$[87.517,91.232]$} & 29 & 0.80 & 3 & 55 \\
& {$[91.227,94.942]$} & 29 & 0.80 & 4 & 55 \\
& {$[103.197,106.913]$} & 24 & 0.80 & 3 & 55 \\
& {$[106.907,110.622]$} & 24 & 0.80 & 3 & 55 \\
& {$[204.583,208.294]$} & 12 & 0.63 & 20 & 41 \\
MP2 & {$[207.184,210.900]$} & 12 & 0.63 & 13 & 64 \\
$\left(0^{\prime \prime},+40^{\prime \prime}\right)$ & {$[216.344,220.059]$} & 11 & 0.63 & 10 & 28 \\
& {$[83.746,87.461]$} & 29 & 0.81 & 4 & 111 \\
& {$[87.517,91.232]$} & 29 & 0.80 & 3 & 46 \\
& {$[91.227,94.942]$} & 29 & 0.80 & 3 & 46 \\
& {$[103.197,106.913]$} & 24 & 0.80 & 3 & 46 \\
& {$[106.907,110.622]$} & 24 & 0.80 & 4 & 46 \\
& {$[204.583,208.294]$} & 12 & 0.63 & 20 & 27 \\
& {$[207.184,210.900]$} & 12 & 0.63 & 20 & 24 \\
& {$[216.344 .220 .059]$} & 11 & 0.63 & 10 & 55 \\
\hline
\end{tabular}

Notes. (1) rms in units of $T_{\mathrm{MB}}$ with WILMA (spectral resolution of $2 \mathrm{MHz}$ ).

identification, and line integrated intensities (Table A.1). We also list the $\geq 4-\sigma$ unidentifed lines and the corresponding frequencies in the signal and image bands. For clarity, upper limits are not included in Table A.1. Since the molecular lines are unresolved, the upper limit to the integrated intensity is simply $3 \times \mathrm{rms} \times$ channel velocity width. The Gaussian fit parameters to the recombination lines are given in Table A.2.

We identified 87 lines, out of a total of 105 lines, towards the $\left(0^{\prime \prime}, 0^{\prime \prime}\right)$ position. The large number of recombination lines shows the presence of ionized gas. In addition, we also have a wealth of lines of complex molecules, which are more typical of warm and dense molecular clouds. Towards the MP1, we detected 101 lines, and identified all but five lines. At this position, the recombination lines are very weak. Towards the MP2, we detected a total of 99 lines with only 8 unidentified lines. We tentatively detected the $\mathrm{H}_{2} \mathrm{CN} 3_{0,2} \rightarrow 2_{0,2}$ line towards the MP1 and MP2. The molecule $\mathrm{H}_{2} \mathrm{CN}$ was firstly detected in TMC1 by Ohishi et al. (1994). If confirmed, this region would be the second one in which this radical has been detected and would corroborate that Mon R2 is a source with an extremely rich carbon chemistry.

In Table 2, we show a summary of the molecular species detected in our survey towards the three positions. We distinguish between certain and tentative detections. Tentative detections correspond to species with only one line detected at a level of $3-4-\sigma$. In these cases, we checked that there were other intense (and undetected) lines of the same species lying in the spectral ranges covered by our survey. In Table 2 , we added the reactive ions $\mathrm{CO}^{+}$and $\mathrm{HOC}^{+}$previously detected by Rizzo et al. (2003) because of their importance in interpreting the PDR chemistry. Rizzo et al. (2003) did not detect these ions towards the MP1 nor search for them in the MP2. Like $\mathrm{CO}^{+}$and $\mathrm{HOC}^{+}$, the reactive ion $\mathrm{SO}^{+}$is expected to have a very low fractional abundance
Table 2. Detected molecules.

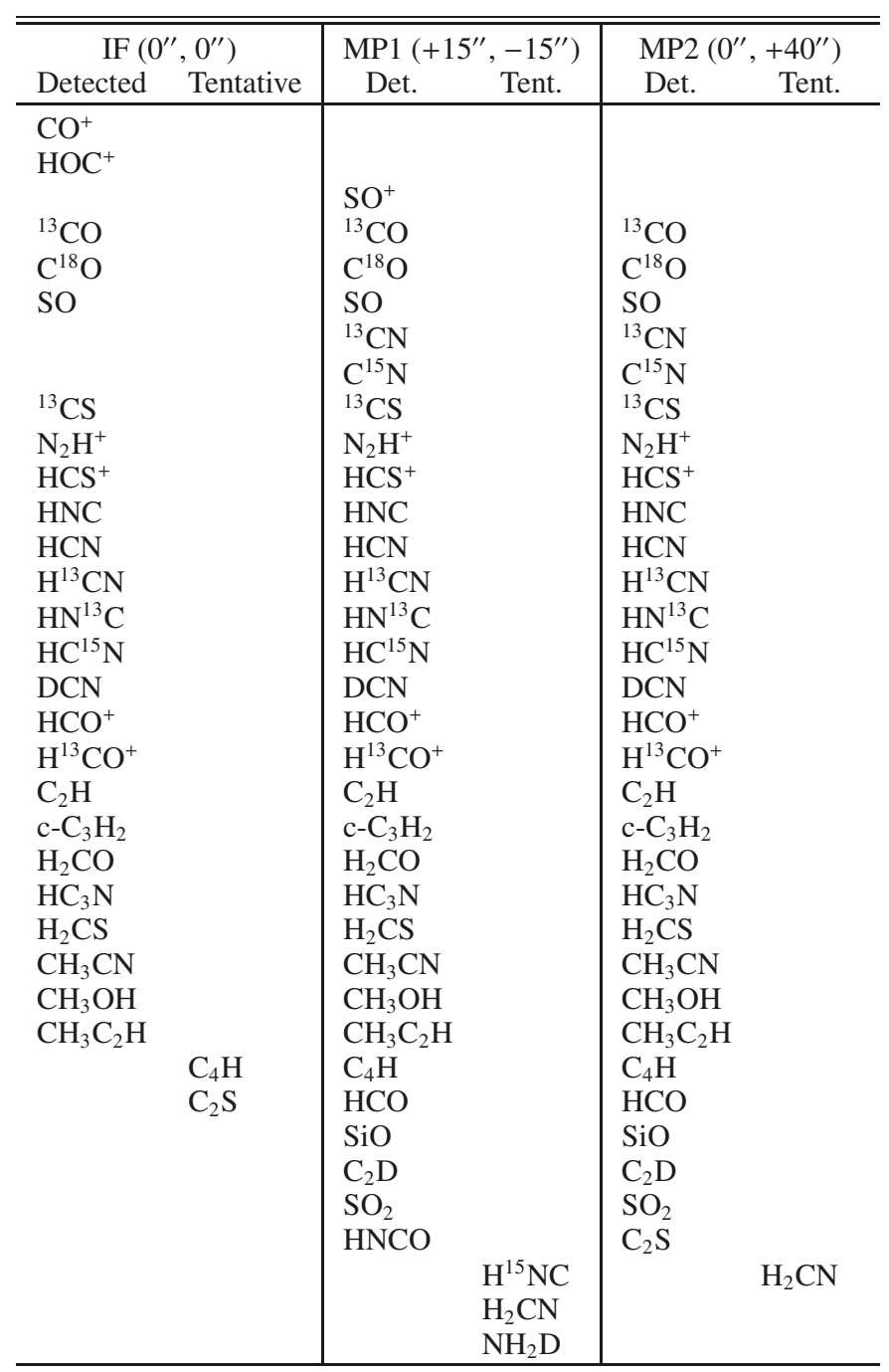

in the shielded part of the cloud. We searched for $\mathrm{SO}^{+}$at each of the three positions but only detected them towards the MP. Many molecules were detected at the three positions. Some are well-known tracers of PDRs such as $\mathrm{HCN}, \mathrm{HCO}, \mathrm{C}_{2} \mathrm{H}$, c- $\mathrm{C}_{3} \mathrm{H}_{2}$, and $\mathrm{C}_{4} \mathrm{H}$. Others, like $\mathrm{CH}_{3} \mathrm{CN}$ and $\mathrm{CH}_{3} \mathrm{OH}$, are complex molecules usually not found in PDRs. At the end of Table 2, we present only species with detections towards the MP1 and the MP2 peaks, such as $\mathrm{C}_{4} \mathrm{H}, \mathrm{HCO}, \mathrm{SiO}, \mathrm{C}_{2} \mathrm{D}$, and $\mathrm{SO}_{2}$. We detected the sulfuratted carbon-chain $\mathrm{C}_{2} \mathrm{~S}$ in the MP2 and tentatively in the IF. HNCO was only detected in the MP.

The detection of recombination lines, PDR tracers, and complex molecules is consistent with the interpretation of the PDR as an expanding envelope around the UC HII region as first proposed by Rizzo et al. (2005) and confirmed by Fuente et al. (2010) and Pilleri et al. (2012). Even in this situation, we expect to see some chemical differences because of the different incident UV fields and mixing ratios of the different PDR layers.

\subsection{High resolution observations: Detection of $\mathrm{SO}^{+}$and $\mathrm{C}_{4} \mathrm{H}$}

In Fig. 2, we show the spectra of the $\mathrm{HCO}^{+} 1 \rightarrow 0, \mathrm{HCN} 1 \rightarrow 0$, $\mathrm{SO} 5_{4} \rightarrow 3_{2}, \mathrm{SO}^{+} 9 / 2 \rightarrow 7 / 2, \mathrm{C}_{2} \mathrm{H} 1 \rightarrow 0$, and $\mathrm{C}_{4} \mathrm{H} 11 \rightarrow$ 10 lines. This is the first detection of $\mathrm{SO}^{+}$and $\mathrm{C}_{4} \mathrm{H}$ towards Mon R2. These lines were observed with the $\sim 40 \mathrm{kHz}$ spectral 
Table 3. $\mathrm{SO}, \mathrm{SO}_{2}, \mathrm{SO}^{+}, \mathrm{C}_{4} \mathrm{H}$ observations.

\begin{tabular}{|c|c|c|c|c|c|c|c|}
\hline Line & & HPBW (") & Freq $(\mathrm{GHz})$ & $I\left(\mathrm{~K} \mathrm{~km} \mathrm{~s}^{-1}\right)$ & $v_{\mathrm{lsr}}\left(\mathrm{km} \mathrm{s}^{-1}\right)$ & $\Delta v\left(\mathrm{~km} \mathrm{~s}^{-1}\right)$ & $T_{\mathrm{MB}}(\mathrm{K})$ \\
\hline \multicolumn{8}{|c|}{ Offset $\left(0^{\prime \prime}, 0^{\prime \prime}\right)$} \\
\hline SO & $5_{4} \rightarrow 4_{3}$ & 12 & 206.176 & $0.70(0.05)$ & $10.56(0.08)$ & $2.55(0.27)$ & 0.26 \\
\hline $\mathrm{SO}^{+}$ & $9 / 2 \rightarrow 7 / 2$ (f) & 12 & 208.965 & $0.11(0.05)^{t}$ & $10.09(1.00)$ & $3.87(1.72)$ & 0.026 \\
\hline $\mathrm{SO}^{+}$ & $9 / 2 \rightarrow 7 / 2(\mathrm{e})$ & 12 & 208.590 & $<0.16$ & & & \\
\hline $\mathrm{SO}_{2}$ & $3_{2,2} \rightarrow 2_{1,1}$ & 12 & 208.700 & $<0.16$ & & & \\
\hline $\mathrm{C}_{4} \mathrm{H}$ & $11 \rightarrow 10$ & 24 & 104.666 & $0.09(0.02)$ & $9.77(0.46)$ & $3.56(1.11)$ & 0.025 \\
\hline $\mathrm{C}_{4} \mathrm{H}$ & $11 \rightarrow 10$ & 24 & 104.705 & $0.11(0.02)$ & $10.17(0.39)$ & $3.77(0.80)$ & 0.028 \\
\hline \multicolumn{8}{|c|}{ Offset $\left(+15^{\prime \prime},-15^{\prime \prime}\right)$} \\
\hline SO & $5_{4} \rightarrow 4_{3}$ & 12 & 206.176 & $1.16(0.04)$ & $10.13(0.04)$ & $2.59(0.09)$ & 0.42 \\
\hline $\mathrm{SO}^{+}$ & $9 / 2 \rightarrow 7 / 2$ (f) & 12 & 208.965 & $0.26(0.03)$ & $10.17(0.12)$ & $2.06(0.21)$ & 0.12 \\
\hline $\mathrm{SO}^{+}$ & $9 / 2 \rightarrow 7 / 2(\mathrm{e})$ & 12 & 208.590 & $0.13(0.04)$ & $10.20(0.21)$ & $1.47(0.53)$ & 0.08 \\
\hline $\mathrm{SO}_{2}$ & $3_{2,2} \rightarrow 2_{1,1}$ & 12 & 208.700 & $<0.07$ & & & \\
\hline $\mathrm{C}_{4} \mathrm{H}$ & $11 \rightarrow 10$ & 24 & 104.666 & $0.09(0.03)$ & $8.70(0.81)$ & $5.14(1.64)$ & 0.017 \\
\hline $\mathrm{C}_{4} \mathrm{H}$ & $11 \rightarrow 10$ & 24 & 104.705 & $0.14(0.03)$ & $9.78(0.63)$ & $5.90(1.17)$ & 0.022 \\
\hline \multicolumn{8}{|c|}{ Offset $\left(0^{\prime \prime},+40^{\prime \prime}\right)$} \\
\hline SO & $5_{4} \rightarrow 4_{3}$ & 12 & 206.176 & $1.19(0.03)$ & $9.65(0.02)$ & $1.70(0.06)$ & 0.66 \\
\hline $\mathrm{SO}^{+}$ & $9 / 2 \rightarrow 7 / 2$ (f) & 12 & 208.965 & $<0.17$ & & & \\
\hline $\mathrm{SO}^{+}$ & $9 / 2 \rightarrow 7 / 2(\mathrm{e})$ & 12 & 208.590 & $<0.17$ & & & \\
\hline $\mathrm{SO}_{2}$ & $3_{2,2} \rightarrow 2_{1,1}$ & 12 & 208.700 & $<0.22$ & & & \\
\hline $\mathrm{C}_{4} \mathrm{H}$ & $11 \rightarrow 10$ & 24 & 104.666 & $0.14(0.02)$ & $6.53(0.07)$ & $1.11(0.16)$ & 0.12 \\
\hline $\mathrm{C}_{4} \mathrm{H}$ & $11 \rightarrow 10$ & 24 & 104.705 & $0.09(0.02)$ & $7.99(0.09)$ & $0.90(0.18)$ & 0.10 \\
\hline
\end{tabular}

Notes. ${ }^{(t)}$ Tentative, $<3-\sigma$.

resolution provided by the VESPA autorrelator. Gaussian fits to the $\mathrm{SO}, \mathrm{SO}^{+}$, and $\mathrm{C}_{4} \mathrm{H}$ lines are shown in Table 3 .

There are significant differences among the profiles of the lines shown in Fig. 2, which testify to the existence of several gas components. A clear absorption is seen in the $\mathrm{HCO}^{+} 1 \rightarrow 0$, $\mathrm{HCN} 1 \rightarrow 0$ and $\mathrm{C}_{2} \mathrm{H} 1 \rightarrow 0$ lines towards the IF position. This self-absorbed feature lies at a velocity of $\sim 10.8 \mathrm{~km} \mathrm{~s}^{-1}$, which is the central velocity of the SO $5_{4} \rightarrow 4_{3}$ line emission. This suggests that the SO $5_{4} \rightarrow 4_{3}$ emission is coming from the cloud around the HII region. Towards the MP1, the profiles of the SO $5_{4} \rightarrow 4_{3}$ and $\mathrm{SO}^{+}$9/2 $\rightarrow 7 / 2$ lines are wider and centered at $\sim 10.0 \mathrm{~km} \mathrm{~s}^{-1}$. The line profiles towards the MP2 are even more complicated (see Fig. 2). As at other positions, there is a self-absorbed feature at $\sim 10.8 \mathrm{~km} \mathrm{~s}^{-1}$ which is the velocity of the external cloud, but the $\mathrm{HCN} 1 \rightarrow 0$ line also displays self-absorption at $\sim 9 \mathrm{~km} \mathrm{~s}^{-1}$. The $\mathrm{C}_{2} \mathrm{H} 1 \rightarrow 0$ and $\mathrm{C}_{4} \mathrm{H} 11 \rightarrow 10$ lines have wide profiles, with a red-shifted wing up to velocities of $\sim 18 \mathrm{~km} \mathrm{~s}^{-1}$. The similarity between the profiles of the $\mathrm{C}_{2} \mathrm{H} 1 \rightarrow 0$ and $\mathrm{C}_{4} \mathrm{H} 11 \rightarrow 10$ lines supports the interpretation that these two species have a similar chemistry and come from the same region. Since $\mathrm{C}_{4} \mathrm{H}$ is found to be abundant in low UV PDRs and has not been detected in the high velocity wings of bipolar outflows (see e.g. Bachiller \& Pérez-Gutiérrez 1997), these high velocity wings are very likely tracing the PDR around the HII region (Fuente et al. 2010; Pilleri et al. 2012). The existence of several bipolar outflows in these regions, however, makes it difficult to distinguish the origin of this high velocity gas. The profile of the SO $5_{4} \rightarrow 4_{3}$ line is Gaussian and centered at the systemic velocity suggesting that its emission originates in the dense cloud.

\section{Gas physical conditions and column densities}

To derive accurate column densities it is important to have a good estimate of the gas physical conditions. For the species $\mathrm{C}^{18} \mathrm{O}, \mathrm{SO},{ }^{13} \mathrm{CN}, \mathrm{SiO}, \mathrm{C}_{2} \mathrm{~S}, \mathrm{SO}_{2}, \mathrm{H}_{2} \mathrm{CO}, \mathrm{H}_{2} \mathrm{CS}, \mathrm{c}-\mathrm{C}_{3} \mathrm{H}_{2}, \mathrm{HC}_{3} \mathrm{~N}$, $\mathrm{C}_{4} \mathrm{H}, \mathrm{CH}_{3} \mathrm{OH}, \mathrm{CH}_{3} \mathrm{CN}$, and $\mathrm{CH}_{3} \mathrm{C}_{2} \mathrm{H}$, we detected several transitions and a multitransitional study was possible. We used the rotational diagram technique to derive beam-averaged rotation temperatures and column densities. This technique is based on the assumption of optically thin emission for all the lines of a given species. For optically thin emission, the integrated intensity of each line is proportional to the population of the upper level of the corresponding transition. In this case, a rotational diagram provides good estimates of the rotation temperature and the total column density (see e.g. Schloerb et al. 1983). In the case of optically thick lines, the integrated intensity of the line is no longer proportional to the population of the upper level and the rotation temperature cannot be derived with this technique.

The lines of the most abundant isotopologues are optically thick and in many cases the lines are self-absorbed (see Fig. 2). For this reason, we only created rotational diagrams for the rarer isotopologues $\mathrm{C}^{18} \mathrm{O}, \mathrm{H}^{13} \mathrm{CO}^{+}$, and $\mathrm{H}^{13} \mathrm{CN}$. The column densities of $\mathrm{CO}, \mathrm{HCO}^{+}$, and $\mathrm{HCN}$ were derived assuming the isotopic ratios ${ }^{12} \mathrm{C} /{ }^{13} \mathrm{C}=50$ (Savage et al. 2002, and references therein) and ${ }^{16} \mathrm{O} /{ }^{18} \mathrm{O}=500$. The information derived from our survey was complemented with that obtained from the $\mathrm{H}^{13} \mathrm{CO}^{+} 3 \rightarrow 2$, $\mathrm{H}^{13} \mathrm{CN} 3 \rightarrow 2$ and $\mathrm{C}_{2} \mathrm{H} 3 \rightarrow 2$ lines detected in our unpublished HERA maps (Pilleri et al., in prep.) after degrading their angular resolution to that of the observed $3 \mathrm{~mm}$ transitions. The resulting integrated line intensities are shown at the end of Table A.1. In these cases, the rotational temperatures and column densites derived from the rotational diagrams are unaffected by the unknown beam filling factor. For the other cases, we assumed a beam filling factor of unity for the $3 \mathrm{~mm}$ and $1 \mathrm{~mm}$ lines. This is reasonable taking into account that the molecular emission extends over a region of about $2^{\prime} \times 2^{\prime}$ (see Fig. 1), which is larger than the beam of the $30 \mathrm{~m}$ telescope at both $3 \mathrm{~mm}$ and $1 \mathrm{~mm}$ wavelengths but would overestimate the rotational temperature if the size of the emission is smaller than $29^{\prime \prime}$. Comparing the rotational temperatures thus derived with those from $\mathrm{H}^{13} \mathrm{CO}^{+}$, $\mathrm{H}^{13} \mathrm{CN}$, and $\mathrm{C}_{2} \mathrm{H}$ lines, we estimate that the uncertainty in the column density estimates because of the unknown filling factor is of a factor of three.

Where possible, we estimated the molecular column densitites and the molecular hydrogen density using the large velocity 
Table 4. Collisional coefficients.

\begin{tabular}{ll}
\hline \hline $\mathrm{C}^{18} \mathrm{O}$ & Yang et al. (2010) \\
$\mathrm{SO}$ & Lique et al. (2006) \\
$\mathrm{CS}$ & Lique et al. (2007) \\
$\mathrm{SiO}$ & Dayou \& Balanca (2006) \\
$\mathrm{HCN}, \mathrm{HNC}$ & Sarrasin et al. (2010) \\
$\mathrm{HCO}^{+}$ & Flower (1999) \\
$\mathrm{HCS}^{+}$ & Monteiro (1984) \\
$\mathrm{N}_{2} \mathrm{H}^{+}$ & Daniel et al. (2005) \\
$\mathrm{SO}_{2}$ & Cernicharo et al. (2011) \\
$\mathrm{H}_{2} \mathrm{CO}$ & Green et al. (1991) \\
$\mathrm{c}-\mathrm{C}_{3} \mathrm{H}_{2}$ & Avery \& Green (1989) \\
$\mathrm{HC}_{3} \mathrm{~N}$ & Wernli et al. (2007) \\
\hline
\end{tabular}

gradient radiative transfer code by Cernicharo et al. (2006). The collisional coefficients adopted in our calculations are shown in Table 4. For ${ }^{13} \mathrm{CS}, \mathrm{H}^{13} \mathrm{CO}^{+}, \mathrm{H}^{13} \mathrm{CN}, \mathrm{HC}^{15} \mathrm{~N}, \mathrm{HN}^{13} \mathrm{C}$, and $\mathrm{DCN}$, we used the collisional coefficients of the main isotopologue. We fixed the gas kinetic temperature and varied the density and column density to fit the line intensities. On the basis of the rotation temperatures of $\mathrm{C}^{18} \mathrm{O}$ and $\mathrm{CH}_{3} \mathrm{CN}$ data, we assumed $T_{\mathrm{k}}=50 \mathrm{~K}$ for the IF and MP1 positions and $T_{\mathrm{k}}=70 \mathrm{~K}$ for the MP2. Since the kinetic temperature is fixed in our calculations, the ratio of the intensities of the two lines observed depends mainly on the density, while the intensity of each line is more dependent on the total column density. The obtained densities vary between $\sim$ a few $10^{5} \mathrm{~cm}^{-3}$ and $\sim 10^{6} \mathrm{~cm}^{-3}$. Our results agree with those of Tafalla et al. (1997) who derived densities of a few $10^{5} \mathrm{~cm}^{-3}$ from the CS lines and its isotopes. For some species, we detected only one line. In these cases we adopted a density $n\left(\mathrm{H}_{2}\right)=$ $5 \times 10^{5} \mathrm{~cm}^{-3}$ in our LVG calculations for the three positions.

In Table 5, we show the column densities derived towards the three observed positions for all the detected species. The corresponding rotational diagrams are shown in Appendix B (see Figs. B.1-B.3). The column densities obtained using the LVG approach agree with the rotational diagram calculations, which confirms our assumption that the emission is optically thin. For those species for which the collisional coefficients were not known and only one transition was observed, we estimated the column densities assuming optically thin emission and local thermodynamic equilibrium (LTE) with the level's population described by a given rotation temperature. The assumed rotation temperatures are based on the results of the rotational diagrams of other molecules with similar excitation conditions. For $\mathrm{SO}^{+},{ }^{13} \mathrm{CN}, \mathrm{C}_{2} \mathrm{D}, \mathrm{C}_{2} \mathrm{~S}, \mathrm{HCO}, \mathrm{HNCO}$, and $\mathrm{C}_{4} \mathrm{H}$, we assumed $T_{\text {rot }}=10 \mathrm{~K}$, which is similar to the temperatures obtained using rotational diagrams for $\mathrm{C}_{2} \mathrm{H}$ and $\mathrm{H}^{13} \mathrm{CO}^{+}$. For $\mathrm{CH}_{3} \mathrm{CN}$ and $\mathrm{CH}_{3} \mathrm{C}_{2} \mathrm{H}$, we adopted $T_{\text {rot }}=30 \mathrm{~K}$. Some cases are marked with the label "bad estimate" in Table 5 because the uncertainty in the column density estimates could be as high as a factor of ten. This is the case for $\mathrm{CH}_{3} \mathrm{CN}$ and $\mathrm{CH}_{3} \mathrm{OH}$. The main source of uncertainty in these molecules is that our spectral resolution does not allow us to resolve all the $\mathrm{K}$-components of the same rotational line. The lack of detection of the $\mathrm{CH}_{3} \mathrm{CN} 5_{0} \rightarrow 4_{0}$ line towards the IF suggests that the emission of this transition could be self-absorbed.

Molecular abundances were calculated assuming a canonical $\mathrm{C}^{18} \mathrm{O}$ for the $\mathrm{H}_{2}$ abundance of $1.7 \times 10^{-7}$. The abundance of each species $X$ with respect to $\mathrm{H}_{2}$ is then given by the expression $f_{X}=N_{X} / N_{\mathrm{H}_{2}}=N_{X} / N_{\mathrm{C}^{18} \mathrm{O}} \times 1.7 \times 10^{-7}$.

\section{Comparison with protypical PDRs}

The $8 \mu \mathrm{m}$ IRAC image undoubtedly shows the existence of an extended PDR in this region. One of the goals of this paper is to establish the role of the UV photons, relative to other phenomena linked to the star formation process such as bipolar outflows, in the chemistry of this molecular cloud. For this aim, we follow a two-fold strategy. First of all, we compare the chemical composition at the three observed positions. Since the average kinetic temperatures and density at the three positions are quite similar, differences in the chemistry can be interpreted as the results of the different incident UV field. Second, we compare Mon R2 with that in other prototypical PDRs such as the Orion Bar, NGC 7023, and the Horsehead.

The IF and MP1 define a cut along the dense PDR in Mon R2, the MP1 being the more shielded position. Comparing the molecular abundances between these two positions, we find that only one molecule, $\mathrm{HCS}^{+}$, has a higher (by a factor of six) abundance towards the IF than the MP1. This suggests that $\mathrm{HCS}^{+}$comes from the inner PDR as for the reactive molecular ions $\mathrm{CO}^{+}$and $\mathrm{HOC}^{+}$(Rizzo et al. 2003, 2005). The reactive ion $\mathrm{SO}^{+}$is, however, more abundant towards the MP1. Fuente et al. (2003) already suggested that this molecular ion comes from a more shielded layer than the ions $\mathrm{CO}^{+}$and $\mathrm{HOC}^{+}$. There are some species that have significantly lower abundance towards the IF. These species are $\mathrm{N}_{2} \mathrm{H}^{+}$and $\mathrm{HC}_{3} \mathrm{~N}$ proving that are easily destroyed by UV photons and are only found in the more shielded gas. A peculiar chemistry is detected towards the MP2. This position is very rich in carbon chains such as $\mathrm{C}_{2} \mathrm{H}, \mathrm{C}_{4} \mathrm{H}$, $\mathrm{C}_{2} \mathrm{~S}$, and $\mathrm{c}-\mathrm{C}_{3} \mathrm{H}_{2}$. As we discuss below this different chemistry could be due to MP2 being related to a low UV PDR.

In Fig. 3, we compare the molecular abundances relative to $\mathrm{C}^{18} \mathrm{O}$ measured in Mon R2 with those in other prototypical PDRs. This kind of comparison is not straightforward since data with different spatial resolutions and calibrations are used. Despite this, we can extract some qualitative conclusions. Mon R2 seems richer in the carbon chains $\mathrm{HCN}$ and $\mathrm{CN}$ than other prototypical PDRs in star forming regions such as the Orion Bar, NGC 7023 and the Horsehead (see Fig. 3). One might speculate that this high $\mathrm{HCN}$ and $\mathrm{CN}$ abundance is related to the bipolar outflows in the region. This interpretation is discussed in Sect. 5.2. The reactive ion $\mathrm{CO}^{+}$is only detected in highly UV irradiated positions such as the IF in Mon R2, the Orion Bar, and NGC 7023. The chemistry of the MP2 position in Mon R2 resembles that of the Horsehead, with a high $\mathrm{C}_{4} \mathrm{H}$ and $\mathrm{HCO}$ abundance.

Abundance ratios of chemically related molecules with similar excitations conditions are more accurate than absolute molecular abundances. The spatial extent of the emission is expected to be the same, and the abundance ratio is insensitive to the unknown beam filling factor. Moreover, as long as the excitation is similar for the two species, the abundance ratio is insensitive to uncertainties in the assumed physical conditions. For these reasons, abundance ratios instead of fractional abundances are often used to compare with models. In Table 6, we show some interesting abundance ratios in Mon R2 and compared them with the values in the other prototypical PDRs.

\section{1. $\mathrm{HCN} / \mathrm{HNC}$}

In this source, the $\mathrm{HCN}$ and $\mathrm{HNC}$ lines are optically thick. Moreover, the clear self-absorption features of these lines prevent us from calculating reliable molecular abundances. We instead, use the rare isotopes $\mathrm{H}^{13} \mathrm{CN}$ and $\mathrm{HN}^{13} \mathrm{C}$. 
Table 5. Physical parameters.

\begin{tabular}{|c|c|c|c|c|c|c|c|c|}
\hline \multirow[b]{2}{*}{ Molecule } & \multicolumn{2}{|r|}{$\mathrm{RD}^{a}$} & \multicolumn{2}{|c|}{$\mathrm{LVG}^{b}$} & \multirow{2}{*}{\multicolumn{2}{|c|}{$\begin{array}{c}\mathrm{LTE}^{c} \\
\quad N \\
\left(\mathrm{~cm}^{-2}\right) \\
\end{array}$}} & \multirow[t]{2}{*}{$f_{X}^{d}$} & \\
\hline & $\begin{array}{l}T_{\text {rot }} \\
(\mathrm{K})\end{array}$ & $\begin{array}{c}N \\
\left(\mathrm{~cm}^{-2}\right) \\
\end{array}$ & $\begin{array}{c}n \\
\left(\mathrm{~cm}^{-3}\right) \\
\end{array}$ & $\begin{array}{c}N \\
\left(\mathrm{~cm}^{-2}\right) \\
\end{array}$ & & & & \\
\hline \multicolumn{9}{|c|}{$\operatorname{IF}\left(0^{\prime \prime}, 0^{\prime \prime}\right)$} \\
\hline $\mathrm{C}^{18} \mathrm{O}$ & $40(5)$ & $7.3(1.0) \times 10^{15}$ & $>3 \times 10^{4}$ & $9.0 \times 10^{15}$ & & & $1.7 \times 10^{-7 e}$ & \\
\hline SO & $100(600)$ & $2.8(10) \times 10^{13}$ & & & & & $6.5 \times 10^{-10}$ & Bad estimate \\
\hline $\mathrm{SO}^{+}$ & & & & & 10 & $<1.0 \times 10^{12}$ & $<2.3 \times 10^{-11}$ & \\
\hline${ }^{13} \mathrm{CN}$ & & & & & 10 & $<1.2 \times 10^{13}$ & $<2.8 \times 10^{-10}$ & \\
\hline${ }^{13} \mathrm{CS}$ & & & $5 \times 10^{5 f}$ & $1.7 \times 10^{12}$ & & & $3.9 \times 10^{-11}$ & Col CS \\
\hline $\mathrm{SiO}$ & & & $5 \times 10^{5 f}$ & $<3.0 \times 10^{11}$ & & & $<7.0 \times 10^{-12}$ & \\
\hline HNC & & & $5 \times 10^{5 f}$ & $4.2 \times 10^{12}$ & & & $9.8 \times 10^{-11}$ & \\
\hline $\mathrm{H}^{13} \mathrm{CN}$ & $9(1)$ & $3.0(1.3) \times 10^{12}$ & $1 \times 10^{6}$ & $3.0 \times 10^{12}$ & & & $7.0 \times 10^{-11}$ & Col HCN \\
\hline $\mathrm{HN}^{13} \mathrm{C}$ & & & $5 \times 10^{5 f}$ & $4.0 \times 10^{11}$ & & & $9.3 \times 10^{-12}$ & Col HNC \\
\hline $\mathrm{HC}^{15} \mathrm{~N}$ & & & $5 \times 10^{5 f}$ & $4.0 \times 10^{11}$ & & & $9.3 \times 10^{-12}$ & Col HCN \\
\hline DCN & & & $5 \times 10^{5 f}$ & $3.0 \times 10^{12}$ & & & $7.0 \times 10^{-11}$ & Col HCN \\
\hline $\mathrm{C}_{2} \mathrm{H}$ & $16(1)$ & $3.7(0.1) \times 10^{14}$ & & & & & $8.6 \times 10^{-9}$ & self-absorption \\
\hline $\mathrm{C}_{2} \mathrm{D}$ & & & & & 10 & $<7.5 \times 10^{12}$ & $<1.7 \times 10^{-10}$ & \\
\hline $\mathrm{H}^{13} \mathrm{CO}^{+}$ & $22(5)$ & $8.7(4.7) \times 10^{11}$ & $1 \times 10^{6}$ & $1 \times 10^{12}$ & & & $2.0 \times 10^{-11}$ & \\
\hline $\mathrm{HCS}^{+}$ & & & $5 \times 10^{5 f}$ & $8.0 \times 10^{12}$ & & & $1.9 \times 10^{-10}$ & \\
\hline $\mathrm{N}_{2} \mathrm{H}^{+}$ & & & $5 \times 10^{5 f}$ & $2.1 \times 10^{12}$ & & & $4.9 \times 10^{-11}$ & \\
\hline $\mathrm{C}_{2} \mathrm{~S}$ & & & & & 10 & $2.0 \times 10^{12}$ & $4.6 \times 10^{-11}$ & Tentative \\
\hline $\mathrm{HCO}$ & & & & & 10 & $<3.0 \times 10^{12}$ & $<7.0 \times 10^{-11}$ & \\
\hline $\mathrm{SO}_{2}$ & & & $5 \times 10^{5 f}$ & $<4.3 \times 10^{12}$ & & & $<1.0 \times 10^{-10}$ & \\
\hline $\mathrm{H}_{2} \mathrm{CO}$ & $65(13)$ & $6.7(4.3) \times 10^{13}$ & $5 \times 10^{5}$ & $5.6 \times 10^{13}$ & & & $1.5 \times 10^{-9}$ & ortho/para $=3$ \\
\hline $\mathrm{H}_{2} \mathrm{CS}$ & $33(11)$ & $5.6(7.5) \times 10^{12}$ & & & & & $1.3 \times 10^{-10}$ & ortho/para $=3$ \\
\hline $\mathrm{HNCO}$ & & & & & 10 & $<8.0 \times 10^{11}$ & $<1.8 \times 10^{-11}$ & \\
\hline c- $\mathrm{C}_{3} \mathrm{H}_{2}$ & 11(2) & $7.1(7.0) \times 10^{12}$ & $7 \times 10^{5}$ & $8.5 \times 10^{12}$ & & & $2.0 \times 10^{-10}$ & ortho/para $=3$, self-absorption \\
\hline $\mathrm{HC}_{3} \mathrm{~N}$ & $33(2)$ & $3.4(0.5) \times 10^{12}$ & $7 \times 10^{5}$ & $3.4 \times 10^{12}$ & & & $7.9 \times 10^{-11}$ & \\
\hline $\mathrm{C}_{4} \mathrm{H}$ & & & & & 10 & $2.7 \times 10^{13}$ & $6.3 \times 10^{-10}$ & \\
\hline $\mathrm{CH}_{3} \mathrm{OH}$ & $9(3)$ & $6.4(10) \times 10^{14}$ & & & & & $1.5 \times 10^{-8}$ & Bad estimate \\
\hline $\mathrm{CH}_{3} \mathrm{CN}$ & & & & & 30 & $1.6 \times 10^{12}$ & $3.7 \times 10^{-11}$ & Bad estimate \\
\hline $\mathrm{CH}_{3} \mathrm{C}_{2} \mathrm{H}$ & $27(6)$ & $8.6(8.6) \times 10^{13}$ & & & & & $2.0 \times 10^{-9}$ & Bad estimate \\
\hline \multicolumn{9}{|c|}{$\operatorname{MP} 1\left(+15^{\prime \prime},-15^{\prime \prime}\right)$} \\
\hline $\mathrm{C}^{18} \mathrm{O}$ & $38(2)$ & $9.7(0.5) \times 10^{15}$ & $>3 \times 10^{4}$ & $9.7 \times 10^{15}$ & & & $1.7 \times 10^{-7 d}$ & \\
\hline SO & $54(15)$ & $3.0(1.2) \times 10^{13}$ & $2 \times 10^{6}$ & $3.2 \times 10^{13}$ & & & $5.2 \times 10^{-10}$ & \\
\hline $\mathrm{SO}^{+}$ & & & & & 10 & $3.0 \times 10^{12}$ & $5.2 \times 10^{-11}$ & \\
\hline${ }^{13} \mathrm{CN}$ & $3(2)$ & $1.4(3.5) \times 10^{15}$ & & & 10 & $9.0 \times 10^{12}$ & $1.6 \times 10^{-10}$ & Bad estimate \\
\hline${ }^{13} \mathrm{CS}$ & & & $5 \times 10^{5 f}$ & $2.5 \times 10^{12}$ & & & $4.4 \times 10^{-11}$ & Col CS \\
\hline $\mathrm{SiO}$ & 11(2) & $6.0(6.0) \times 10^{11}$ & $8 \times 10^{5}$ & $6.0 \times 10^{11}$ & & & $1.0 \times 10^{-11}$ & \\
\hline HNC & & & $5 \times 10^{5 f}$ & $1.5 \times 10^{13}$ & & & $2.6 \times 10^{-10}$ & \\
\hline $\mathrm{H}^{13} \mathrm{CN}$ & $8(1)$ & $3.7(1.6) \times 10^{12}$ & $7 \times 10^{5}$ & $3.0 \times 10^{12}$ & & & $6.5 \times 10^{-11}$ & Col HCN \\
\hline $\mathrm{HN}^{13} \mathrm{C}$ & & & $5 \times 10^{5 f}$ & $8.0 \times 10^{11}$ & & & $1.4 \times 10^{-11}$ & Col HNC \\
\hline $\mathrm{HC}^{15} \mathrm{~N}$ & & & $5 \times 10^{5 f}$ & $8.0 \times 10^{11}$ & & & $1.4 \times 10^{-11}$ & Col HCN \\
\hline $\mathrm{H}^{15} \mathrm{NC}$ & & & $5 \times 10^{5 f}$ & $1.8 \times 10^{11}$ & & & $3.1 \times 10^{-12}$ & Col HNC \\
\hline DCN & & & $5 \times 10^{5 f}$ & $6.0 \times 10^{12}$ & & & $1.0 \times 10^{-10}$ & Col HCN \\
\hline $\mathrm{C}_{2} \mathrm{H}$ & 13(1) & $4.6(0.5) \times 10^{14}$ & & & & & $8.1 \times 10^{-9}$ & \\
\hline $\mathrm{C}_{2} \mathrm{D}$ & & & & & 10 & $1.3 \times 10^{13}$ & $2.3 \times 10^{-10}$ & \\
\hline $\mathrm{H}^{13} \mathrm{CO}^{+}$ & 11(1) & $1.5(0.1) \times 10^{12}$ & $3 \times 10^{5}$ & $1.4 \times 10^{12}$ & & & $2.6 \times 10^{-11}$ & \\
\hline $\mathrm{HCS}^{+}$ & & & $5 \times 10^{5 f}$ & $1.6 \times 10^{12}$ & & & $2.8 \times 10^{-11}$ & \\
\hline $\mathrm{N}_{2} \mathrm{H}^{+}$ & & & $5 \times 10^{5 f}$ & $1.2 \times 10^{13}$ & & & $2.1 \times 10^{-10}$ & \\
\hline $\mathrm{C}_{2} \mathrm{~S}$ & & & & & 10 & $<1.1 \times 10^{12}$ & $1.9 \times 10^{-11}$ & \\
\hline $\mathrm{HCO}$ & & & & & 10 & $5.0 \times 10^{12}$ & $8.8 \times 10^{-11}$ & \\
\hline $\mathrm{SO}_{2}$ & & & $5 \times 10^{5 f}$ & $4.5 \times 10^{12}$ & & & $7.9 \times 10^{-11}$ & \\
\hline $\mathrm{H}_{2} \mathrm{CO}$ & $53(1)$ & $1.1(0.1) \times 10^{14}$ & $5 \times 10^{5}$ & $8.9 \times 10^{13}$ & & & $1.9 \times 10^{-9}$ & ortho/para $=3$ \\
\hline $\mathrm{H}_{2} \mathrm{CS}$ & $22(6)$ & $9.0(5.9) \times 10^{12}$ & & & & & $1.6 \times 10^{-10}$ & ortho $/$ para $=3$ \\
\hline HNCO & & & & & 10 & $1.5 \times 10^{12}$ & $2.6 \times 10^{-11}$ & \\
\hline $\mathrm{c}-\mathrm{C}_{3} \mathrm{H}_{2}$ & $11(2)$ & $9.3(3.6) \times 10^{12}$ & $3 \times 10^{5}$ & $8.0 \times 10^{12}$ & & & $1.6 \times 10^{-10}$ & ortho $/$ para $=3$ \\
\hline $\mathrm{HC}_{3} \mathrm{~N}$ & $26(1)$ & $9.3(1.3) \times 10^{12}$ & $5 \times 10^{5}$ & $9.0 \times 10^{12}$ & & & $1.6 \times 10^{-10}$ & \\
\hline $\mathrm{C}_{4} \mathrm{H}$ & & & & & 10 & $4.0 \times 10^{13}$ & $7.0 \times 10^{-10}$ & \\
\hline $\mathrm{CH}_{3} \mathrm{OH}$ & $16(8)$ & $1.1(4.8) \times 10^{13}$ & & & & & $1.9 \times 10^{-10}$ & Bad estimate \\
\hline $\mathrm{CH}_{3} \mathrm{CN}$ & $30(6)$ & $4.2(3.6) \times 10^{12}$ & & & & & $7.3 \times 10^{-11}$ & Bad estimate \\
\hline $\mathrm{CH}_{3} \mathrm{C}_{2} \mathrm{H}$ & $39(16)$ & $7.6(10) \times 10^{13}$ & & & & & $1.3 \times 10^{-9}$ & \\
\hline
\end{tabular}


Table 5. continued.

\begin{tabular}{|c|c|c|c|c|c|c|c|c|}
\hline \multirow[b]{2}{*}{ Molecule } & \multicolumn{2}{|r|}{$\mathrm{RD}^{a}$} & \multicolumn{2}{|c|}{$\mathrm{LVG}^{b}$} & \multicolumn{2}{|r|}{$\mathrm{LTE}^{c}$} & \multirow[t]{2}{*}{$f_{X}^{d}$} & \\
\hline & $\begin{array}{l}T_{\text {rot }} \\
(\mathrm{K}) \\
\end{array}$ & $\begin{array}{c}N \\
\left(\mathrm{~cm}^{-2}\right) \\
\end{array}$ & $\begin{array}{c}n \\
\left(\mathrm{~cm}^{-3}\right) \\
\end{array}$ & $\begin{array}{c}N \\
\left(\mathrm{~cm}^{-2}\right) \\
\end{array}$ & $\begin{array}{r}T_{\text {rot }}^{e} \\
(\mathrm{~K}) \\
\end{array}$ & $\begin{array}{c}N \\
\left(\mathrm{~cm}^{-2}\right) \\
\end{array}$ & & \\
\hline \multicolumn{9}{|c|}{$\operatorname{MP} 2\left(0^{\prime \prime},+40^{\prime \prime}\right)$} \\
\hline $\mathrm{C}^{18} \mathrm{O}$ & $65(8)$ & $1.3(0.2) \times 10^{16}$ & $>3 \times 10^{4}$ & $1.3 \times 10^{16}$ & & & $1.7 \times 10^{-7 d}$ & \\
\hline SO & $21(8)$ & $2.9(2.3) \times 10^{13}$ & $2 \times 10^{5}$ & $5.0 \times 10^{13}$ & & & $3.8 \times 10^{-10}$ & \\
\hline $\mathrm{SO}^{+}$ & & & & & 10 & $<1.8 \times 10^{12}$ & $<2.3 \times 10^{-11}$ & \\
\hline${ }^{13} \mathrm{CN}$ & $4(2)$ & $3.5(1.5) \times 10^{13}$ & & & & & $4.6 \times 10^{-10}$ & \\
\hline${ }^{13} \mathrm{CS}$ & & & $5 \times 10^{5 f}$ & $2.5 \times 10^{12}$ & & & $3.3 \times 10^{-11}$ & Col CS \\
\hline $\mathrm{SiO}$ & $11(1)$ & $6.5(1.2) \times 10^{11}$ & $5 \times 10^{5}$ & $1.0 \times 10^{12}$ & & & $8.5 \times 10^{-12}$ & \\
\hline HNC & & & $5 \times 10^{5 f}$ & $1.2 \times 10^{13}$ & & & $1.6 \times 10^{-10}$ & \\
\hline $\mathrm{H}^{13} \mathrm{CN}$ & $8(1)$ & $2.9(0.5) \times 10^{12}$ & $6 \times 10^{5}$ & $2.6 \times 10^{12}$ & & & $3.8 \times 10^{-11}$ & Col HCN \\
\hline $\mathrm{HN}^{13} \mathrm{C}$ & & & $5 \times 10^{5 f}$ & $5.0 \times 10^{11}$ & & & $6.5 \times 10^{-12}$ & Col HNC \\
\hline $\mathrm{HC}^{15} \mathrm{~N}$ & & & $5 \times 10^{5 f}$ & $5.0 \times 10^{11}$ & & & $6.5 \times 10^{-12}$ & $\mathrm{Col} \mathrm{HCN}$ \\
\hline $\mathrm{DCN}$ & & & $5 \times 10^{5 f}$ & $3.2 \times 10^{12}$ & & & $4.2 \times 10^{-11}$ & Col HCN \\
\hline $\mathrm{C}_{2} \mathrm{H}$ & $12(1)$ & $4.1(0.3) \times 10^{14}$ & & & & & $5.4 \times 10^{-9}$ & \\
\hline $\mathrm{C}_{2} \mathrm{D}$ & & & & & 10 & $2.0 \times 10^{13}$ & $2.6 \times 10^{-10}$ & \\
\hline $\mathrm{H}^{13} \mathrm{CO}^{+}$ & $10(1)$ & $1.1(0.3) \times 10^{12}$ & $2 \times 10^{5}$ & $1.3 \times 10^{12}$ & & & $1.4 \times 10^{-11}$ & \\
\hline $\mathrm{HCS}^{+}$ & & & $5 \times 10^{5 f}$ & $5.0 \times 10^{12}$ & & & $6.5 \times 10^{-11}$ & \\
\hline $\mathrm{N}_{2} \mathrm{H}^{+}$ & & & $5 \times 10^{5 f}$ & $4.0 \times 10^{12}$ & & & $5.2 \times 10^{-11}$ & \\
\hline $\mathrm{C}_{2} \mathrm{~S}$ & $11(7)$ & $1.9(5.3) \times 10^{12}$ & & & & & $2.5 \times 10^{-11}$ & \\
\hline $\mathrm{HCO}$ & & & & & 10 & $1.3 \times 10^{13}$ & $1.7 \times 10^{-10}$ & \\
\hline $\mathrm{SO}_{2}$ & $28(15)$ & $1.0(1.4) \times 10^{13}$ & $5 \times 10^{6}$ & $1.0 \times 10^{13}$ & & & $1.3 \times 10^{-10}$ & only $3 \mathrm{~mm}$ lines fitted \\
\hline $\mathrm{H}_{2} \mathrm{CO}$ & $52(4)$ & $9.3(2.0) \times 10^{13}$ & $1 \times 10^{7}$ & $8.0 \times 10^{13}$ & & & $1.2 \times 10^{-9}$ & ortho/para $=3$ \\
\hline $\mathrm{H}_{2} \mathrm{CS}$ & $60(38)$ & $1.3(2.1) \times 10^{13}$ & & & & & $1.7 \times 10^{-10}$ & ortho/para $=3$ \\
\hline HNCO & & & & & 10 & $<9.0 \times 10^{11}$ & $<1.2 \times 10^{-11}$ & \\
\hline c- $-\mathrm{C}_{3} \mathrm{H}_{2}$ & $12(1)$ & $1.3(0.1) \times 10^{13}$ & $4 \times 10^{5}$ & $1.3 \times 10^{13}$ & & & $1.7 \times 10^{-10}$ & ortho/para $=3$ \\
\hline $\mathrm{HC}_{3} \mathrm{~N}$ & $35(3)$ & $6.1(1.2) \times 10^{12}$ & $5 \times 10^{5}$ & $6.0 \times 10^{12}$ & & & $8.0 \times 10^{-11}$ & \\
\hline $\mathrm{C}_{4} \mathrm{H}$ & $9(4)$ & $1.2(1.6) \times 10^{14}$ & & & & & $1.6 \times 10^{-9}$ & \\
\hline $\mathrm{CH}_{3} \mathrm{OH}$ & $41(74)$ & $2.1(7.0) \times 10^{14}$ & & & & & $2.7 \times 10^{-9}$ & Bad estimate \\
\hline $\mathrm{CH}_{3} \mathrm{CN}$ & $59(20)$ & $5.6(2.2) \times 10^{12}$ & & & & & $7.3 \times 10^{-11}$ & Bad estimate \\
\hline $\mathrm{CH}_{3} \mathrm{C}_{2} \mathrm{H}$ & & & & & 30 & $9.0 \times 10^{13}$ & $1.2 \times 10^{-10}$ & Bad estimate \\
\hline
\end{tabular}

Notes. ${ }^{(a)}$ Rotational diagrams. Numbers in parenthesis are the mathematical error of the fitting. ${ }^{(b)}$ LVG calculations assuming $T_{\mathrm{k}}=50 \mathrm{~K}$, $\Delta v=5 \mathrm{~km} \mathrm{~s}^{-1}$ for the IF and MP1 and $T_{\mathrm{k}}=70 \mathrm{~K}$ for the MP2 positions. When only one transition is observed, a molecular hydrogen density of $5 \times 10^{5} \mathrm{~cm}^{-3}$. ${ }^{(c)}$ Local Thermodynamic Equilibrium calculations. ${ }^{(d)}$ Fractional abundance derived assuming $N\left(\mathrm{C}^{18} \mathrm{O}\right) / N\left(\mathrm{H}_{2}\right)=1.7 \times 10^{-7}$. ${ }^{(e)}$ Assumed $\mathrm{C}^{18} \mathrm{O}$ wrt $\mathrm{H}_{2}$ abundance. ${ }^{(f)}$ Assumed molecular hydrogen density.

Using a ${ }^{12} \mathrm{C} /{ }^{13} \mathrm{C}$ ratio of 50 , we derived $X(\mathrm{HCN}) \sim 5 \times 10^{-9}$ and $[\mathrm{HCN}] /[\mathrm{HNC}] \approx 5-8$ at the three observed positions. The $[\mathrm{HCN}] /[\mathrm{HNC}]$ ratio is a factor of about two larger than in NGC 7023 and the Orion Bar (Fuente et al. 1996, 2003). In addition to $\mathrm{H}^{13} \mathrm{CN}$, we detected $\mathrm{HC}^{15} \mathrm{~N}$ towards the three targeted positions. The $\left[\mathrm{H}^{13} \mathrm{CN}\right] /\left[\mathrm{HC}^{15} \mathrm{~N}\right]$ is about 10 towards the three offsets, which would imply that ${ }^{14} \mathrm{~N} /{ }^{15} \mathrm{~N}=500$ for our assumed ${ }^{12} \mathrm{C} /{ }^{13} \mathrm{C}$ isotopic ratio. This ratio is similar to that measured by Gerin et al. (2009c) in dark clouds and low-mass star-forming regions, and consistent with the protosolar value of $\sim 424$. Assuming a higher ${ }^{12} \mathrm{C} /{ }^{13} \mathrm{C}$ isotopic ratio, $\sim 89$, would imply that ${ }^{14} \mathrm{~N} /{ }^{15} \mathrm{~N}=890$. In MP1, we have a tentative detection of the $\mathrm{H}^{15} \mathrm{NC} 1 \rightarrow 0$ line. Using this 3- $\sigma$ detection, we derive $\left[\mathrm{HC}^{15} \mathrm{~N}\right] /\left[\mathrm{H}^{15} \mathrm{NC}\right]=4$, which is similar to the values found in NGC 7023 and the Orion Bar. A complete multitransitional study of $\mathrm{HCN}$ and its isotopologues and detailed source modeling is required to derive a more accurate estimate of the $[\mathrm{HCN}] /[\mathrm{HNC}]$ ratio and how it varies across the envelope in Mon R2.

\section{2. $\mathrm{CN} / \mathrm{HCN}$}

Fuente et al. (1993) detected a $[\mathrm{CN}] /[\mathrm{HCN}]$ abundance ratio larger than unity in the north-west PDR of NGC 7023 and interpreted this as the consequence of the photodissociation of $\mathrm{HCN}$ into $\mathrm{CN}$. Since then, the $[\mathrm{CN}] /[\mathrm{HCN}]$ ratio has been successfully used as a PDR tracer in different environments, PDRs associated with star forming regions such as the Orion Bar and NGC 7023, planetary nebulae, protoplanetary disks, and even external galaxies. In Mon R2, we use the rarer isotopes ${ }^{13} \mathrm{CN}$ and $\mathrm{H}^{13} \mathrm{CN}$ to derive the $[\mathrm{CN}] /[\mathrm{HCN}]$ abundance ratio. We derive a $[\mathrm{CN}] /[\mathrm{HCN}]$ abundance ratio of $\sim 2-12$ towards the three positions. This high $[\mathrm{CN}] /[\mathrm{HCN}]$ abundance ratio is consistent with that found in other environments such as NGC 7023, the Orion Bar, the planetary nebula NGC 7027, and the starburst galaxy $\mathrm{M}$ 82. The $[\mathrm{CN}] /[\mathrm{HCN}]$ ratio in typical bipolar outflows is <1 (see Bachiller \& Pérez-Gutiérrez 1997). This supports the interpretation that $\mathrm{CN}$ and $\mathrm{HCN}$ originate from the PDR instead of the bipolar outflows.

\section{3. $\mathrm{CS} / \mathrm{HCS}^{+}$}

We detected $\mathrm{HCS}^{+}$towards the ionization front with an abundance of $\sim 1.9 \times 10^{-10}$. This is one of the few molecules that has a higher abundance at this position and argues in favor of $\mathrm{HCS}^{+}$arising from the surface of the PDR. The $\mathrm{HCS}^{+}$abundance measured towards the IF is a factor of about five higher 
D. Ginard et al.: Spectral line survey of the ultracompact HII region Mon R2
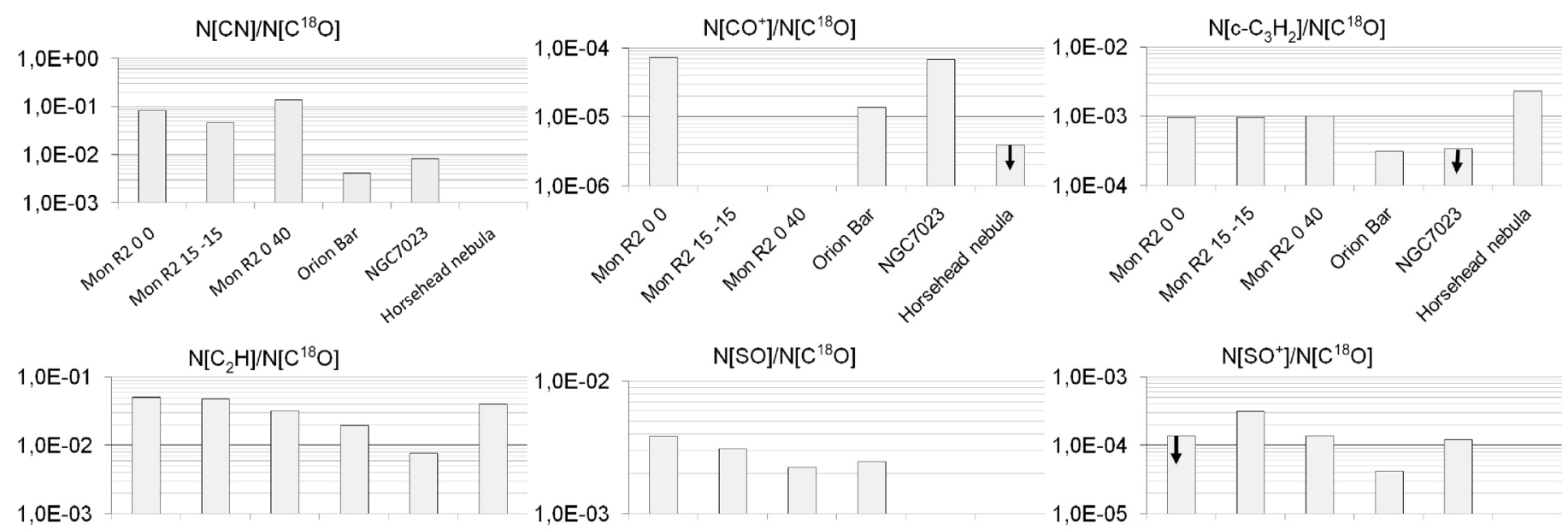

$\mathrm{N}[\mathrm{SO}] / \mathrm{N}\left[\mathrm{C}^{18} \mathrm{O}\right]$
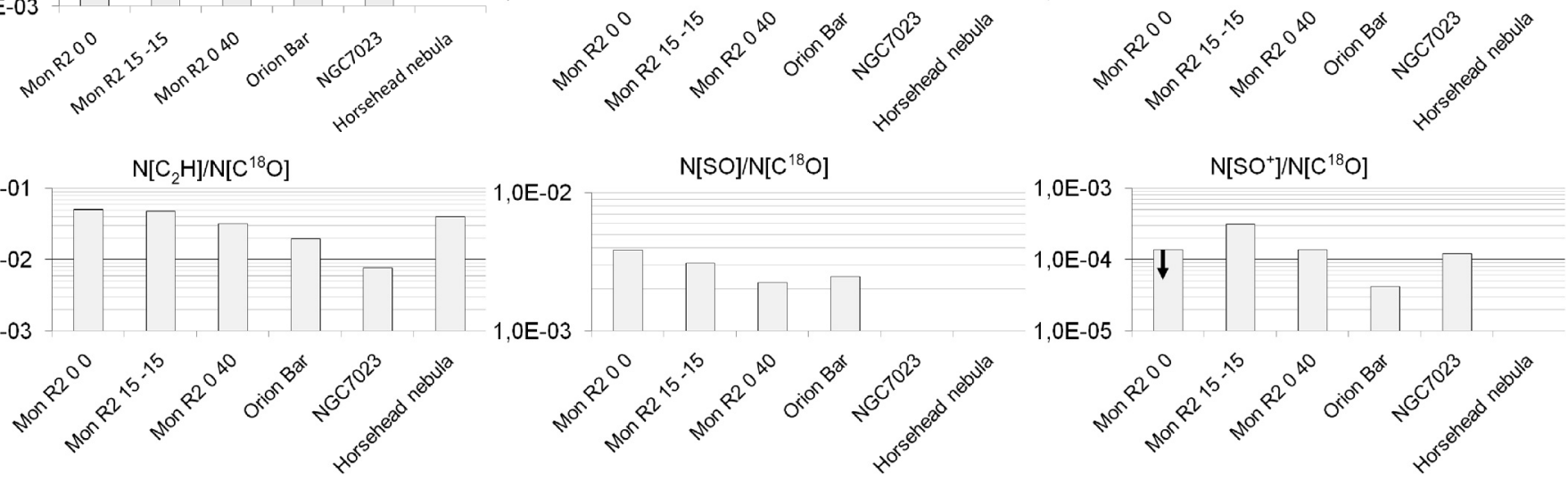
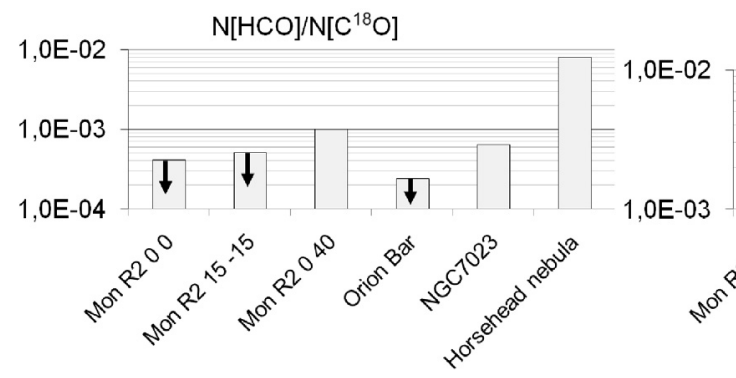

$\mathrm{N}\left[\mathrm{HCO}^{+}\right] / \mathrm{N}\left[\mathrm{C}^{18} \mathrm{O}\right]$

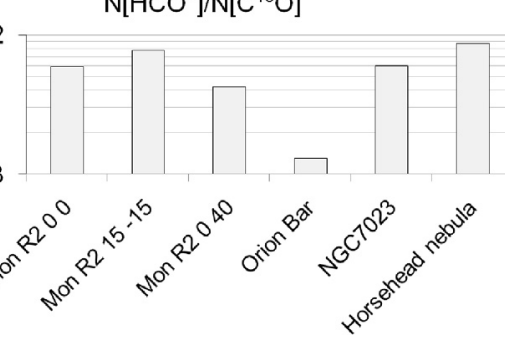

$\mathrm{N}[\mathrm{HCN}] / \mathrm{N}\left[\mathrm{C}^{18} \mathrm{O}\right]$

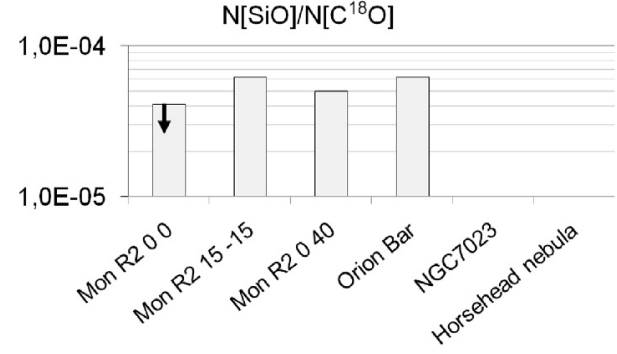

$\mathrm{N}\left[\mathrm{C}_{4} \mathrm{H}\right] \mathrm{N}\left[\mathrm{C}^{18} \mathrm{O}\right]$
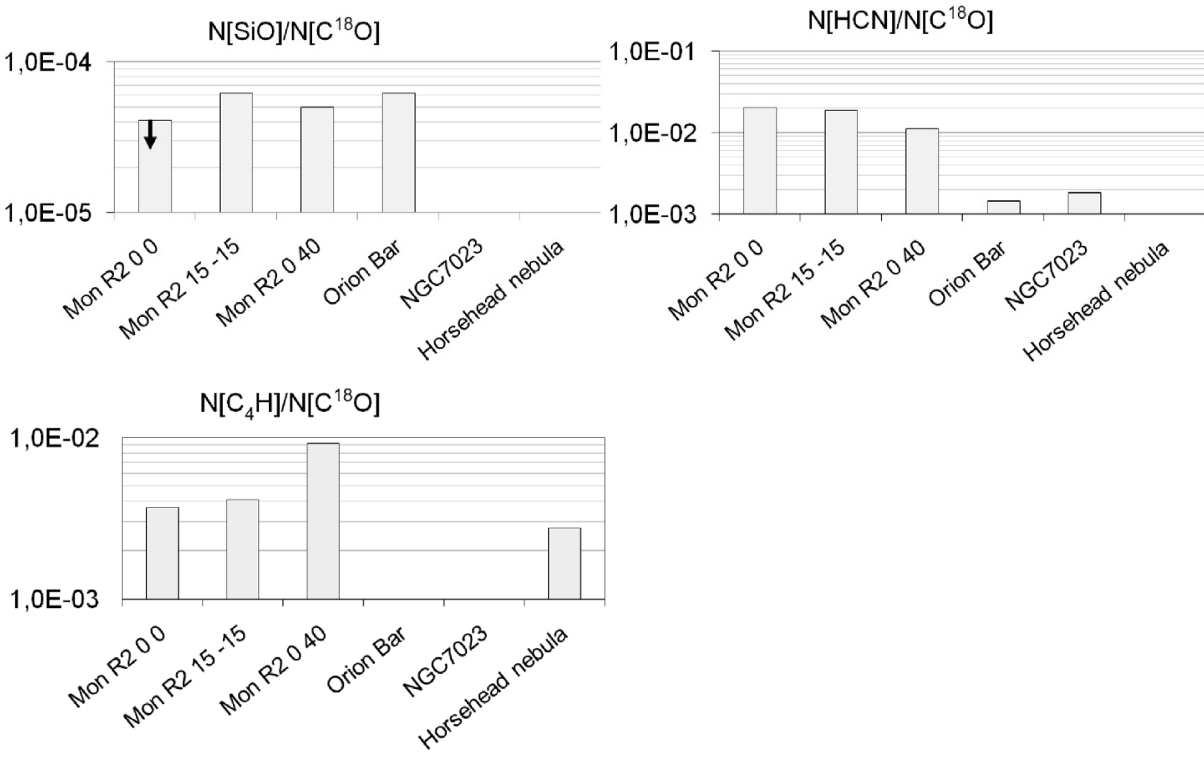
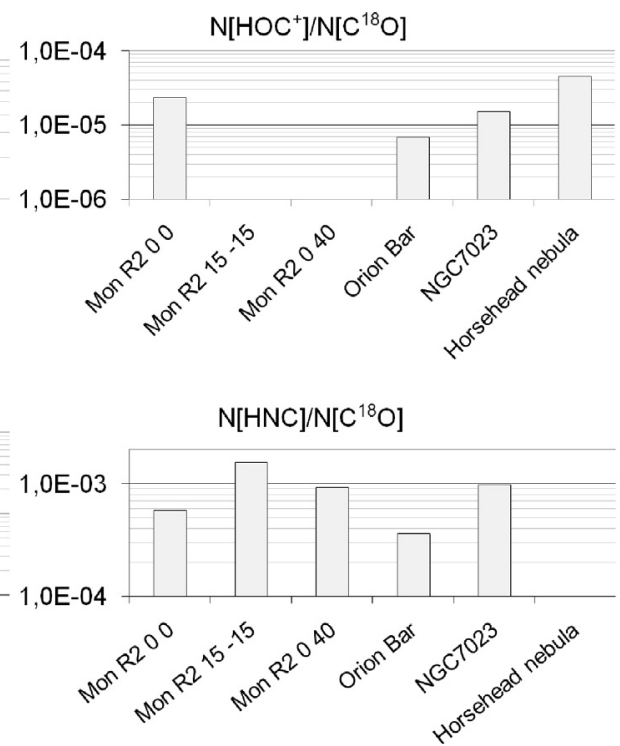

Fig. 3. Comparison of the abundance of the most representative species among the prototypical PDRs: Mon R2, NGC 7023, Orion Bar, and the Horsehead.

than that observed in the Horsehead nebula (Goicoechea et al. 2006) but comparable with that measured by Lucas \& Liszt (2002) towards diffuse clouds. The $\mathrm{HCS}^{+}$abundance towards the other two positions, MP1 and the MP2 peaks, is lower by a factor of $>4$ and more similar to that measured in the Horsehead nebula. The derived $[\mathrm{CS}] /\left[\mathrm{HCS}^{+}\right]$ratio is uncertain because the $\mathrm{CS}$ lines are optically thick. From our ${ }^{13} \mathrm{CS}$ observations and assuming ${ }^{12} \mathrm{CS} /{ }^{13} \mathrm{CS}=50$, we find that the $[\mathrm{CS}] /\left[\mathrm{HCS}^{+}\right] \sim 11$ in IF and $\sim 25$ in MP2. Tafalla et al. (1997) derived column densities of $N(\mathrm{CS})=5.6 \times 10^{13} \mathrm{~cm}^{-2}$ towards the IF from an LVG analysis using the CS $J=2 \rightarrow 1, J=3 \rightarrow 2$, and $5 \rightarrow 4$ lines, which would imply that $[\mathrm{CS}] /\left[\mathrm{HCS}^{+}\right] \sim 7$. These values are closer to the value $[\mathrm{CS}] /\left[\mathrm{HCS}^{+}\right] \sim 10$ measured in diffuse clouds than to the value $\sim 175$ measured towards the Horsehead nebula.

\section{4. $\mathrm{SO}^{+}, \mathrm{SO}, \mathrm{SO}_{2}$, and $\mathrm{H}_{2} \mathrm{CS}$}

In previous studies, $\mathrm{SO}^{+}$has been detected in warm and cold clouds with abundances ranging from $\sim 10^{-9}-10^{-11}$. These 
Table 6. Comparison with prototypical PDRs.

\begin{tabular}{|c|c|c|c|c|c|c|c|c|c|c|}
\hline & $\left(0^{\prime \prime}, 0^{\prime \prime}\right)$ & $\begin{array}{c}\text { Mon R2 } \\
\left(+15^{\prime \prime},-15^{\prime \prime}\right)\end{array}$ & $\left(0^{\prime \prime},+40^{\prime \prime}\right)$ & Ref & $\begin{array}{l}\text { Orion Bar } \\
\text { IF }\end{array}$ & Ref & $\begin{array}{c}\text { NGC } 7023 \\
\left(-25^{\prime \prime},+40^{\prime \prime}\right)\end{array}$ & Ref & $\begin{array}{l}\text { Horsehead } \\
\text { PDR peak }\end{array}$ & Ref \\
\hline $\begin{array}{l}G_{0} \text { (Habing) } \\
n\left(\mathrm{~cm}^{-3}\right)^{a}\end{array}$ & & $\begin{array}{l}5 \times 10^{5} \\
4 \times 10^{6} \\
\end{array}$ & & 1,2 & $\begin{array}{c}2 \times 10^{4} \\
\sim 5 \times 10^{5} \\
\end{array}$ & 3,4 & $\begin{array}{c}2 \times 10^{3} \\
\sim 2 \times 10^{5} \\
\end{array}$ & 5 & $\begin{array}{c}100 \\
\sim 10^{5}\end{array}$ & $6,7,8$ \\
\hline $\begin{array}{l}\mathrm{H}^{13} \mathrm{CN} / \mathrm{HN}^{13} \mathrm{C} \\
\mathrm{HCN} / \mathrm{HNC}\end{array}$ & 7.5 & 5 & 4 & 1 & $\begin{array}{c}>2 \\
3\end{array}$ & $\begin{array}{l}3 \\
3\end{array}$ & 2 & 5 & & \\
\hline $\begin{array}{l}{ }^{13} \mathrm{CN} / \mathrm{H}^{13} \mathrm{CN} \\
\mathrm{CN} / \mathrm{HCN}\end{array}$ & $<4$ & 2 & $5-12$ & 1 & 3.0 & 3 & 4.5 & 5 & & \\
\hline $\begin{array}{l}\mathrm{H}^{13} \mathrm{CO}^{+} / \mathrm{H}^{13} \mathrm{CN} \\
\mathrm{HCO}^{+} / \mathrm{HCN}\end{array}$ & 0.29 & 0.40 & 0.37 & 1 & 0.9 & 3 & 3.3 & 5 & & \\
\hline $\begin{array}{l}\mathrm{CO}^{+} / \mathrm{H}^{13} \mathrm{CO}^{+} \\
\mathrm{H}^{13} \mathrm{CO}^{+} / \mathrm{HOC}^{+}\end{array}$ & $\begin{array}{c}0.53 \\
5.8\end{array}$ & & & $\begin{array}{l}1,2 \\
1,2\end{array}$ & $\begin{array}{c}0.52 \\
3.8\end{array}$ & $\begin{array}{l}3,4 \\
3,4\end{array}$ & $\begin{array}{c}0.6 \\
5-14^{b}\end{array}$ & $\begin{array}{l}4,5 \\
4,5\end{array}$ & $\begin{array}{c}<0.03 \\
\sim 4\end{array}$ & $\begin{array}{l}6 \\
6\end{array}$ \\
\hline $\begin{array}{l}\mathrm{c}-\mathrm{C}_{3} \mathrm{H}_{2} / \mathrm{C}_{2} \mathrm{H} \\
\mathrm{C}_{4} \mathrm{H} / \mathrm{C}_{2} \mathrm{H} \\
\mathrm{HCO} / \mathrm{H}^{13} \mathrm{CO}^{+}\end{array}$ & $\begin{array}{c}0.02 \\
0.07 \\
<3 \\
\end{array}$ & $\begin{array}{c}0.02 \\
0.09 \\
<3 \\
\end{array}$ & $\begin{array}{c}0.03 \\
0.3 \\
12 \\
\end{array}$ & $\begin{array}{l}1 \\
1 \\
1 \\
\end{array}$ & 0.016 & 3,4 & 0.03 & 4,5 & $\begin{array}{c}0.06 \\
0.1 \\
50^{c} \\
\end{array}$ & $\begin{array}{c}7 \\
7 \\
8,9 \\
\end{array}$ \\
\hline $\begin{array}{l}\mathrm{SO}^{+} / \mathrm{SO} \\
\mathrm{CS} / \mathrm{HCS}^{+}\end{array}$ & $11^{d}$ & $\begin{array}{l}0.1 \\
78^{d}\end{array}$ & $\begin{array}{l}<0.06 \\
25^{d}\end{array}$ & $\begin{array}{l}1 \\
1\end{array}$ & & & & & 0.008 & 10 \\
\hline
\end{tabular}

Notes. ${ }^{(a)}$ The density is not uniform in these regions. We indicate the representative density of the clumps/filaments. ${ }^{(b)}$ Depending on the assumed excitation conditions. ${ }^{(c)}$ It strongly depends on the position, varying between $\sim 1$ in the shielded core to $\sim 50$ in the HCO peak. The value in the table corresponds to the HCO peak derived from $\sim 14^{\prime \prime}$ angular resolution observations. ${ }^{(d)}$ Obtained from our ${ }^{13} \mathrm{CS}$ data assuming ${ }^{12} \mathrm{C} /{ }^{13} \mathrm{C}=50$.

References. (1) This work; (2) Rizzo et al. (2003); (3) Fuente et al. (1996); (4) Fuente et al. (2003); (5) Fuente et al. (1993); (6) Goicoechea et al. (2009); (7) Teyssier et al. (2004); (8) Gerin et al. (2009a); (9) Gerin et al. (2009b); (10) Goicoechea et al. (2006).

fractional abundances can be explained by gas-phase ionmolecule chemistry (Turner 1994). In PDRs, $\mathrm{SO}^{+}$has been detected in NGC 7023 and the Orion Bar. The $\mathrm{SO}^{+}$abundance in these regions is $5 \times 10^{-11}$ and $1 \times 10^{-10}$, respectively. In Mon R2, we detected $\mathrm{SO}^{+}$in the MP1, with an abundance of $\sim 5 \times 10^{-11}$. We did not detect $\mathrm{SO}^{+}$towards the MP2 peak. In PDRs, $\mathrm{SO}^{+}$ is primarily formed via $\mathrm{S}^{+}+\mathrm{OH} \rightarrow \mathrm{SO}^{+}+\mathrm{H}$ and removed by dissociative recombination in $\mathrm{S}+\mathrm{O}$. The lack of $\mathrm{SO}^{+}$in the MP2 peak is very likely related to a lower abundance of $\mathrm{OH}$ at this position. The radical $\mathrm{OH}$ is formed by endothermic reactions in the outer layers of the PDR and very sensitive to the gas kinetic temperature.

In addition to $\mathrm{CS}, \mathrm{HCS}^{+}, \mathrm{SO}$, and $\mathrm{SO}^{+}$, we have also detected the more complex sulfurated species $\mathrm{C}_{2} \mathrm{~S}, \mathrm{H}_{2} \mathrm{CS}$, and $\mathrm{SO}_{2}$. While SO has similar fractional abundances towards the three positions, there are some differences in the abundances of the other compounds. The carbon chains such as $\mathrm{C}_{2} \mathrm{~S}$ and $\mathrm{H}_{2} \mathrm{CS}$ are more abundant towards the MP2 than towards the IF and MP1. $\mathrm{SO}_{2}$ is not detected towards both the IF, corroborating a previous interpretation that this molecule is easily destroyed by UV radiation (see e.g. Fuente et al. 2003).

\section{5. $\mathrm{SiO}$}

$\mathrm{SiO}$ was detected in Mon R2 by Rizzo et al. (2005). They derived a $\mathrm{SiO}$ column density of $1.1 \times 10^{11} \mathrm{~cm}^{-2}$ towards the IF, which is consistent with our upper limit of $<3.0 \times 10^{11} \mathrm{~cm}^{-2}$. We detected $\mathrm{SiO}$ towards MP1 and MP2 with an abundance of $\sim 10^{-11}$, which is lower than that determined by Schilke et al. (2001) towards the Orion Bar $\left(\sim 7 \times 10^{-11}\right.$ in the IF) and consistent with that expected in PDRs. There is no hint of an enhanced $\mathrm{SiO}$ abundance produced by the shocks associated with the bipolar outflows or the expected shock front associated with the expansion of the UC HII. This is unsurprising since an expansion velocity of $\lesssim 1.0 \mathrm{~km} \mathrm{~s}^{-1}$ (Fuente et al. 2010; Pilleri et al. 2012) is not high enough to destroy the core of the silicates grains. The low $\mathrm{SiO}$ abundance argues against a dominant role of shocks in the chemistry of this region.

\section{6. $\mathrm{C}_{2} \mathrm{H}, \mathrm{C}-\mathrm{C}_{3} \mathrm{H}_{2}$, and $\mathrm{C}_{4} \mathrm{H}$}

Intense $\mathrm{C}_{2} \mathrm{H}$ and $\mathrm{c}-\mathrm{C}_{3} \mathrm{H}_{2}$ emission is detected towards all the observed positions with the maximum column density being found towards MP2. The maximum fractional abundances are $X\left(\mathrm{C}_{2} \mathrm{H}\right) \sim 5 \times 10^{-9}$ and $X\left(\mathrm{c}-\mathrm{C}_{3} \mathrm{H}_{2}\right) \sim 1.7 \times 10^{-10}$. These values are a factor about three lower than those measured towards the Horsehead and the Orion Bar but are similar to those measured in NGC 7023. Taking into account, the uncertainties in the calculation of the fractional abundances, these differences are insignificant. We note that for the Horsehead we compared the single-dish column densities published by Teyssier et al. (2004) with our data because interferometric observations filter out the extended emission tracing only the small spatial scales. The $\left[\mathrm{c}-\mathrm{C}_{3} \mathrm{H}_{2}\right] /\left[\mathrm{C}_{2} \mathrm{H}\right]$ ratio is quite uniform with a value of $\sim 0.03$. The large chain $\mathrm{C}_{4} \mathrm{H}$ had only been detected in low-UV PDRs (IC 63, $\rho$-Oph and the Horsehead) thus far (Teyssier et al. 2004; Pety et al. 2005). The $\left[\mathrm{C}_{4} \mathrm{H}\right] /\left[\mathrm{C}_{2} \mathrm{H}\right]$ ratio reaches a maximum at the MP2 confirming that the PDR at this position is particularly rich in carbon chains.

\section{7. $\mathrm{HCO}$}

The formyl radical, HCO, was detected in the interstellar medium by Snyder et al. (1976). Pioneering studies by Schenewerk et al. (1988) pointed out that there is an association of large HCO abundances with the gas around HII regions. Schilke et al. (2001) detected HCO towards NGC 2023, the offset $\left(-30^{\prime \prime}, 80^{\prime \prime}\right)$ in NGC 7023 , the position referred to as $\operatorname{Bar}(\mathrm{CO})$ in the Orion Bar and the IF in S140. From a limited mapping, they concluded that HCO is associated with the PDR component and explained the enhancement of 
$\mathrm{HCO}$ abundance as the consequence of the photodissociation of the $\mathrm{H}_{2} \mathrm{CO}$ molecules released from the grain mantles by UV photons. García-Burillo et al. (2002) mapped this radical in the starburst M 82 and also interpreted it as arising in the giant PDR in the disk of this galaxy. Gerin et al. (2009a) carried out a high angular resolution mapping of the Horsehead in this radical. The maximum of the $\mathrm{HCO}$ emission was found towards a position where the PAH band emission is particularly intense. The $\mathrm{HCO}$ emission becomes fainter in the more shielded molecular gas. After updating some reaction rates, in particular $\mathrm{O}+\mathrm{CH}_{2} \rightarrow$ $\mathrm{HCO}+\mathrm{H}$, they found that gas-phase chemistry could account for the high $\mathrm{HCO}$ abundance without invoking the photodesorption of $\mathrm{H}_{2} \mathrm{CO}$ from the ice mantles. In Mon R2, we have detected HCO towards MP2 with a fractional abundance of $\sim 1.7 \times 10^{-10}$. Towards the IF and the MP1, the HCO abundance is at least a factor of about two lower than towards the MP2. We note that Schilke et al. (2001) did not detect HCO towards the IF but only in the position referred to as $\operatorname{Bar}(\mathrm{CO})$ in their paper, which could correspond to a lower UV radiation field.

\section{8. $\mathrm{H}_{2} \mathrm{CO}$}

We derived a $\mathrm{H}_{2} \mathrm{CO}$ abundance of $\approx 1-2 \times 10^{-9}$ in Mon R2. This abundance is close to that found in hot cores (see e.g. Sutton et al. 1995) and higher than that expected in a PDR. Guzmán et al. (2011) studied the formation of $\mathrm{H}_{2} \mathrm{CO}$ in the Horsehead. They derived an $\mathrm{H}_{2} \mathrm{CO}$ abundance of $4-6 \times 10^{-10}$ in the PDR peak, similar to that found in the shielded core position. They could not explain the $\mathrm{H}_{2} \mathrm{CO}$ abundance in this PDR only with gas phase chemistry. However, they obtained a good agreement between model predictions and observations with a gas phase+surface chemistry model in which $\mathrm{H}_{2} \mathrm{CO}$ can be formed on the grain surfaces and photo-desorbed to the gas phase, in addition to the gas phase route. In Mon R2, the emission of $\mathrm{H}_{2} \mathrm{CO}$ is ubiquitous (Giannakopoulou et al. 1997) and the low spatial resolution of our observations makes it difficult to determine whether its origin is either the PDR, the more shielded molecular gas, or the bipolar outflows.

\subsection{Complex molecules: $\mathrm{CH}_{3} \mathrm{OH}, \mathrm{CH}_{3} \mathrm{CN}$, and $\mathrm{HC}_{3} \mathrm{~N}$}

In addition to PDR-like molecules, we detected in our survey other complex species that are not expected to be abundant in PDRs and are usually associated with the chemistry of warm clouds. This is the case for $\mathrm{CH}_{3} \mathrm{OH}, \mathrm{CH}_{3} \mathrm{CN}$, and $\mathrm{HC}_{3} \mathrm{~N}$. In the case of methanol, our fractional abundance estimates are very uncertain. The abundance of $\mathrm{CH}_{3} \mathrm{CN}$ is also quite constant and equal to $\approx 7 \times 10^{-11}$. For $\mathrm{HC}_{3} \mathrm{~N}$, we measured abundances of $7 \times 10^{-11}-10^{-10}$. These values are lower than those found in hot cores, but very similar to those found in warm molecular clouds such as the Orion Ridge and the envelopes of massive protostars.

Complex molecules are rapidly destroyed by UV radiation. Assuming a typical photodissociation rate of $10^{-10} \mathrm{~s}^{-1}$, the lifetime of complex molecules would be $>10^{5} \mathrm{yr}$ but only for $A_{\mathrm{V}}>$ 10 mag. Fuente et al. (2010) and Pilleri et al. (2012) estimated an expansion velocity of $\lesssim 1.0 \mathrm{~km} \mathrm{~s}^{-1}$ for this UC HII, which implies a dynamical time of $\sim 10^{5} \mathrm{yr}$. This means that complex molecules of the initial core might have survived as long as they were within clumps in which the visual extinction is $>10$ mag. High spatial resolution observations are required to distinguish the region from which the emission of complex molecules arises and place additional constraints on their formation mechanism.

\subsection{Deuteration: $D C N, C_{2} D$}

We detected DCN and $\mathrm{C}_{2} \mathrm{D}$ towards the MP1 and MP2. The DCN abundances are $X(\mathrm{DCN})=1.0 \times 10^{-10}(\mathrm{MP} 1)$ and $X(\mathrm{DCN})=4.2 \times 10^{-11}(\mathrm{MP} 2)$. The $\mathrm{C}_{2} \mathrm{D}$ abundances are $X\left(\mathrm{C}_{2} \mathrm{D}\right)=2.3 \times 10^{-10}(\mathrm{MP} 1)$ and $X\left(\mathrm{C}_{2} \mathrm{D}\right)=2.6 \times 10^{-10}(\mathrm{MP} 2)$. These abundances correspond to deuterium fractionation values of $\sim 0.03-0.05$ for both $\mathrm{HCN}$ and $\mathrm{C}_{2} \mathrm{H}$. The deuterium fractionation of $\mathrm{HCN}$ is a factor of about ten higher than that measured by Parise et al. (2009) in the position $\mathrm{Bar}(\mathrm{HCN})$ of the Orion Bar. The deuterated species $\mathrm{C}_{2} \mathrm{D}$ was not detected in Orion with a lower limit to the $\mathrm{C}_{2} \mathrm{D} / \mathrm{C}_{2} \mathrm{H}$ ratio of $<0.04$. Pety et al. (2007) detected $\mathrm{DCO}^{+}$in a cold clump $\left(T_{\mathrm{k}} \sim 10-20 \mathrm{~K}\right)$ towards the Horsehead and measured $\left[\mathrm{DCO}^{+}\right] /\left[\mathrm{H}^{13} \mathrm{CO}^{+}\right]=0.02$. There is no intense transition of $\mathrm{DCO}^{+}$in the frequency range covered by our survey. Therefore, we were unable to estimate the $\mathrm{DCO}^{+}$abundance.

Several mechanisms have been proposed to explain the high values of deuterium fractionation (which is higher than the deuterium abundance in the Universe, of $\mathrm{D} / \mathrm{H} \sim 10^{-5}$ ) observed in the interstellar medium. Deuterated isotopologues of methanol and formaldehyde have been detected in hot cores and corinos (see e.g. Parise et al. 2002, 2004; Fuente et al. 2005), where the gas kinetic temperatures is $>100 \mathrm{~K}$. In these cases, the fractionation is thought to occur on grain surfaces. The deuterated compounds are released into the gas phase when the ice is evaporated, producing a transient deuterium enhancement in gas phase. In Mon R2, we detected the deuterated compounds of $\mathrm{HCN}$ and $\mathrm{C}_{2} \mathrm{H}$. Since these molecules are not mainly formed on grain surfaces, it is more plausible to ascertain that the deuteration has occurred in gas phase.

In molecular clouds, deuterium is mainly locked into HD. The efficient transfer of deuterium from this reservoir to other species occurs by means of ion-molecule reactions. In cold clumps at temperatures of $T_{\mathrm{k}} \approx 10-20 \mathrm{~K}$, deuteration is usually transferred via reactions with $\mathrm{H}_{2} \mathrm{D}^{+}$. This mechanism is very efficient, for instance, in pre-stellar cores where molecules are highly depleted (see e.g. Caselli et al. 2003). For slightly higher temperatures of $T_{\mathrm{k}} \approx 30-50 \mathrm{~K}$, the transfer is more efficient via $\mathrm{CH}_{2} \mathrm{D}^{+}$(Roueff et al. 2007; Parise et al. 2009). The high temperatures measured in Mon R2 favor a deuteration mechanism based on $\mathrm{CH}_{2} \mathrm{D}^{+}$. Our measurements agree with the gas-phase model predictions of Roueff et al. (2007) and Parise et al. (2009) for $T_{\mathrm{k}} \sim 30-50 \mathrm{~K}$ and densities of about a few $10^{6} \mathrm{~cm}^{-3}$. These densities are not unrealistic in this region (Rizzo et al. 2005). One possibility is that $\mathrm{C}_{2} \mathrm{D}$ comes from the densest part of this PDR. Other possibilities are that a fraction of these molecules are formed on grain surfaces or that their chemistry is related to some of the evaporated species.

\section{Chemical diagnostics}

From the discussion in Sect. 5, it seems clear that the emission of some of the detected species comes from the extended PDR around this HII region. In the following, we try to understand the differences between MP1 and MP2 in terms of PDR chemistry. We developed a grid of isochoric models using the updated version (1.4.2) of the PDR Meudon code (Le Petit et al. 2006; Goicoechea et al. 2007) and the parameters listed in Table 7. Our grid of models range in terms of density 
Table 7. Input parameters for the Meudon PDR code.

\begin{tabular}{llc}
\hline \hline Parameter & Value \\
\hline$G_{0}$ & Radiation field intensity (Habing) & 10 to $10^{6}$ \\
$G_{0}^{\text {ext }}$ & External Radiation field intensity (Habing) & 1 \\
$n$ & Hydrogen nuclei density & $10^{4}$ to $10^{7} \mathrm{~cm}^{-3}$ \\
$A_{\mathrm{V}}$ & Cloud depth & $10 \mathrm{mag}$ \\
Extinction & Standard Galactic & \\
$R_{\mathrm{V}}$ & $A_{\mathrm{V}} / E(B-V)$ & 3.1 \\
$\zeta$ & Cosmic ray ionization rate & $5 \times 10^{-17} \mathrm{~s}^{-1}$ \\
$a_{\min }$ & Dust minimum radius & $3 \times 10^{-7} \mathrm{~cm}$ \\
$a_{\max }$ & Dust maximum radius & $3 \times 10^{-5} \mathrm{~cm}$ \\
$\alpha$ & MRN dust size distribution index & 3.5 \\
$\mathrm{He} / \mathrm{H}$ & Helium abundance & 0.1 \\
$\mathrm{O} / \mathrm{H}$ & Oxygen abundance & $3.2 \times 10^{-4}$ \\
$\mathrm{C} / \mathrm{H}$ & Carbon abundance & $1.3 \times 10^{-4}$ \\
$\mathrm{~N} / \mathrm{H}$ & Nitrogen abundance & $7.5 \times 10^{-5}$ \\
$\mathrm{~S} / \mathrm{H}$ & Sulphur abundance & $1.9 \times 10^{-5}$ \\
$\mathrm{Fe} / \mathrm{H}$ & Metal abundance & $1.5 \times 10^{-8}$ \\
\hline
\end{tabular}

between $10^{4} \mathrm{~cm}^{-3}$ and $10^{7} \mathrm{~cm}^{-3}$, and FUV field between 10 and $10^{6}$ Habing fields. We ran the same grid of models using the standard Galactic and the Orion extinction curves but the results are essentially the same for the molecular abundance ratios discussed below. For each model, we represent the cumulative column densities summed up to $10 \mathrm{mag}$. For higher visual extinctions, UV radiation has a negligible effect on the physical conditions and chemistry of the molecular gas. Our long-term goal is to investigate the influence of the incident UV radiation and the density on the studied molecular abundance ratios and explore the possibility of using them as chemical diagnostics. These models are useful for interpreting molecular observations, although to reproduce the results for a particular PDR a good knowledge of its geometry is required.

Some representative cumulative column density ratios have been selected as candidates of the chemical diagnostics. Figure 4 shows these ratios as a function of the incident UV field and the hydrogen nuclei density for the standard interstellar extinction curve. Since we use a gas phase model, we avoided the species for which the formation on grain surfaces could be important. This is the case for $\mathrm{H}_{2} \mathrm{CO}, \mathrm{CH}_{3} \mathrm{CN}$, and $\mathrm{CH}_{3} \mathrm{OH}$. Another important reason to neglect these complex molecules is that they could come from a shielded component of dense gas instead of the PDRs. We are aware, however, that the injection of complex molecules in the gas phase by photo-desorption changes the gas chemical composition and could influence the chemistry of the more simple species. We consider, for instance, HCO, which is the photodissociation product of $\mathrm{H}_{2} \mathrm{CO}$. The abundance of $\mathrm{HCO}$ in the PDR would increase if the evaporation of $\mathrm{H}_{2} \mathrm{CO}$ from the grain surfaces were included to help improve the agreement with the observations. As discussed below, PAHs and grain destruction are also required to account for the observed abundances of small hydrocarbons.

Our chemical modeling shows that for the range of parameters considered, the $\mathrm{CN} / \mathrm{HCN}$ ratio does not depend on the incident UV field but on the density. Therefore, the $\mathrm{CN} / \mathrm{HCN}$ ratio is a good tracer of PDRs but it is incapable of differentiating between PDRs with different UV fields for $G_{0}>100$. The value measured in Mon $\mathrm{R} 2, \mathrm{CN} / \mathrm{HCN}=2-12$, is consistent with a hydrogen nuclei density of $\approx 10^{6} \mathrm{~cm}^{-3}\left(n\left(\mathrm{H}_{2}\right) \approx 5 \times 10^{5} \mathrm{~cm}^{-3}\right)$ in agreement with our density estimates. As commented on Sect. 5, the $\mathrm{HCN}$ and $\mathrm{CN}$ abundances in this region are higher than in other prototypical PDRs. We cannot discard the possibility that bipolar outflows help to enhance the abundance of these molecules. However, the measured $\mathrm{CN} / \mathrm{HCN}=2-12$ is more consistent with a PDR origin.

According to our models, the $\mathrm{HCO}^{+} / \mathrm{HCN}$ ratio must be a good tracer of the UV field and density. Figure $4 \mathrm{~b}$ shows that the $\mathrm{HCO}^{+} / \mathrm{HCN}$ ratio is smaller than one for a wide range of physical conditions but increases to larger values for high values of both $G_{0}\left(>10^{3}\right)$ and density $\left(\sim 10^{6} \mathrm{~cm}^{-3}\right)$. Taking into account the extreme values of $G_{0}$ and $n$ in Mon R2, one would expect a higher ratio than that observed. As mentioned above, the detailed geometry of the PDR has to be taken into account when comparing with chemical models. In Mon R2, several gas components lie along the line of sight. The dense PDR is surrounded by a lower density envelope that very likely contributes to the emission of the low $\mathrm{J}$ rotational lines of $\mathrm{HCO}^{+}$and $\mathrm{HCN}$. Although we use the rare isotopologues, $\mathrm{H}^{13} \mathrm{CO}^{+}$and $\mathrm{H}^{13} \mathrm{CN}$, to compute this abundance ratio, optical depth effects could still be important.

One of the most effective diagnostic of the UV incident field is the $\mathrm{CO}^{+} / \mathrm{HCO}^{+}$ratio. This ratio is $>0.05$ only when the UV field is higher than $10^{3}$. This is consistent with the lack of detection of $\mathrm{CO}^{+}$in the Horsehead nebula and at the MP2 position of Mon R2. The same dependence on the UV incident field stands also for the $\mathrm{HOC}^{+} / \mathrm{HCO}^{+}$ratio. In contrast, the formyl radical is abundant only in PDRs with moderate or low UV radiation fields (see also Gerin et al. 2009ab). The $\mathrm{HCO} / \mathrm{HCO}^{+}$ratio takes values $>0.2$ only for UV fields $<10^{3}$. The $\mathrm{CO}^{+} / \mathrm{HCO}^{+}$ and $\mathrm{HCO} / \mathrm{HCO}^{+}$abundance ratios are excellent diagnostics to help us differentiate between low and high UV PDRs. There is a good qualitative agreement between models and observations, although they still fail to quantitatively predict these ratios.

Observations show that the $\mathrm{SO}^{+} / \mathrm{SO}$ ratio is also larger for dense and highly ionized regions and the value towards Mon R2 is well-predicted by our gas-phase chemical models. However, observationally this ratio does not follow the same trend that the $\mathrm{CO}^{+} / \mathrm{HCO}^{+}$(see e.g. Fuente et al. 2003). This ratio is influenced by the amount of sulfur in gas phase that could be changed, for instance, by the existence of bipolar outflows and slow shocks. Therefore, we do not propose that it is a good diagnostic of PDRs.

Small hydrocarbons can be good tracers of PDRs, and they are especially abundant in low UV PDRs. According to our gas phase calculations, the $\mathrm{c}-\mathrm{C}_{3} \mathrm{H}_{2} / \mathrm{C}_{2} \mathrm{H}$ ratio is fairly uniform across a wide region of the parameter space. Although our models can explain the value measured in MP2, they are unable to account for the value measured in the Horsehead. In the case of the $\mathrm{C}_{4} \mathrm{H} / \mathrm{C}_{2} \mathrm{H}$ ratio, our models are unable to reproduce the observed values in both MP2 and the Horsehead. Different authors have pointed out that the observed abundances of these hydrocarbons in PDRs indicates that there is another production mechanism than gas-phase reactions, possibly the destruction of PAHs and/or very small grains (VSGs). A weaker UV field would prevent too the rapid destruction of hydrocarbons, even if the PAHs/VSGs were destroyed at a reasonable rate. Going further would require a full modeling of formation/destruction processes that is beyond the scope of this paper.

Summarizing, the $\mathrm{CO}^{+} / \mathrm{HCO}^{+}$and $\mathrm{HCO} / \mathrm{HCO}^{+}$ratios are excellent chemical diagnostics of the UV field, while the $\mathrm{CN} / \mathrm{HCN}$ and $\mathrm{HCN} / \mathrm{HNC}$ ratios depend more on the density. Applying these chemical diagnostics to the three positions observed in Mon R2, we can conclude that the incident UV radiation fields in the IF and MP1 are different, the highest being that in IF, with a value consistent with that estimated by 
a) $\mathrm{CN} / \mathrm{HCN}$

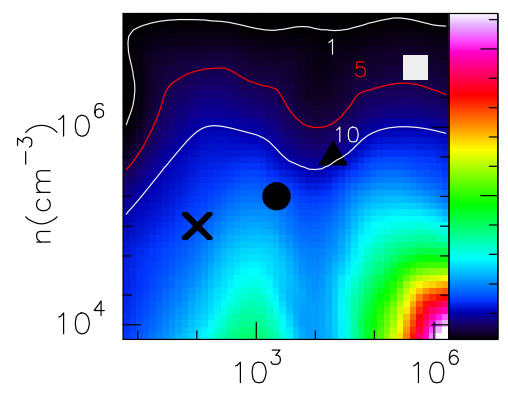

d) $\mathrm{CO}^{+} / \mathrm{HCO}^{+}$ b) $\mathrm{HCO}^{+} / \mathrm{HCN}$

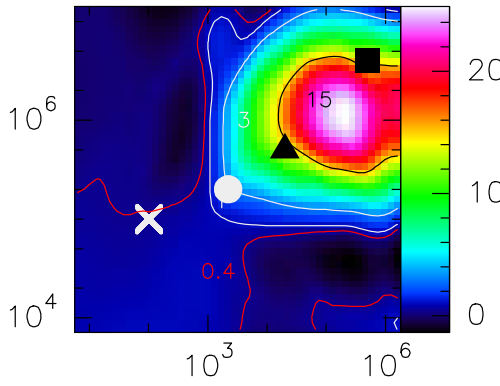

e) $\mathrm{HOC}^{+} / \mathrm{HCO}^{+}$ c) $\mathrm{HCN} / \mathrm{HNC}$

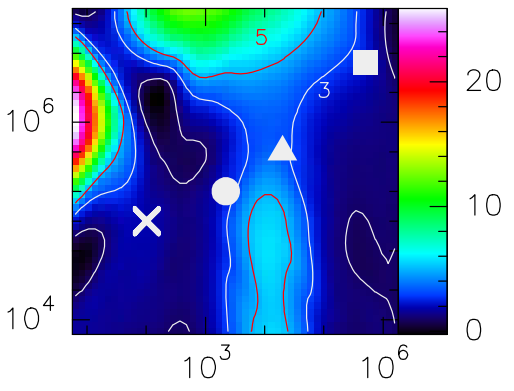

f) $\mathrm{SO}^{+} / \mathrm{SO}$
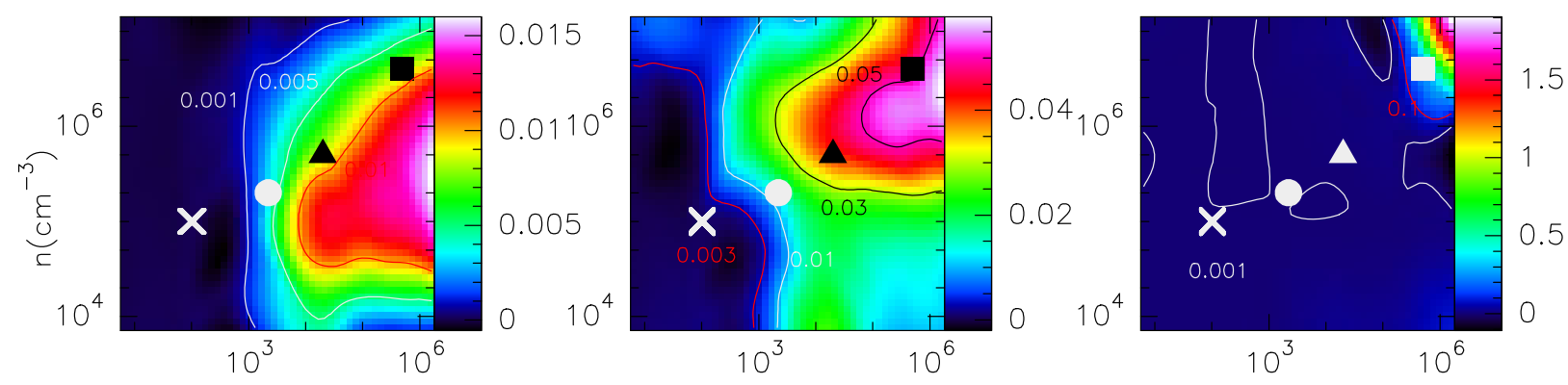

g) $\mathrm{HCO} / \mathrm{HCO}^{+}$

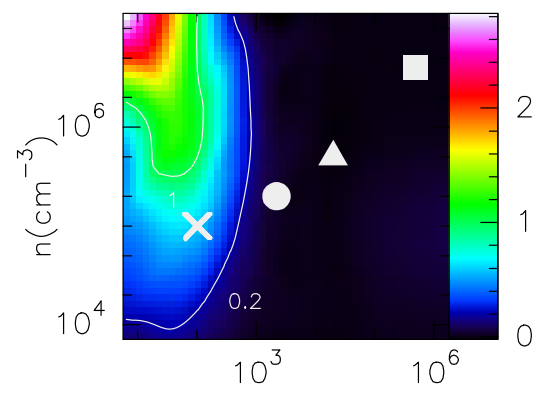

$G_{0}$

i) $\mathrm{C}-\mathrm{C}_{3} \mathrm{H}_{2} / \mathrm{C}_{2} \mathrm{H}$

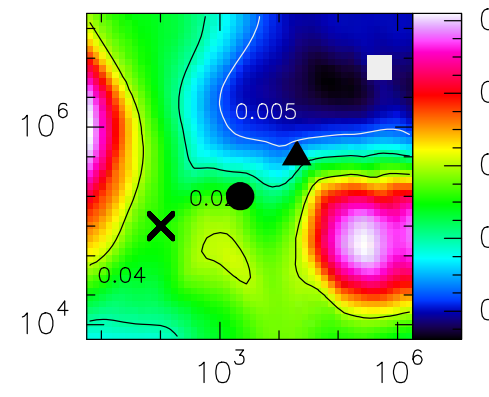

$\mathrm{G}_{0}$
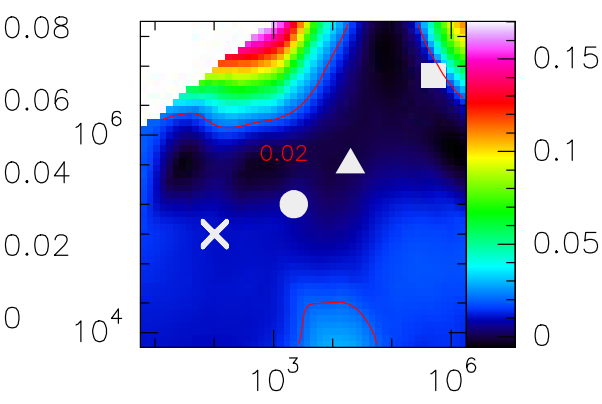

$\mathrm{G}_{0}$

Fig. 4. Cumulative column density ratios in a plane slab of $A_{\mathrm{V}}=10$ mag illuminated by the left side for a grid of UV fields and hydrogen nuclei densities. The ratios were calculated using the Meudon code (Le Petit et al. 2006; Goicoechea et al. 2007). $G_{0}$ is given in units of the Habing field. Levels drawn in red correspond to the values measured in Mon R2. Symbols indicate the physical conditions of the protypical PDRs: Mon R2 (square), Orion Bar (triangle), NGC 7023 (circle), and Horsehead (cross). Note that the $\mathrm{CO}^{+} / \mathrm{HCO}^{+}$and $\mathrm{HCO} / \mathrm{HCO}^{+}$ratios are excellent diagnostics of the UV incident field. The IF and MP positions in Mon R2 have the abundance characteristics of dense PDRs with high UV fields, while the chemistry of the MP2 position is more typical of a low UV PDR.

Rizzo et al. (2003). Towards the MP2, the incident UV field must be weaker. The morphology of the $8 \mu \mathrm{m}$ emission (see Fig. 1) suggests that this PDR is the consequence of the border of the molecular cloud being illuminated by IRS 1 .

\section{Summary and conclusions}

We have carried out a mm survey towards three positions of the PDR that represent different physical and chemical environments: (i) the ionization front (IF) and two positions in the molecular cloud; (ii) MP1; and (iii) MP2. Our goal has been to investigate the chemistry of the molecular gas around the UC HII region and the possible variations caused by the different local physical conditions. Our results can be summarized as follows:

- We have detected more than 30 different species (including isotopologues and deuterated compounds) in Mon R2.
In particular, we have detected $\mathrm{SO}^{+}$and $\mathrm{C}_{4} \mathrm{H}$ towards this region, which are well-known tracers of PDRs. In addition to $\mathrm{SO}^{+}$and $\mathrm{C}_{4} \mathrm{H}$, the list of identified species includes typical tracers of PDRs such as $\mathrm{CN}, \mathrm{HCN}, \mathrm{HCO}, \mathrm{C}_{2} \mathrm{H}$, and c- $\mathrm{C}_{3} \mathrm{H}_{2}$ but also other complex molecules more common in warm molecular clouds, such as $\mathrm{CH}_{3} \mathrm{CN}, \mathrm{H}_{2} \mathrm{CO}, \mathrm{HC}_{3} \mathrm{~N}$, $\mathrm{CH}_{3} \mathrm{OH}$, or $\mathrm{CH}_{3} \mathrm{C}_{2} \mathrm{H}$. The origin of these complex species, which are embedded in dense and well-shielded clumps within the molecular cloud or PDR, is still to be investigated. The existence of high velocity molecular outflows in the region could also affect the abundance of some molecules such as HCN and the sulfurated species.

- Within the PDR component, the comparison of the fractional abundances measured in Mon R2 with those in the prototypical PDRs shows that the positions IF and MP1 have a chemistry similar to that in high-UV PDRs $\left(G_{0}>10^{3}\right.$ Habing fields), while the chemistry in the position MP2 resembles that of the Horsehead $\left(<10^{3}\right.$ Habing field). Chemical 
models predict that the $\left[\mathrm{CO}^{+}\right] /\left[\mathrm{HCO}^{+}\right]$and $[\mathrm{HCO}] /\left[\mathrm{HCO}^{+}\right]$ ratios can help us to reliably differentiate between these two types of PDRs.

- The deuterated species DCN and $\mathrm{C}_{2} \mathrm{D}$ are detected in our spectral survey. The observed deuteration fractionations, $[\mathrm{DCN}] /[\mathrm{HCN}] \sim 0.03$ and $\left[\mathrm{C}_{2} \mathrm{D}\right] /\left[\mathrm{C}_{2} \mathrm{H}\right] \sim 0.05$, are among the highest in the warm regions.

One important question is whether these stationary models are adequate for PDRs associated with rapidly evolving star-forming regions. The time to reach the equilibrium for each species at a given $A_{\mathrm{V}}$ depends on the density and the UV radiation (see e.g Bayet et al. 2009). The higher the density and incident UV radiation, the more rapidly the equilibrium is reached at a given $A_{\mathrm{v}}$. For the physical conditions in Mon R2, simple species are expected to have reached the equilibrium in $\sim 10^{5} \mathrm{yr}$, which explains the success of our chemical diagnostics. However, we cannot exclude there being small deviations from equilibrium especially in regions of high extinction and a low incident UV field. In future studies, we will investigate the role of grain surface chemistry and time-dependent effects on the chemistry of the molecular gas in Mon R2.

Acknowledgements. We are grateful to the IRAM staff for their great help during the observations and data reduction. This paper was partially supported within the programme CONSOLIDER INGENIO 2010, under grant "Molecular Astrophysics: The Herschel and ALMA Era. - ASTROMOL" (Ref.: CSD200900038). J.C. and J.R.G. thank the Spanish MICINN for funding support through grants AYA2006-14876 and AYA2009-07304. J.R.G. is supported by a Ramón y Cajal research contract. Part of this work was supported by the Deutsche Forschungsgemeinschaft, project number Os 177/1-1.

\section{References}

Avery, L. W., \& Green, S. 1989, ApJ, 337, 306

Bachiller, R., \& Pérez Gutiérrez, M. 1997, ApJ, 487, L93

Bayet, E., Viti, S., Williams, D. A., Rawlings, J. M. C., \& Bell, T. 2009, ApJ, 696, 1466

Berné, O., Fuente, A., Goicoechea, J. R., et al. 2009, ApJ, 706, L160

Caselli, P., van der Tak, F. F. S., Ceccarelli, C., \& Bacmann, A. 2003, A\&A, 403, L37

Cernicharo, J., Goicoechea, J. R., Pardo, J. R., \& Asensio-Ramos, A. 2006, ApJ, 642, 940

Cernicharo, J., Spielfiedel, A., Balança, C., et al. 2011, A\&A, 531, A103

Choi, M., Evans, N. J., II, Tafalla, M., \& Bachiller, R. 2000, ApJ, 538, 738

Churchwell, E. 2002, ARA\&A, 40, 27

Daniel, F., Dubernet, M.-L., Meuwly, M., Cernicharo, J., \& Pagani, L. 2005, MNRAS, 363, 1083

Dayou, F., \& Balança, C. 2006, A\&A, 459, 297

Flower, D. R. 1999, MNRAS, 305, 651

Fuente, A., Martín-Pintado, J., Cernicharo, J., \& Bachiller, R. 1993, A\&A, 276, 473

Fuente, A., Rodríguez-Franco, A., \& Martín-Pintado, J. 1996, A\&A, 312, 599
Fuente, A., Rodrtíguez-Franco, A., García-Burillo, S., Martín-Pintado, J., \& Black, J. H. 2003, A\&A, 406, 899

Fuente, A., Neri, R., \& Caselli, P. 2005, A\&A, 444, 48

Fuente, A., Berné, O., Cernicharo, J., et al. 2010, A\&A, 521, L23

García-Burillo, S., Martín-Pintado, J., Fuente, A., Usero, A., \& Neri, R. 2002, ApJ, 575, L55

Giannakopoulou, J., Mitchell, G. F., Hasegawa, T. I., Matthews, H. E., \& Maillard, J.-P. 1997, ApJ, 487, 346

Gerin, M., Goicoechea, J. R., Pety, J., \& Hily-Blant, P. 2009a, A\&A, 494, 977

Gerin, M., Pety, J., \& Goicoechea, J. R. 2009b, Submillimeter Astrophysics and Technology: a Symposium Honoring Thomas G. Phillips, 417, 165

Gerin, M., Marcelino, N., Biver, N., et al. 2009c, A\&A, 498, L9

Goicoechea, J. R., \& Le Bourlot, J. 2007, A\&A, 467, 1

Goicoechea, J. R., Pety, J., Gerin, M., et al. 2006, A\&A, 456, 565

Goicoechea, J. R., Pety, J., Gerin, M., Hily-Blant, P., \& Le Bourlot, J. 2009, A\&A, 498, 771

Green, S. 1991, ApJS, 76, 979

Guzmán, V., Pety, J., Goicoechea, J. R., Gerin, M., \& Roueff, E., 2011, A\&A, 534, A49

Henning, T., Chini, R., \& Pfau, W. 1992, A\&A, 263, 285

Herbst, W., \& Racine, R. 1976, AJ, 81, 840

Le Petit, F., Nehmé, C., Le Bourlot, J., \& Roueff, E. 2006, ApJS, 164, 506

Lique, F., \& Spielfiedel, A. 2007, A\&A, 462, 1179

Lique, F., Spielfiedel, A., Dhont, G., \& Feautrier, N. 2006, A\&A, 458, 331

Lucas, R., \& Liszt, H. S. 2002, A\&A, 384, 1054

Monteiro, T. 1984, MNRAS, 210, 1

Massi, M., Felli, M., \& Simon, M. 1985, A\&A, 152, 387

Meyers-Rice, B. A., \& Lada, C. J. 1991, ApJ, 368, 445

Ohishi, M., McGonagle, D., Irvine, W. M., Yamamoto, S., \& Saito, S. 1994, ApJ, 427, L51

Parise, B., Ceccarelli, C., Tielens, A. G. G. M., et al. 2002, A\&A, 393, L49

Parise, B., Castets, A., Herbst, E., et al. 2004, A\&A, 416, 159

Parise, B., Leurini, S., Schilke, P., et al. 2009, A\&A, 508, 737

Pety, J., Teyssier, D., Fossé, D., et al. 2005, A\&A, 435, 885

Pety, J., Goicoechea, J. R., Hily-Blant, P., Gerin, M., \& Teyssier, D. 2007, A\&A, 464, L41

Pilleri, P., Fuente, A., Cernicharo, J., et al. 2012, A\&A, accepted [arXiv: 1206. 1249]

Rizzo, J. R., Fuente, A., Rodríguez-Franco, A., \& García-Burillo, S. 2003, ApJ, 597, L153

Rizzo, J. R., Fuente, A., \& García-Burillo, S. 2005, ApJ, 634, 1133

Roueff, E., Parise, B., \& Herbst, E. 2007, A\&A, 464, 245

Sarrasin, E., Abdallah, D. B., Wernli, M., et al. 2010, MNRAS, 404, 518

Savage, C., Apponi, A. J., Ziurys, L. M., \& Wyckoff, S. 2002, ApJ, 578, 211

Schilke, P., Pineau des Forêts, G., Walmsley, C. M., \& Martín-Pintado, J. 2001, A\&A, 372, 291

Schenewerk, M. S., Jewell, P. R., Snyder, L. E., Hollis, J. M., \& Ziurys, L. M. 1988, ApJ, 328, 785

Schloerb, F. P., Irvine, W. M., Friberg, P., Hjalmarson, A., \& Hoglund, B. 1983, ApJ, 264, 161

Snyder, L. E., Hollis, J. M., Lovas, F. J., \& Ulich, B. L. 1976, ApJ, 209, 67

Sutton, E. C., Peng, R., Danchi, W. C., et al. 1995, ApJS, 97, 455

Tafalla, M., Bachiller, R., \& Wright, M. C. H. 1994, ApJ, 432, L127

Tafalla, M., Bachiller, R., Wright, M. C. H., \& Welch, W. J. 1997, ApJ, 474, 329

Teyssier, D., Fossé, D., Gerin, M., et al. 2004, A\&A, 417, 135

Turner, B. E. 1994, ApJ, 430, 727

van der Wiel, M. H. D., van der Tak, F. F. S., Ossenkopf, V., et al. 2010, A\&A, 510, A1

Wernli, M., Wiesenfeld, L., Faure, A., \& Valiron, P. 2007, A\&A, 464, 1147

Wood, D. O. S., \& Churchwell, E. 1989, ApJS, 69, 831

Yang, B., Stancil, P. C., Balakrishnan, N., \& Forrey, R. C. 2010, ApJ, 718, 1062

Pages 15 to 31 are available in the electronic edition of the journal at http: //www . aanda.org 
D. Ginard et al.: Spectral line survey of the ultracompact HiI region Mon R2

\section{Appendix A: Identified lines}

Table A.1. Observed transitions and line intensities.

\begin{tabular}{|c|c|c|c|c|}
\hline $\begin{array}{l}\text { Frequency } \\
(\mathrm{MHz})\end{array}$ & Transition & $\begin{array}{l}\text { Intensity (IF) } \\
\left(\mathrm{K} \times \mathrm{km} \mathrm{s}^{-1}\right)\end{array}$ & $\begin{array}{c}\text { Intensity (MP1) } \\
\left(\mathrm{K} \times \mathrm{km} \mathrm{s}^{-1}\right)\end{array}$ & $\begin{array}{c}\text { Intensity (MP2) } \\
\left(\mathrm{K} \times \mathrm{km} \mathrm{s}^{-1}\right)\end{array}$ \\
\hline 83302 & $\mathrm{H}(66) \delta$ & $1.23(0.11)$ & $0.24(0.06)$ & \\
\hline 84307 & $\mathrm{C}(40) \alpha+\mathrm{He}(40) \alpha$ in the image band & & $0.66(0.14)$ & \\
\hline 84321 & $\mathrm{CH}_{3} \mathrm{OH} 5_{-1,5} \rightarrow 4_{0,4}$ & $0.48(0.08)$ & $0.35(0.04)$ & $0.62(0.04)$ \\
\hline 84314 & $\mathrm{H}(60) \gamma$ & $2.26(0.12)$ & $0.70(0.04)$ & \\
\hline 85397 & CS $2 \rightarrow 1$ in the image band & & $0.39(0.19)$ & $0.39(0.09)$ \\
\hline 85339 & $\mathrm{c}-\mathrm{C}_{3} \mathrm{H}_{2} 2_{1,2} \rightarrow \mathrm{I}_{0,1}$ & $1.18(0.20)^{a}$ & $1.50(0.07)^{a}$ & $2.09(0.09)^{a}$ \\
\hline 85348 & $\mathrm{HCS}^{+} 2 \rightarrow 1$ & $0.76(0.09)$ & $0.32(0.02)$ & $0.33(0.09)$ \\
\hline 85357 & $\mathrm{CH}_{3} \mathrm{C}_{2} \mathrm{H} 5_{k} \rightarrow 4_{k} k=0,1$ & $0.41(0.07)$ & $0.47(0.16)$ & $0.53(0.07)$ \\
\hline 85334 & $\mathrm{C}_{4} \mathrm{H} 9 \rightarrow 8 \mathrm{~J}=19 / 2 \rightarrow 17 / 2$ & & & $0.29(0.08)$ \\
\hline 85373 & $\mathrm{C}_{4} \mathrm{H} 9 \rightarrow 8 \mathrm{~J}=17 / 2 \rightarrow 15 / 2$ & & & $0.53(0.15)$ \\
\hline 85388 & $\mathrm{H}(42) \alpha$ & $15.97(0.13)$ & $4.08(0.13)$ & $0.89(0.16)$ \\
\hline 85331 & $\mathrm{C}(42) \alpha$ & & $0.23(0.06)$ & \\
\hline 85325 & $\mathrm{NH}_{2} \mathrm{D} 1_{1,1}-1_{0,1}{ }^{t}$ & & $0.19(0.04)$ & \\
\hline 86355 & $\mathrm{HC}^{15} \mathrm{~N} 1 \rightarrow 0$ & $0.29(0.07)$ & $0.52(0.14)$ & $0.37(0.06)$ \\
\hline 86394 & $\mathrm{SO} 2_{2} \rightarrow 1_{1}$ & $0.38(0.05)$ & $0.31(0.12)$ & $0.54(0.01)$ \\
\hline 86339 & $\mathrm{H}^{13} \mathrm{CN} 1 \rightarrow 0$ & $1.78(0.08)$ & $2.11(0.03)$ & $1.64(0.03)$ \\
\hline 86388 & $\mathrm{H}(70) \epsilon$ & $0.95(0.12)$ & & \\
\hline 86371 & $\mathrm{HCO} 1_{0,1} \rightarrow 0_{0,0} J=3 / 2 \rightarrow 1 / 2 \quad F=2 \rightarrow 1$ & & $0.22(0.05)$ & $0.54(0.05)$ \\
\hline 86390 & $\mathrm{H}(74) \zeta$ & $0.99(0.17)$ & & \\
\hline 86308 & HCO $1_{0,1} \rightarrow 0_{0,0} J=3 / 2 \rightarrow 1 / 2 \quad F=1 \rightarrow 0$ & & $0.15(0.03)$ & $0.37(0.05)$ \\
\hline 86354 & $\mathrm{H}^{13} \mathrm{CO}^{+} 1 \rightarrow 0$ & $0.55(0.09)$ & $1.43(0.02)$ & $1.14(0.09)$ \\
\hline 86377 & $\mathrm{HCO} 1_{0,1} \rightarrow 0_{0,0} J=1 / 2 \rightarrow 1 / 2 F=1 \rightarrow 1$ & & $0.12(0.03)$ & $0.31(0.04)$ \\
\hline 86347 & $\mathrm{SiO} 2 \rightarrow 1$ & & $0.32(0.04)$ & $0.35(0.01)$ \\
\hline 87391 & $\mathrm{HN}^{13} \mathrm{C} 1 \rightarrow 0$ & $0.31(0.06)$ & $0.57(0.04)$ & $0.35(0.04)$ \\
\hline 87384 & $\mathrm{C}_{2} \mathrm{H} N=1 \rightarrow 0 \quad J=3 / 2 \rightarrow 1 / 2 \quad F=1 \rightarrow 1$ & $0.42(0.08)$ & $0.68(0.02)$ & $0.69(0.04)$ \\
\hline 87317 & $\mathrm{C}_{2} \mathrm{H} N=1 \rightarrow 0 \quad J=3 / 2 \rightarrow 1 / 2 \quad F=2 \rightarrow 1$ & $4.37(0.38)$ & $5.47(0.49)$ & $5.77(0.46)$ \\
\hline 87329 & $\mathrm{C}_{2} \mathrm{H} N=1 \rightarrow 0 \quad J=3 / 2 \rightarrow 1 / 2 \quad F=1 \rightarrow 0$ & $2.12(0.11)$ & $2.97(0.06)$ & $3.00(0.36)$ \\
\hline 87302 & $\mathrm{C}_{2} \mathrm{H} N=1 \rightarrow 0 \quad J=1 / 2 \rightarrow 1 / 2 \quad F=1 \rightarrow 1$ & $2.17(0.14)$ & $3.24(0.06)$ & $3.38(0.13)$ \\
\hline 87307 & $\mathrm{C}_{2} \mathrm{H} N=1 \rightarrow 0 \quad J=1 / 2 \rightarrow 1 / 2 \mathrm{~F}=0 \rightarrow 1$ & $0.84(0.15)$ & $1.15(0.05)$ & $1.10(0.06)$ \\
\hline 87346 & $\mathrm{C}_{2} \mathrm{H} N=1 \rightarrow 0 \quad J=1 / 2 \rightarrow 1 / 2 \quad F=1 \rightarrow 0$ & & $0.77(0.06)$ & $0.68(0.05)$ \\
\hline 87315 & $\mathrm{H}(65) \delta$ & $1.86(0.08)$ & $0.41(0.09)$ & \\
\hline 87306 & Unidentified $\left(F_{\text {image }}=110433 \mathrm{MHz}\right)$ & $1.47(0.30)$ & & \\
\hline 87338 & ${ }^{13} \mathrm{CO} 1 \rightarrow 0$ in the image band & $0.96(0.10)$ & $1.05(0.05)$ & $0.84(0.05)$ \\
\hline 88358 & $\mathrm{C}^{18} \mathrm{O} 1 \rightarrow 0$ in the image band & & $0.36(0.03)$ & $0.27(0.04)$ \\
\hline 88306 & $\mathrm{H}(52) \beta$ & $6.77(0.08)$ & $1.01(0.07)$ & $0.47(0.06)$ \\
\hline 88378 & Unidentified $\left(F_{\text {image }}=109560 \mathrm{MHz}\right)$ & $0.47(0.06)$ & & \\
\hline 88332 & $\mathrm{HCN} l \rightarrow O F=1-1, F=2-1$ and $F=0-1$ & $8.47(0.06)$ & $20.58(0.05)$ & $23.24(0.04)$ \\
\hline 88366 & $\mathrm{H}^{15} \mathrm{NC} 1 \rightarrow 0^{t}$ & & $0.14(0.04)$ & \\
\hline 88342 & Unidentified $\left(F_{\text {iimage }}=109196 \mathrm{MHz}\right)$ & & & $0.20(0.04)$ \\
\hline 89312 & Unidentified $\left(F_{\text {iimage }}=109027 \mathrm{MHz}\right)$ & $0.24(0.05)$ & & \\
\hline 89365 & Unidentified $\left(F_{\text {iimage }}=108974.5 \mathrm{MHz}\right)$ & $0.66(0.02)$ & & \\
\hline 89389 & $\mathrm{HCO}^{+} 1 \rightarrow 0$ & $11.59(0.02)^{a}$ & $13.90(0.22)$ & $17.67(0.11)^{a}$ \\
\hline 89399 & $\mathrm{H}(59) \gamma$ & $2.50(0.21)$ & & \\
\hline 90374 & $\mathrm{H}(69) \epsilon$ and $\mathrm{H}(73) \zeta$ & $1.63(0.12)$ & & \\
\hline 90364 & $\mathrm{HNC} 1 \rightarrow 0$ & $3.19(0.05)$ & $10.58(0.14)$ & $8.33(0.06)$ \\
\hline 90379 & $\mathrm{HC}_{3} \mathrm{~N} 10 \rightarrow 9$ & $0.90(0.06)$ & $2.41(0.08)$ & $1.41(0.03)$ \\
\hline 91306 & $\mathrm{H}(39) \alpha$ in the image band & $0.61(0.13)$ & & \\
\hline 91363 & $\mathrm{H}(64) \delta$ & $1.86(0.11)$ & $0.52(0.08)$ & \\
\hline 91342 & $\mathrm{CH}_{3}{ }^{13} \mathrm{CN} 5_{0} \rightarrow 4_{0}$ & $0.59(0.16)$ & & \\
\hline 91371 & $\mathrm{CH}_{3} \mathrm{CN} 5_{3} \rightarrow 4_{3}$ & $0.64(0.14)$ & $0.11(0.05)$ & $0.11(0.03)$ \\
\hline 91380 & $\mathrm{CH}_{3} \mathrm{CN} 5_{2} \rightarrow 4_{2}$ & & & $0.12(0.03)$ \\
\hline 91387 & $\mathrm{CH}_{3} \mathrm{CN} 5_{k} \rightarrow 4_{k} k=0,1$ & & $0.52(0.05)$ & $0.41(0.04)$ \\
\hline 92334 & $\mathrm{H}(41) \alpha$ & $20.45(0.17)$ & $4.01(0.18)$ & $1.39(0.05)$ \\
\hline 92380 & $\mathrm{C}(41) \alpha$ & $0.38(0.08)^{t}$ & & \\
\hline 92336 & Unidentified $\left(F_{\text {image }}=105702 \mathrm{MHz}\right)$ & $0.39(0.05)$ & & \\
\hline 92394 & ${ }^{13} \mathrm{CS} 2 \rightarrow 1$ & $0.30(0.05)$ & $0.42(0.06)$ & $0.37(0.03)$ \\
\hline 93374 & $\mathrm{~N}_{2} \mathrm{H}^{+} 1 \rightarrow 0 F=1 \rightarrow 1,1 \rightarrow 2$ and $1 \rightarrow 0$ & $1.53(0.06)$ & $8.66(0.09)$ & $2.47(0.04)$ \\
\hline 93307 & $\mathrm{H}(51) \beta$ & $6.04(0.10)$ & $1.06(0.08)$ & $0.35(0.08)$ \\
\hline 93376 & $\mathrm{H}(58) \gamma$ & $2.77(0.17)$ & $0.56(0.09)$ & \\
\hline 93327 & $\mathrm{H}(72) \zeta$ & $0.89(0.09)$ & & \\
\hline 93370 & $\mathrm{C}_{2} \mathrm{~S} 7_{8} \rightarrow 6_{7}$ & $0.14(0.04)$ & & $0.16(0.02)$ \\
\hline
\end{tabular}


Table A.1. continued.

\begin{tabular}{|c|c|c|c|c|}
\hline $\begin{array}{l}\text { Frequency } \\
(\mathrm{MHz})\end{array}$ & Transition & $\begin{array}{l}\text { Intensity (IF) } \\
\left(\mathrm{K} \times \mathrm{km} \mathrm{s}^{-1}\right)\end{array}$ & $\begin{array}{c}\text { Intensity (MP1) } \\
\left(\mathrm{K} \times \mathrm{km} \mathrm{s}^{-1}\right)\end{array}$ & $\begin{array}{c}\text { Intensity (MP2) } \\
\left(\mathrm{K} \times \mathrm{km} \mathrm{s}^{-1}\right)\end{array}$ \\
\hline 94373 & $\mathrm{H}(68) \epsilon$ & $1.03(0.07)$ & & \\
\hline 103452 & Unidentified $\left(F_{\text {image }}=94889 \mathrm{MHz}\right)$ & $0.52(0.04)$ & & \\
\hline 103466 & $\mathrm{C}_{4} \mathrm{H} v=121 / 2 \rightarrow 19 / 2^{t}$ & $0.47(0.05)$ & & \\
\hline 103415 & $\mathrm{H}(56) \gamma$ & $3.02(0.07)$ & $0.46(0.07)$ & \\
\hline 104429 & $\mathrm{SO}_{2} 3_{1,3} \rightarrow 2_{0,2}^{t}$ & & $0.16(0.06)$ & $0.11(0.03)$ \\
\hline 104462 & Unidentifed $\left(F_{\text {image }}=93900 \mathrm{MHz}\right)$ & & & $0.16(0.03)$ \\
\hline 104439 & $\mathrm{SO}_{2} 10_{1,9} \rightarrow 10_{0,10^{t}}$ & & & $0.10(0.03)$ \\
\hline 104433 & $\mathrm{H}(51) \beta$ in the image band & $0.44(0.03)$ & & \\
\hline 104417 & $\mathrm{H}_{2} \mathrm{CS} 3_{1,2} \rightarrow 2_{1,1}$ & $0.19(0.03)$ & $0.38(0.03)$ & $0.21(0.02)$ \\
\hline 104467 & $\mathrm{C}_{4} \mathrm{H} 11 \rightarrow 10 \mathrm{~J}=23 / 2 \rightarrow 21 / 2$ & & $0.19(0.03)$ & $0.30(0.06)$ \\
\hline 104405 & $\mathrm{C}_{4} \mathrm{H} 11 \rightarrow 10 \mathrm{~J}=21 / 2 \rightarrow 19 / 2$ & & $0.27(0.05)$ & $0.30(0.04)$ \\
\hline 104466 & $\mathrm{~N}_{2} \mathrm{H}^{+} 1 \rightarrow 0$ in the image band & & $0.52(0.03)$ & \\
\hline 105402 & $\mathrm{H}(49) \beta$ & $6.22(0.10)$ & $0.66(0.06)$ & $0.39(0.05)$ \\
\hline 105410 & $\mathrm{H}(61) \delta$ & $1.70(0.07)$ & & \\
\hline 105416 & Unidentified $\left(F_{\text {image }}=92625 \mathrm{MHz}\right)$ & $0.36(0.10)$ & & \\
\hline 106479 & $\mathrm{H}(69) \zeta$ & $0.71(0.09)$ & & \\
\hline 106404 & $\mathrm{H}(41) \alpha$ in the image band & $0.45(0.10)$ & & \\
\hline 106448 & $\mathrm{C}_{2} \mathrm{~S} N=8 \rightarrow 7 J=9 \rightarrow 8$ & & & $0.13(0.02)$ \\
\hline 106437 & $\mathrm{H}(39) \alpha$ & $18.80(0.11)$ & $2.33(0.07)$ & $0.57(0.06)$ \\
\hline 107414 & $\mathrm{CH}_{3} \mathrm{OH} 3_{1,3} \rightarrow 4_{0,4}$ & & $0.14(0.06)$ & $0.55(0.07)$ \\
\hline 107406 & $\mathrm{H}(65) \epsilon$ & $1.23(0.12)$ & & \\
\hline 107454 & Unidentified $\left(F_{\text {image }}=90887 \mathrm{MHz}\right)$ & $0.59(0.18)$ & & \\
\hline 107424 & Unidentified $\left(F_{\text {image }}=90720 \mathrm{MHz}\right)$ & $0.51(0.03)$ & & \\
\hline 107476 & HNC $1 \rightarrow 0$ in the image band & $0.25(0.07)$ & $0.46(0.03)$ & $0.48(0.04)$ \\
\hline 108427 & ${ }^{13} \mathrm{CN} \mathrm{N}=1 \rightarrow 0 \quad J=1 / 2 \rightarrow 1 / 2$ & & $0.27(0.01)$ & $0.16(0.01)$ \\
\hline 108480 & ${ }^{13} \mathrm{CN} \mathrm{N}=1 \rightarrow 0 \quad J=3 / 2 \rightarrow 1 / 2$ & & $0.24(0.01)$ & $0.39(0.03)$ \\
\hline 108494 & $\mathrm{CH}_{3} \mathrm{OH} O_{0,0} \rightarrow 1_{-1,1}$ & & $0.20(0.09)$ & $0.19(0.03)$ \\
\hline 108450 & $\mathrm{HCO}^{+} 1 \rightarrow 0$ in the image band & $0.21(0.21)$ & $0.47(0.13)$ & $0.72(0.05)$ \\
\hline 109474 & $\mathrm{HC}_{3} \mathrm{~N} 12 \rightarrow 11$ & $0.70(0.04)$ & $2.41(0.04)$ & $1.45(0.04)$ \\
\hline 109406 & Unidentified $\left(F_{\text {image }}=88935 \mathrm{MHz}\right)$ & & & $0.13(0.03)$ \\
\hline 109452 & $\mathrm{SO} 2_{3} \rightarrow 1_{2}$ & $0.21(0.18)$ & $0.34(0.01)$ & $0.59(0.01)$ \\
\hline 109436 & $\mathrm{H}(55) \gamma$ & $3.25(0.10)$ & & \\
\hline 109482 & $\mathrm{C}^{18} \mathrm{O} 1 \rightarrow 0$ & $3.47(0.06)$ & $4.63(0.05)$ & $3.75(0.06)$ \\
\hline 109406 & $\mathrm{HNCO} 5 \rightarrow 4$ & & $0.13(0.04)$ & \\
\hline 109498 & Unidentified $\left(F_{\text {image }}=88142 \mathrm{MHz}\right)$ & $0.43(0.05)$ & & \\
\hline 110425 & $\mathrm{C}^{15} \mathrm{~N} \mathrm{~N}=1 \rightarrow 0 \quad J=3 / 2 \rightarrow 1 / 2 \quad F=2 \rightarrow 1$ and $1 \rightarrow 0$ & & $0.13(0.03)$ & $0.25(0.04)$ \\
\hline 110419 & Unidentified $\left(F_{\text {image }}=88022 \mathrm{MHz}\right)$ & & & $0.18(0.04)$ \\
\hline 110401 & ${ }^{13} \mathrm{CO} l \rightarrow 0$ & $42.31(0.03)$ & $49.18(1.07)$ & $41.61(0.15)$ \\
\hline 110464 & $\mathrm{CH}_{3} \mathrm{CN} 6_{3} \rightarrow 5_{3}$ & & & $0.21(0.06)$ \\
\hline 110475 & $\mathrm{CH}_{3} \mathrm{CN} 6_{2} \rightarrow 5_{2}$ & & $0.12(0.04)$ & $0.13(0.04)$ \\
\hline 110483 & $\mathrm{CH}_{3} \mathrm{CN} \sigma_{k} \rightarrow 5_{k} k=0,1$ & $1.13(0.13)$ & $0.59(0.04)$ & $0.34(0.05)$ \\
\hline 110401 & $\mathrm{H}(60) \delta$ & $1.66(0.13)$ & & \\
\hline 205481 & $\mathrm{CH}_{3} \mathrm{C}_{2} \mathrm{H} 12_{0} \rightarrow 11_{0}$ & $0.49(0.08)$ & $0.71(0.10)$ & \\
\hline 205492 & $\mathrm{C}^{18} \mathrm{O} 2 \rightarrow 1$ in the image band & & & $1.01(0.08)$ \\
\hline 205486 & $\mathrm{H}_{2} \mathrm{CS} 6_{0,6} \rightarrow 5_{0,5}$ & & $0.26(0.06)$ & \\
\hline 206476 & $\mathrm{SO} 4_{5} \rightarrow 3_{4}$ & $1.41(0.09)$ & $1.30(0.07)$ & $1.60(0.09)$ \\
\hline 206476 & Unidentified $\left(F_{\text {image }}=218175 \mathrm{MHz}\right)$ & $1.31(0.12)$ & $0.79(0.06)$ & $0.65(0.05)$ \\
\hline 206407 & Unidentified $\left(F_{\text {image }}=217944 \mathrm{MHz}\right)$ & $0.49(0.11)$ & & \\
\hline 207436 & Unidentified $\left(F_{\text {image }}=217015 \mathrm{MHz}\right)$ & & & $0.40(0.08)$ \\
\hline 208400 & $\mathrm{SO}_{2} 3_{2,2} \rightarrow 2_{1,1}$ & & & $0.35(0.07)$ \\
\hline 208467 & Unidentified $\left(F_{\text {image }}=221286 \mathrm{MHz}\right)$ & & $0.29(0.07)$ & \\
\hline 209497 & Unidentified $\left.F_{\text {image }}=220956 \mathrm{MHz}\right)$ & $0.64(0.06)$ & $0.76(0.05)$ & $0.86(0.12)$ \\
\hline 209401 & $\mathrm{H}_{2} \mathrm{CS} \sigma_{1,5} \rightarrow 5_{1,4}$ & $0.39(0.04)$ & $0.53(0.08)$ & $0.70(0.16)$ \\
\hline 209430 & $\mathrm{HC}_{3} \mathrm{~N} 23 \rightarrow 22$ & $0.22(0.10)$ & $0.28(0.11)$ & $0.59(0.15)$ \\
\hline 209477 & Unidentified $\left(F_{\text {image }}=220777 \mathrm{MHz}\right)$ & $0.37(0.08)$ & $0.32(0.08)$ & \\
\hline 209491 & Unidentified $\left(F_{\text {image }}=220462 \mathrm{MHz}\right)$ & $1.84(0.54)$ & & \\
\hline 209455 & ${ }^{13} \mathrm{CO} 2 \rightarrow 1$ in the image band & $1.97(0.10)$ & $2.13(0.07)$ & $2.18(0.11)$ \\
\hline 209494 & $\mathrm{H}(44) \gamma$ & $2.37(0.16)$ & & \\
\hline 209499 & $\mathrm{C}(44) \gamma$ & & & $0.51(0.11)$ \\
\hline 210495 & $\mathrm{C}^{18} \mathrm{O} 2 \rightarrow 1$ in the image band & $1.18(0.07)$ & $0.32(0.06)$ & $1.28(0.09)$ \\
\hline 210402 & $\mathrm{H}(31) \alpha$ & $15.18(0.20)$ & & \\
\hline 216473 & $\mathrm{CCD} \mathrm{N}=3 \rightarrow 2 J=7 / 2 \rightarrow 5 / 2$ & & $0.31(0.05)$ & $0.49(0.10)$ \\
\hline 216428 & $\mathrm{CCD} \mathrm{N}=3 \rightarrow 2 J=5 / 2 \rightarrow 3 / 2$ & & $0.31(0.05)$ & $0.40(0.07)$ \\
\hline 216411 & $\mathrm{H}_{2} \mathrm{~S} 2_{2,0} \rightarrow 2_{1,1}$ & & & $0.21(0.05)$ \\
\hline 217405 & $\mathrm{SiO} 5 \rightarrow 4$ & & $0.22(0.05)$ & $0.23(0.01)$ \\
\hline
\end{tabular}


D. Ginard et al.: Spectral line survey of the ultracompact HII region Mon R2

Table A.1. continued.

\begin{tabular}{|c|c|c|c|c|}
\hline $\begin{array}{l}\text { Frequency } \\
(\mathrm{MHz})\end{array}$ & Transition & $\begin{array}{l}\text { Intensity (IF) } \\
\left(\mathrm{K} \times \mathrm{km} \mathrm{s}^{-1}\right)\end{array}$ & $\begin{array}{c}\text { Intensity (MP1) } \\
\left(\mathrm{K} \times \mathrm{km} \mathrm{s}^{-1}\right)\end{array}$ & $\begin{array}{c}\text { Intensity (MP2) } \\
\left(\mathrm{K} \times \mathrm{km} \mathrm{s}^{-1}\right)\end{array}$ \\
\hline 217439 & DCN $J=3 \rightarrow 2$ & $1.23(0.11)$ & $2.94(0.06)$ & $1.32(0.06)$ \\
\hline 217467 & ${ }^{13} \mathrm{CN} N=2 \rightarrow 1 \quad J=5 / 2 \rightarrow 3 / 2 \quad F=4 \rightarrow 3,3 \rightarrow 2$ and $2 \rightarrow 1$ & & $0.12(0.01)$ & $0.38(0.03)$ \\
\hline 217422 & $\mathrm{c}-\mathrm{C}_{3} \mathrm{H}_{2} \sigma_{1,6} \rightarrow 5_{0,5}$ and $6_{0,6} \rightarrow 5_{1,5}$ & $0.80(0.20)$ & $1.20(0.20)$ & $1.86(0.20)$ \\
\hline 217435 & $\mathrm{CO} 2 \rightarrow 1$ in the image band & $1.80(0.16)$ & $1.95(0.45)$ & $3.04(0.40)$ \\
\hline 217440 & $\mathrm{c}-\mathrm{C}_{3} \mathrm{H}_{2} 5_{1,4} \rightarrow 4_{2,3}$ & & $0.52(0.05)$ & $1.13(0.05)$ \\
\hline 218460 & $\mathrm{c}-\mathrm{C}_{3} \mathrm{H}_{2} 5_{2,4} \rightarrow 4_{13}$ & & $0.33(0.15)$ & $0.40(0.03)$ \\
\hline 218482 & Unidentified $\left(F_{\text {image }}=230192 \mathrm{MHz}\right)$ & & $0.50(0.09)$ & $0.58(0.11)$ \\
\hline 218422 & $\mathrm{H}_{2} \mathrm{CO} 3_{0,3} \rightarrow 2_{0,2}$ & $3.78(0.13)$ & $7.71(0.10)$ & $6.24(0.12)$ \\
\hline 218425 & $\mathrm{HC}_{3} \mathrm{~N} 24 \rightarrow 23$ & $0.17(0.06)$ & $0.27(0.04)$ & $0.32(0.03)$ \\
\hline 218440 & $\mathrm{CH}_{3} \mathrm{OH} 4_{2,2} \rightarrow 3_{1,2}$ & $0.63(0.13)$ & $0.74(0.04)$ & $0.35(0.06)$ \\
\hline 218476 & $\mathrm{H}_{2} \mathrm{CO} 3_{2,2} \rightarrow 2_{2,1}$ & $1.02(0.12)$ & $1.77(0.09)$ & $1.42(0.07)$ \\
\hline 218467 & Unidentified $\left(F_{\text {image }}=229707 \mathrm{MHz}\right)$ & $0.90(0.11)$ & & \\
\hline 218460 & $\mathrm{H}_{2} \mathrm{CO} 3_{2,1} \rightarrow 2_{2,0}$ & $0.87(0.08)$ & $1.75(0.05)$ & $1.41(0.06)$ \\
\hline 219460 & $\mathrm{C}^{18} \mathrm{O} 2 \rightarrow 1$ & $10.68(0.17)$ & $14.0(0.07)$ & $12.74(0.07)$ \\
\hline 219497 & Unidentified $\left(F_{\text {image }}=228776 \mathrm{MHz}\right)$ & $1.90(0.13)$ & & \\
\hline 219452 & $\mathrm{H}_{2} \mathrm{CN} 3_{0,3} \rightarrow 2_{0,2}{ }^{t}$ & $1.03(0.29)$ & $0.57(0.05)$ & $0.48(0.06)$ \\
\hline 219411 & $\mathrm{H}_{2}{ }^{13} \mathrm{CO} 3_{1,2}-2_{1,1}{ }^{t}$ & $1.06(0.15)$ & & \\
\hline 219449 & $\mathrm{SO} 6_{5} \rightarrow 5_{4}$ & $1.45(0.07)$ & $2.07(0.01)$ & $1.83(0.03)$ \\
\hline 259412 & $\mathrm{H}^{13} \mathrm{CN} 3 \rightarrow 2^{b}$ & $1.65(0.21)$ & $2.50(0.25)$ & $1.10(0.06)$ \\
\hline 260455 & $\mathrm{H}^{13} \mathrm{CO}^{+} 3 \rightarrow 2^{b}$ & $2.00(0.04)$ & $2.12(0.04)$ & $1.52(0.03)$ \\
\hline 262404 & $\mathrm{C}_{2} \mathrm{H} N=3 \rightarrow 2 \mathrm{~J}=7 / 2 \rightarrow 5 / 2^{b}$ & $14.59(0.60)$ & $15.60(0.60)$ & $12.89(0.47)$ \\
\hline
\end{tabular}

Notes. ${ }^{(a)}$ The profile shows self-absorption; ${ }^{(t)}$ tentative detection; ${ }^{(b)}$ obtained by degrading the HERA maps to the angular resolution of the $3 \mathrm{~mm}$ lines. 
Table A.2. Summary of recombination lines.

\begin{tabular}{|c|c|c|c|c|c|}
\hline \multicolumn{6}{|c|}{ IF $\left(0^{\prime \prime}, 0^{\prime \prime}\right)$} \\
\hline Freq $(\mathrm{MHz})$ & Line & $I\left(\mathrm{~K} \mathrm{~km} \mathrm{~s}^{-1}\right)$ & $v_{\mathrm{lsr}}\left(\mathrm{km} \mathrm{s}^{-1}\right)$ & $\Delta v\left(\mathrm{~km} \mathrm{~s}^{-1}\right)$ & $T_{\mathrm{MB}}(\mathrm{K})$ \\
\hline 83301.829 & $\mathrm{H}(66) \delta$ & $1.23(0.11)$ & $13.3(1.3)$ & $27.8(2.9)$ & 0.04 \\
\hline 84314.394 & $\mathrm{H}(60) \gamma$ & $2.26(0.12)$ & $11.8(0.8)$ & $30.7(1.8)$ & 0.07 \\
\hline 85388.390 & $\mathrm{H}(42) \alpha$ & $15.97(0.13)$ & $12.4(0.1)$ & $30.9(0.28)$ & 0.48 \\
\hline 85331.144 & $\mathrm{C}(42) \alpha$ & $0.23(0.06)$ & $12.2(1.6)$ & $9.0(2.9)$ & 0.02 \\
\hline 86388.417 & $\mathrm{H}(70) \epsilon$ & $0.95(0.12)$ & $14.8(2.6)$ & $36.9(5.5)$ & 0.02 \\
\hline 86389.621 & $\mathrm{H}(74) \zeta$ & $0.99(0.17)$ & $8.2(2.7)$ & $32.5(8.0)$ & 0.03 \\
\hline 87314.996 & $\mathrm{H}(65) \delta$ & $1.86(0.08)$ & $9.7(0.7)$ & $30.3(1.5)$ & 0.06 \\
\hline 88305.687 & $\mathrm{H}(52) \beta$ & $6.77(0.08)$ & $9.3(0.2)$ & $34.2(0.5)$ & 0.19 \\
\hline 89398.545 & $\mathrm{H}(59) \gamma$ & $2.50(0.21)$ & $7.2(1.1)^{a}$ & $26.8(2.5)$ & 0.09 \\
\hline 90364.065 & $\mathrm{H}(73) \zeta^{b}$ & $0.63(0.10)$ & $9.8(2.3)$ & $31.0(7.0)$ & 0.02 \\
\hline 90374.339 & $\mathrm{H}(69) \epsilon^{b}$ & $0.98(0.12)$ & $8.4(1.3)$ & $32.0(3.0)$ & 0.03 \\
\hline 91363.133 & $\mathrm{H}(64) \delta$ & $1.86(0.11)$ & $9.0(1.0)$ & $33.2(2.0)$ & 0.05 \\
\hline 92334.434 & $\mathrm{H}(41) \alpha$ & $20.45(0.17)$ & $9.6(0.2)$ & $30.8(0.3)$ & 0.62 \\
\hline 92380.355 & $\mathrm{C}(41) \alpha^{t}$ & $0.38(0.08)$ & $7.0(1.2)$ & 11.7(3.1) & 0.03 \\
\hline 93307.316 & $\mathrm{H}(51) \beta$ & $6.04(0.10)$ & $9.8(0.3)$ & $30.9(0.6)$ & 0.18 \\
\hline 93375.871 & $\mathrm{H}(58) \gamma$ & $2.77(0.17)$ & $8.7(0.9)$ & $30.5(2.1)$ & 0.08 \\
\hline 93326.790 & $\mathrm{H}(72) \zeta$ & $0.89(0.09)$ & $10.7(1.5)$ & $29.6(3.8)$ & 0.03 \\
\hline 94372.811 & $\mathrm{H}(68) \epsilon$ & $1.03(0.07)$ & $11.4(0.9)$ & $26.8(2.1)$ & 0.04 \\
\hline 103414.838 & $\mathrm{H}(56) \gamma$ & $3.02(0.07)$ & $12.6(0.4)$ & $33.0(0.9)$ & 0.09 \\
\hline 105401.857 & $\mathrm{H}(49) \beta$ & $6.22(0.10)$ & $12.4(0.3)$ & $31.5(0.6)$ & 0.19 \\
\hline 105410.216 & $\mathrm{H}(61) \delta$ & $1.70(0.07)$ & $12.7(0.7)$ & $29.5(1.4)$ & 0.05 \\
\hline 106479.529 & $\mathrm{H}(69) \zeta$ & $0.71(0.09))$ & $14.0(1.9)$ & $28.8(4.1)$ & 0.02 \\
\hline 106437.357 & $\mathrm{H}(39) \alpha$ & $18.80(0.11)$ & $12.53(0.09)$ & $31.0(0.2)$ & 0.57 \\
\hline 107406.108 & $\mathrm{H}(65) \epsilon$ & $1.23(0.12)$ & $10.31(1.8)$ & $35.5(3.9)$ & 0.03 \\
\hline 109436.001 & $\mathrm{H}(55) \gamma$ & $3.25(0.10)$ & $12.5(0.5)$ & $33.5(1.2)$ & 0.09 \\
\hline 110400.675 & $\mathrm{H}(60) \delta$ & $1.66(0.13)$ & $10.4(1.3)$ & $34.0(3.2)$ & 0.04 \\
\hline 209494.050 & $\mathrm{H}(44) \gamma$ & $2.37(0.16)$ & $13.3(1.1)$ & $31.6(2.6)$ & 0.07 \\
\hline 210401.771 & $\mathrm{H}(31) \alpha^{c}$ & $15.18(0.20)$ & $13.7(0.3)$ & $33.0(0.4)$ & 0.43 \\
\hline \multicolumn{6}{|c|}{ MP1 $\left(15^{\prime \prime},-15^{\prime \prime}\right)$} \\
\hline Freq $(\mathrm{MHz})$ & Line & $I\left(\mathrm{~K} \mathrm{~km} \mathrm{~s}^{-1}\right)$ & $v_{\mathrm{lsr}}\left(\mathrm{km} \mathrm{s}^{-1}\right)$ & $\Delta v\left(\mathrm{~km} \mathrm{~s}^{-1}\right)$ & $T_{\mathrm{MB}}(\mathrm{K})$ \\
\hline 83301.829 & $\mathrm{H}(66) \delta$ & $0.24(0.06)$ & $16.1(2.4)$ & $\begin{array}{l}17.0(4.9) \\
\end{array}$ & 0.01 \\
\hline 84314.394 & $\mathrm{H}(60) \gamma$ & $0.70(0.04)$ & $15.8(0.9)$ & $31.5(1.8)$ & 0.02 \\
\hline 85388.390 & $\mathrm{H}(42) \alpha$ & $4.08(0.13)$ & $15.3(0.5)$ & $29.7(1.2)$ & 0.13 \\
\hline 85331.144 & $\mathrm{C}(42) \alpha$ & $0.22(0.03)$ & $8.7(0.7)$ & $12.0(1.7)$ & 0.02 \\
\hline 87314.996 & $\mathrm{H}(65) \delta$ & $0.41(0.09)$ & $10.0(4.2)$ & $35.7(8.5)$ & 0.01 \\
\hline 88305.687 & $\mathrm{H}(52) \beta$ & $1.01(0.07)$ & $14.2(0.9)$ & $27.2(2.2)$ & 0.03 \\
\hline 91363.133 & $\mathrm{H}(64) \delta$ & $0.52(0.08)$ & $18.0(2.3)$ & $26.7(4.5)$ & 0.02 \\
\hline 92334.434 & $\mathrm{H}(41) \alpha$ & $4.01(0.18)$ & $12.8(0.7)$ & $33.9(1.8)$ & 0.11 \\
\hline 93307.316 & $\mathrm{H}(51) \beta$ & $1.06(0.08)$ & $14.5(1.3)$ & $34.2(3.0)$ & 0.03 \\
\hline 93375.871 & $\mathrm{H}(58) \gamma$ & $0.56(0.09)$ & $15.6(2.9)$ & $33.8(5.8)$ & 0.016 \\
\hline 103414.838 & $\mathrm{H}(56) \gamma$ & $0.46(0.07)$ & $18.3(2.7)$ & $40.1(7.2)$ & 0.01 \\
\hline 105401.857 & $\mathrm{H}(49) \beta$ & $0.66(0.06)$ & $17.1(1.3)$ & $27.3(3.3)$ & 0.02 \\
\hline 106437.357 & $\mathrm{H}(39) \alpha$ & $2.33(0.07)$ & $16.4(0.5)$ & $31.5(1.1)$ & 0.07 \\
\hline \multicolumn{6}{|c|}{ MP2 $\left(0^{\prime \prime}, 40^{\prime \prime}\right)$} \\
\hline Freq $(\mathrm{MHz})$ & Line & $I\left(\mathrm{~K} \mathrm{~km} \mathrm{~s}^{-1}\right)$ & $v_{\mathrm{lsr}}\left(\mathrm{km} \mathrm{s}^{-1}\right)$ & $\Delta v\left(\mathrm{~km} \mathrm{~s}^{-1}\right)$ & $T_{\mathrm{MB}}(\mathrm{K})$ \\
\hline 85388.390 & $\mathrm{H}(42) \alpha$ & $0.89(0.16)$ & $11.0(2.1)$ & $23.2(4.8)$ & 0.04 \\
\hline 88305.687 & $\mathrm{H}(52) \beta$ & $0.47(0.06)$ & $9.3(2.2)$ & $35.0(5.3)$ & 0.01 \\
\hline 92334.434 & $\mathrm{H}(41) \alpha$ & $1.39(0.05)$ & $6.7(0.6)$ & $33.4(1.4)$ & 0.04 \\
\hline 93307.316 & $\mathrm{H}(51) \beta$ & $0.35(0.08)$ & $6.6(2.7)$ & $29.6(10.7)$ & 0.01 \\
\hline 105401.857 & $\mathrm{H}(49) \beta$ & $0.39(0.05)$ & $9.4(2.4)$ & $33.4(4.4)$ & 0.01 \\
\hline 106437.357 & $\mathrm{H}(39) \alpha$ & $0.57(0.06)$ & $8.0(1.5)$ & $26.6(3.2)$ & 0.02 \\
\hline 209498.777 & $\mathrm{C}(44) \gamma$ & $0.51(0.11)$ & $19.1(0.9)$ & $8.2(1.8)$ & 0.06 \\
\hline
\end{tabular}

Notes. ${ }^{(a)}$ Overlapped with the $\mathrm{HCO}^{+} J=1 \rightarrow 0$ line and self-absorbed; ${ }^{(b)}$ these two recombination lines are overlapped and the fit of the two each lines is uncertain; ${ }^{(t)}$ doubtful detection; ${ }^{(c)}$ this recombination line is contaminated by the emission of $\mathrm{C}^{18} \mathrm{O} J=2 \rightarrow 1$ from the image band. 
D. Ginard et al.: Spectral line survey of the ultracompact HII region Mon R2
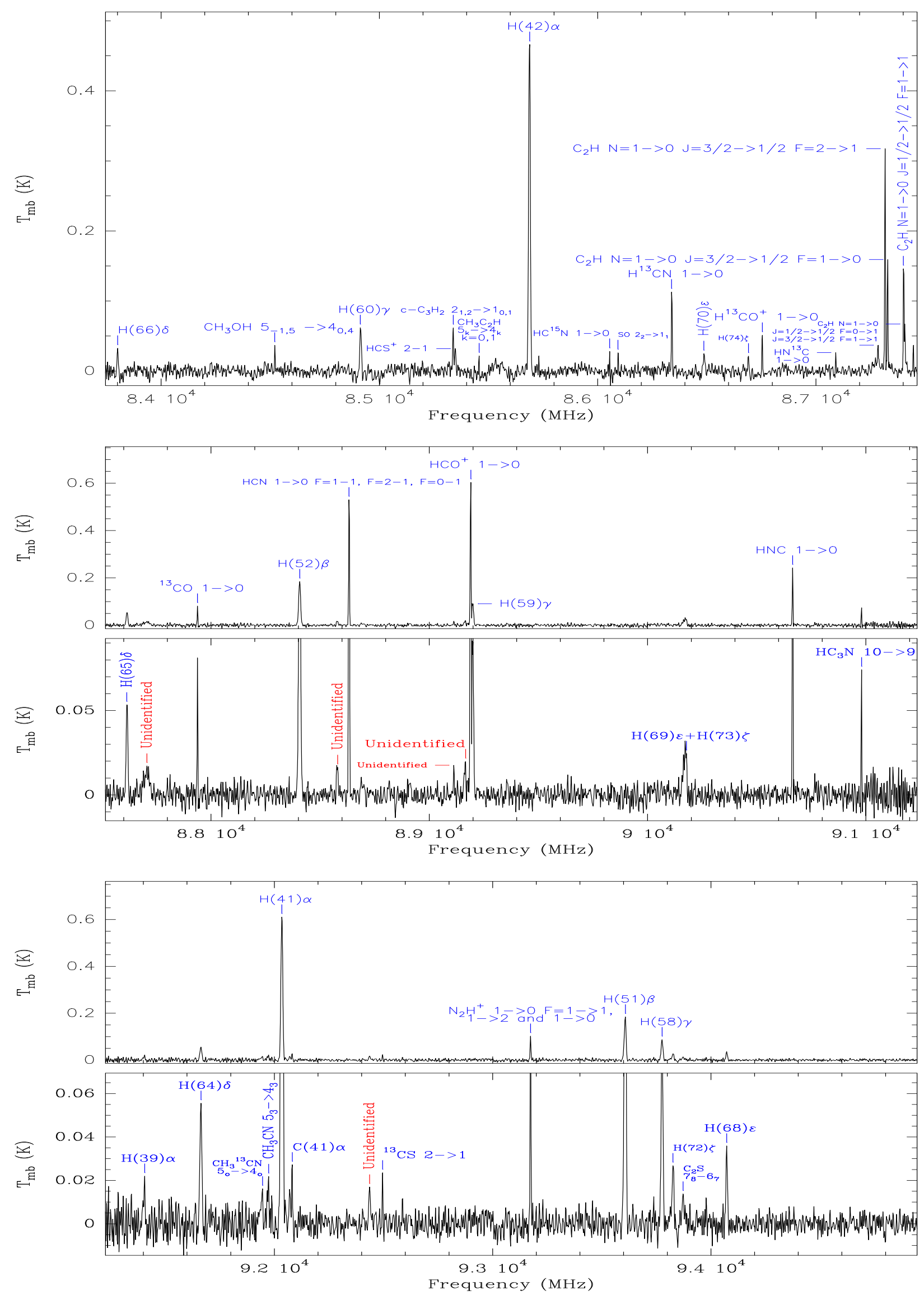

Fig. A.1. Identified lines in the observation for an offset $\left(0^{\prime \prime}, 0^{\prime \prime}\right)$. Blue labels are lines detected in the signal band, green labels are lines identified in the image band, and red labels are lines detected but not identified. 
A\&A 543, A27 (2012)
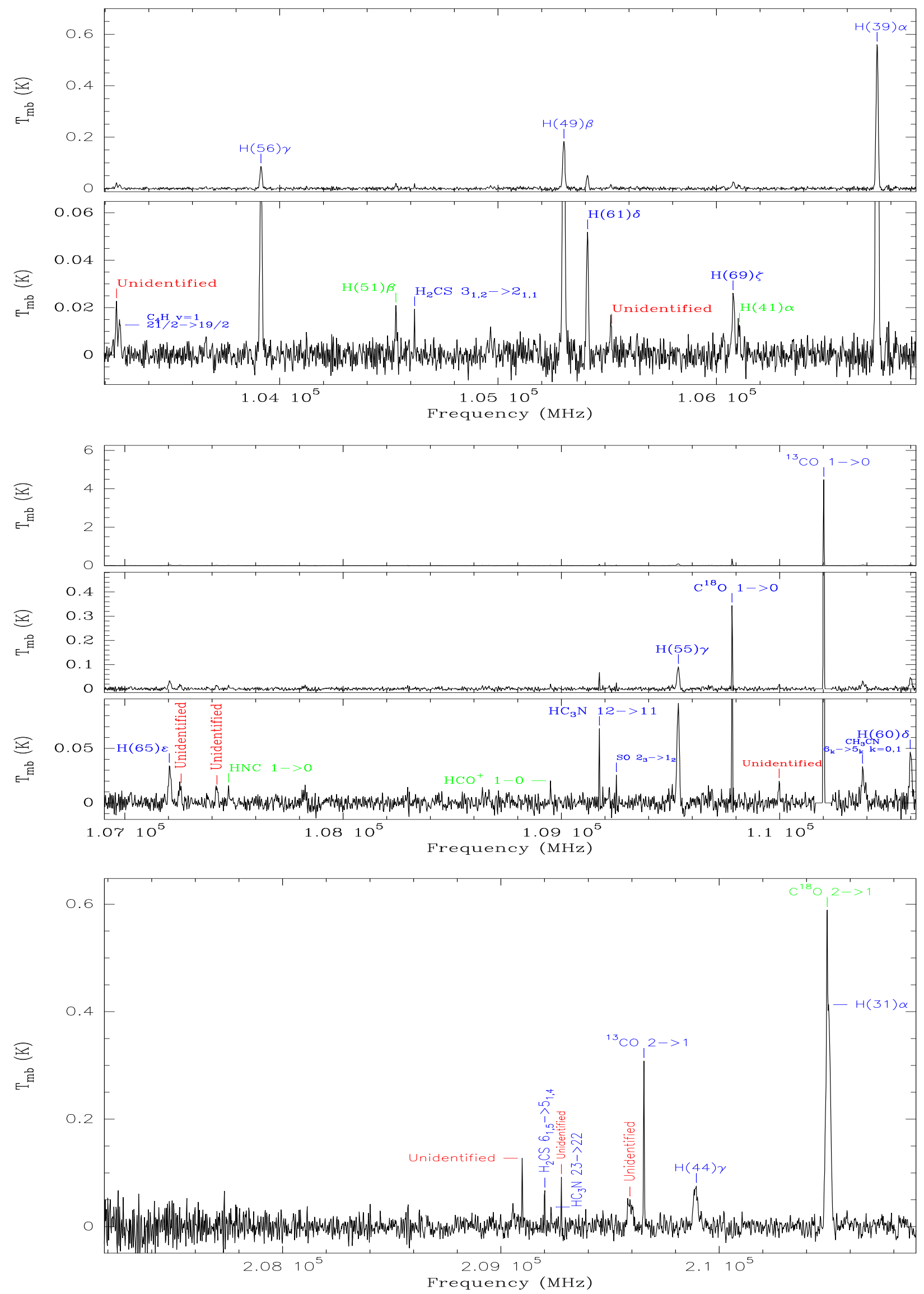

Fig. A.1. continued. 
D. Ginard et al.: Spectral line survey of the ultracompact HII region Mon R2
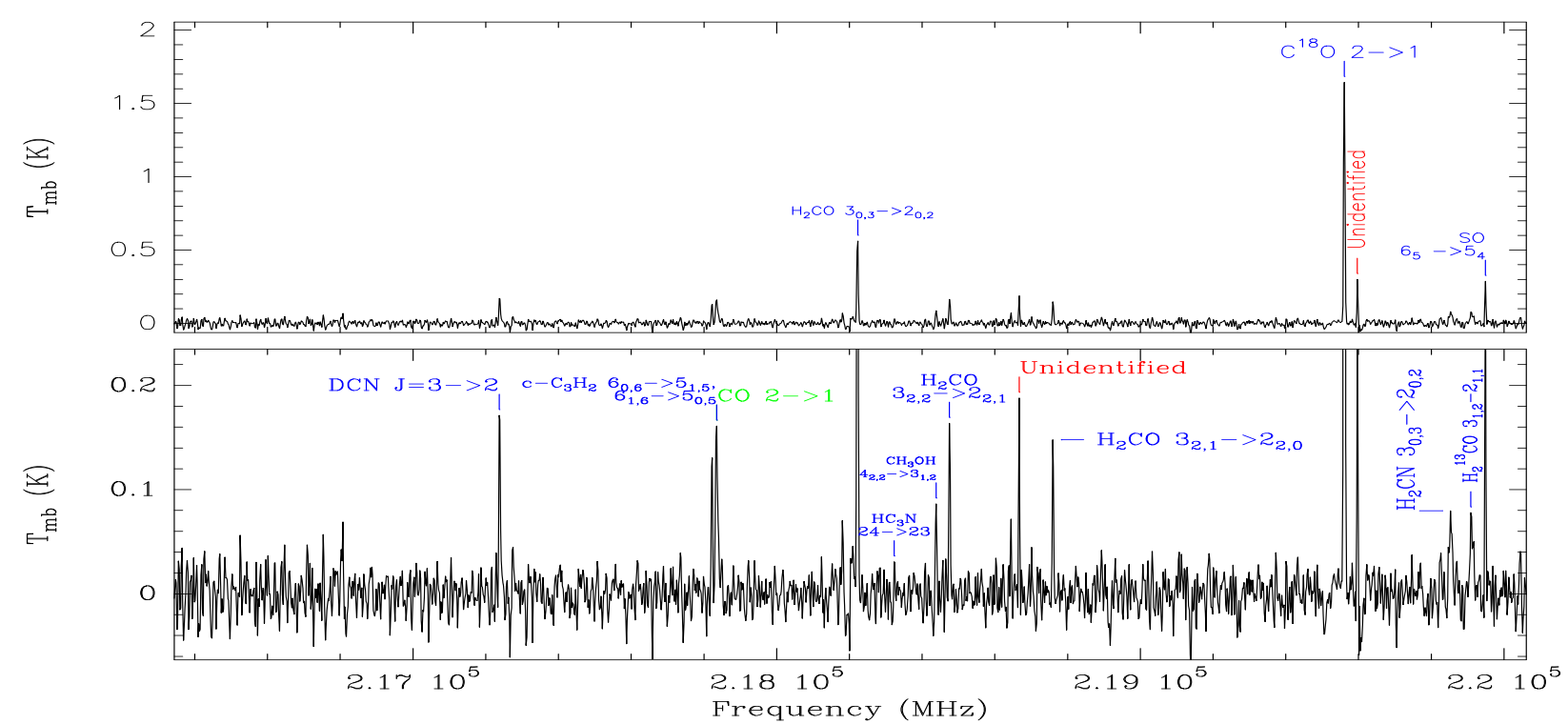

Fig. A.1. continued. 
A\&A 543, A27 (2012)
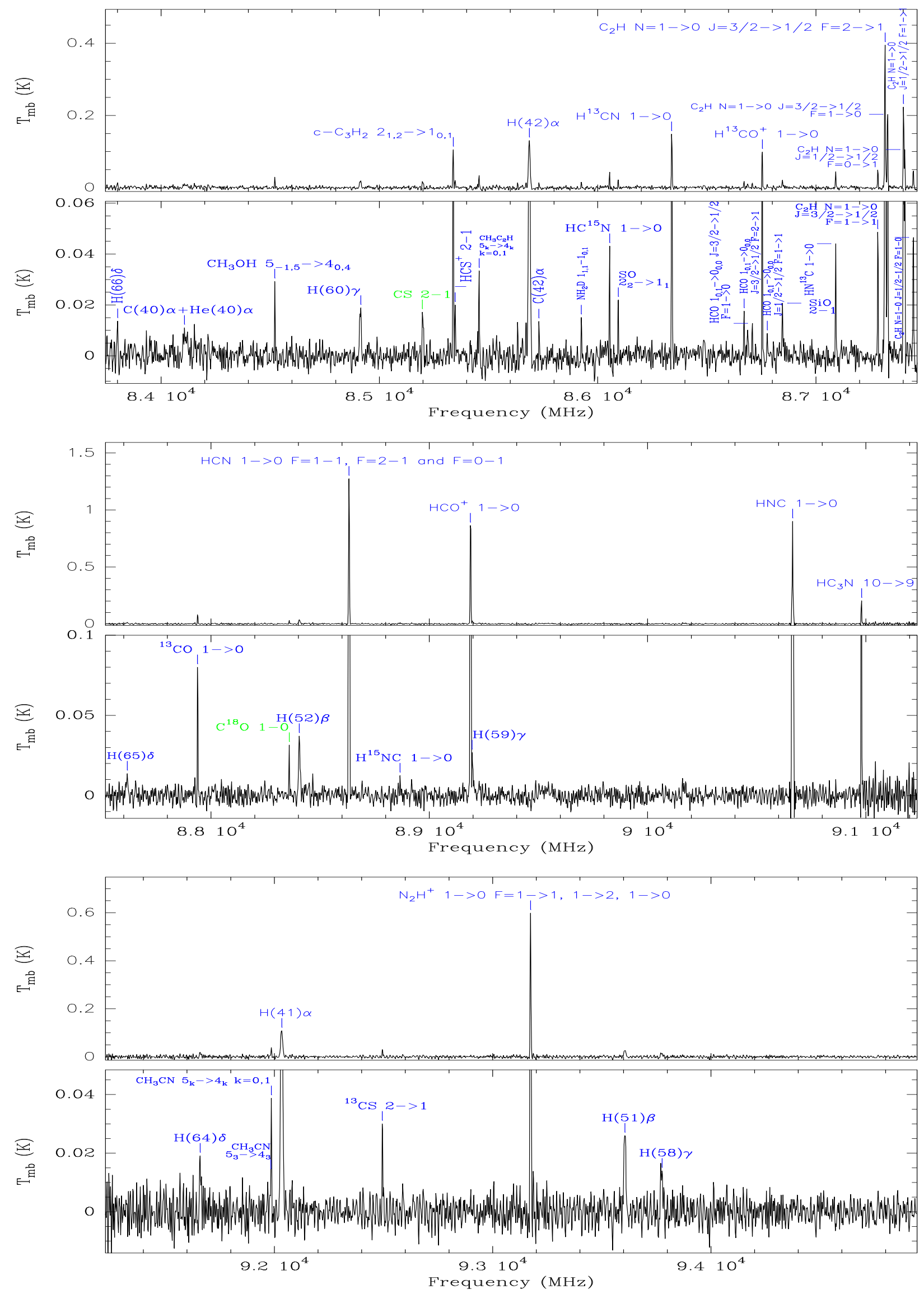

Fig. A.2. Identified lines in offset $\left(+15^{\prime \prime},-15^{\prime \prime}\right)$. Blue labels represent those lines detected in the signal band, green labels those lines identified in the image band, and red labels are lines detected but not identified. 
D. Ginard et al.: Spectral line survey of the ultracompact HII region Mon R2
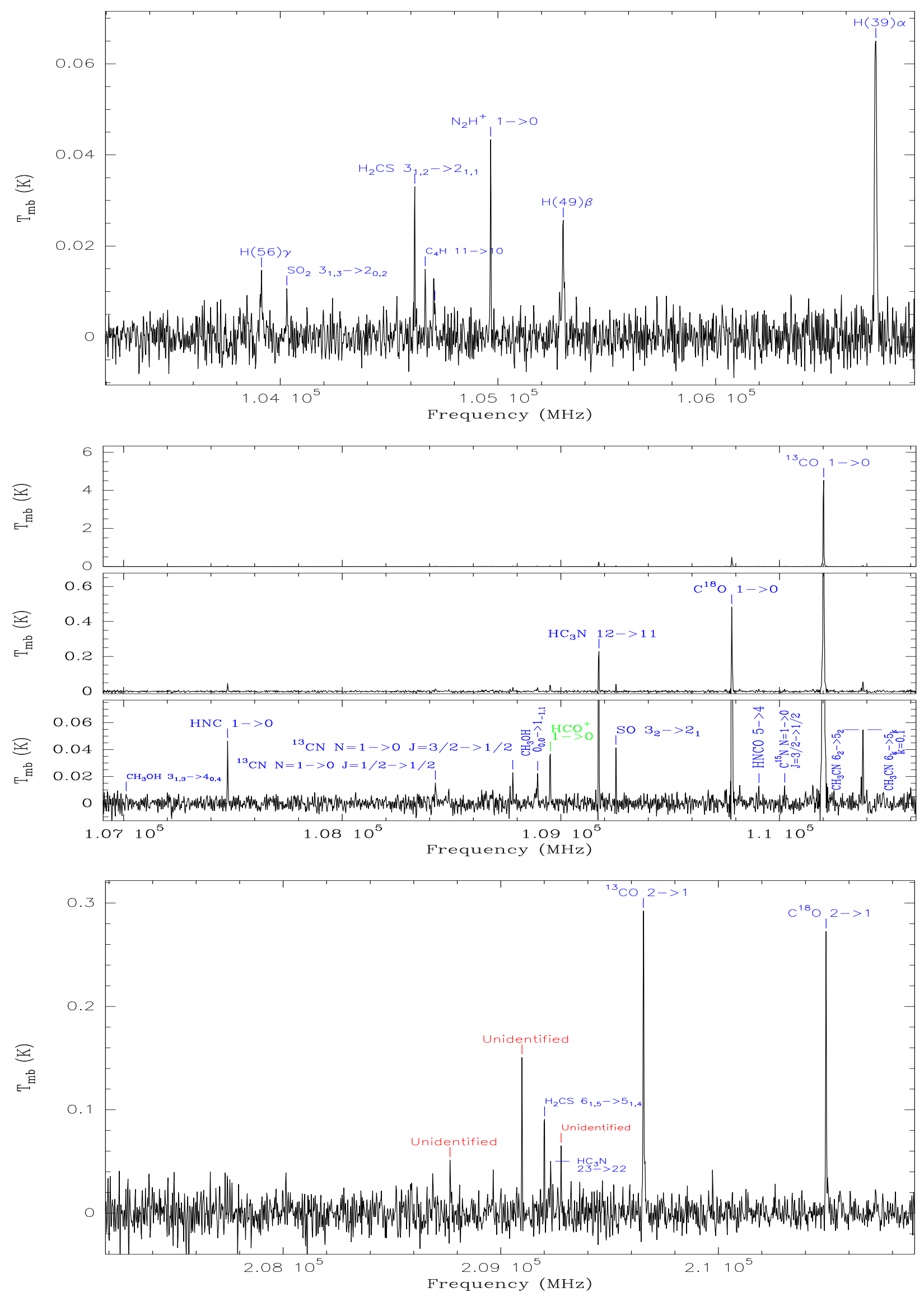

Fig. A.2. continued. 
A\&A 543, A27 (2012)

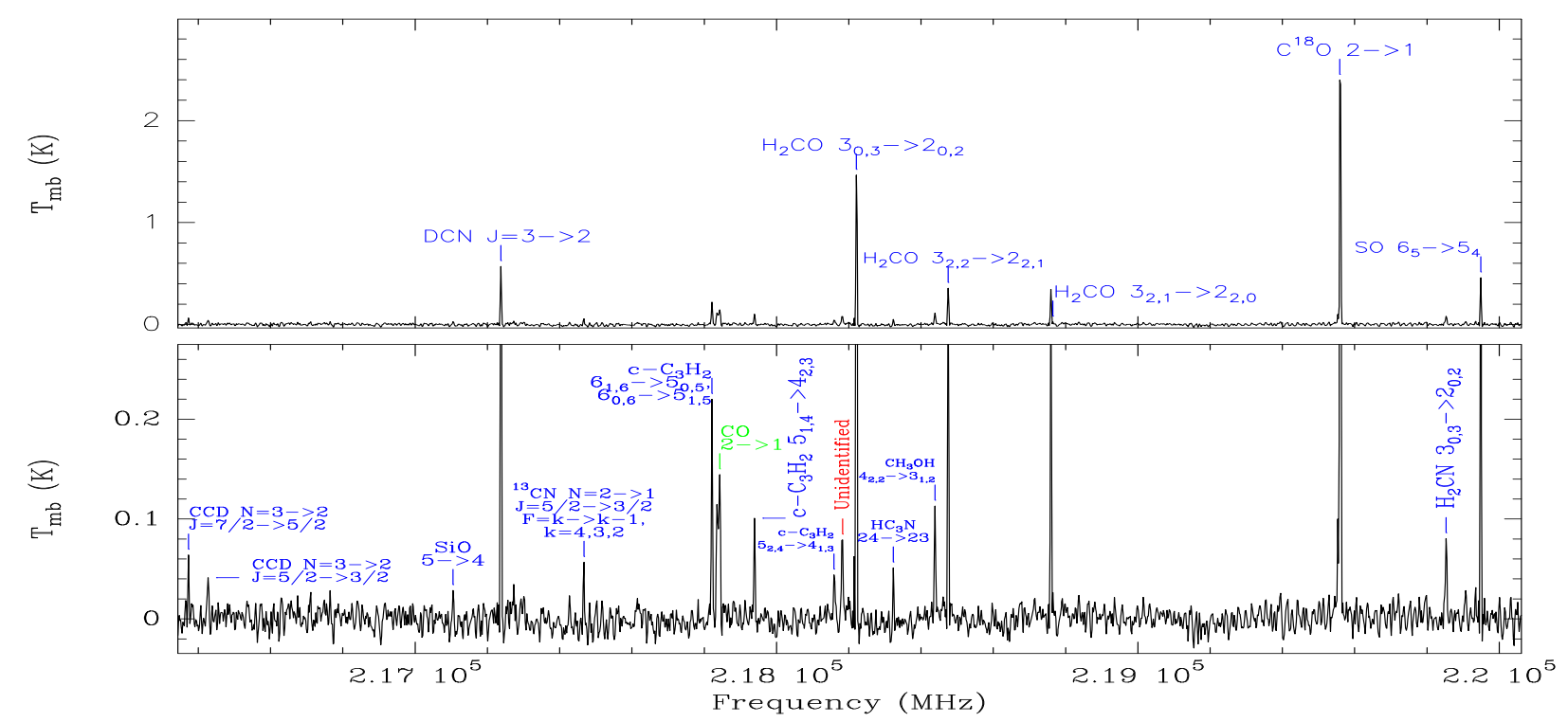

Fig. A.2. continued. 
D. Ginard et al.: Spectral line survey of the ultracompact HII region Mon R2
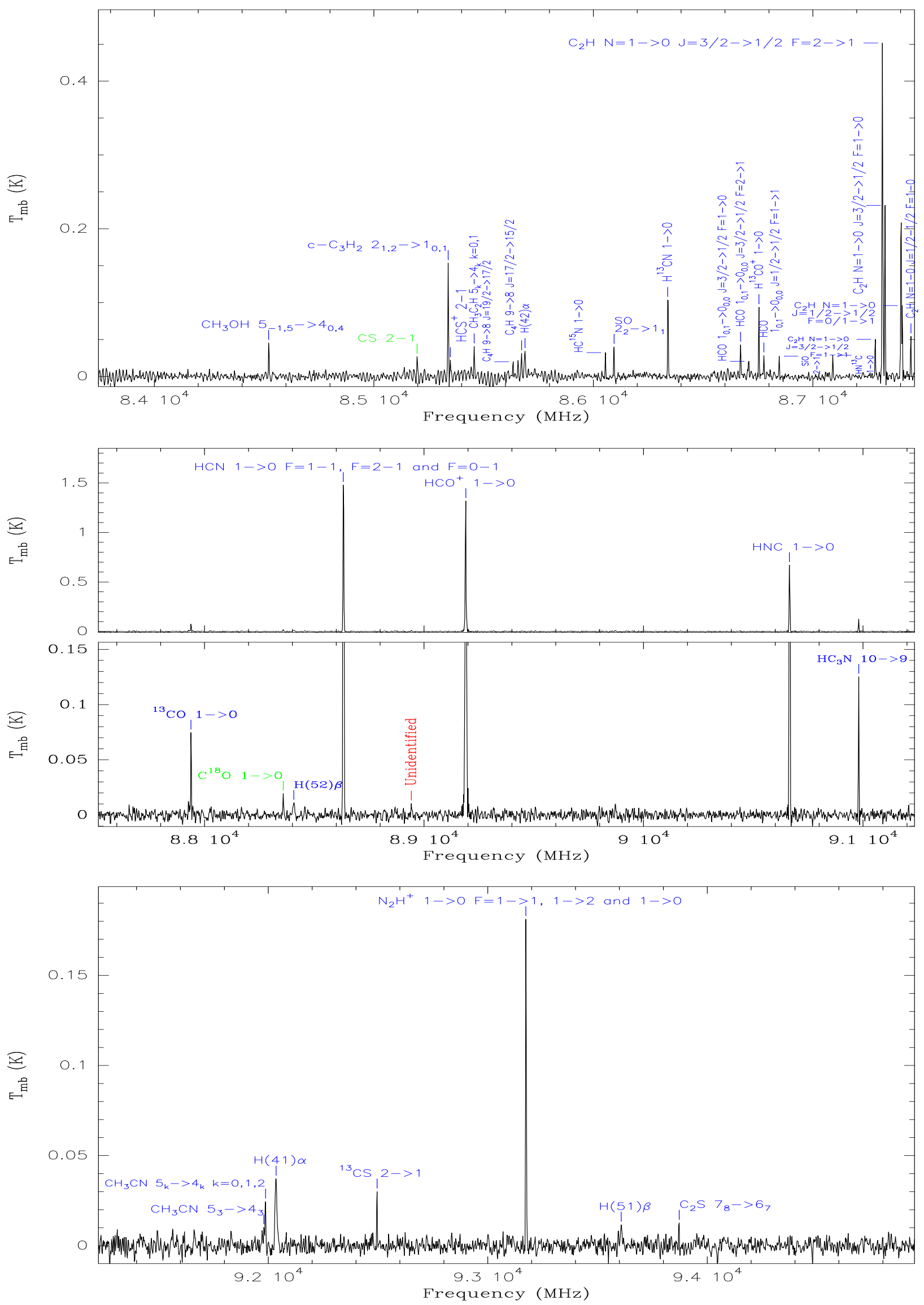

Fig. A.3. Identified lines in the observation for an offset $\left(0^{\prime \prime}, 40^{\prime \prime}\right)$. Blue labels indicate lines detected in signal band, green labels those lines identified in the image band, and red labels are lines detected but not identified. 
A\&A 543, A27 (2012)
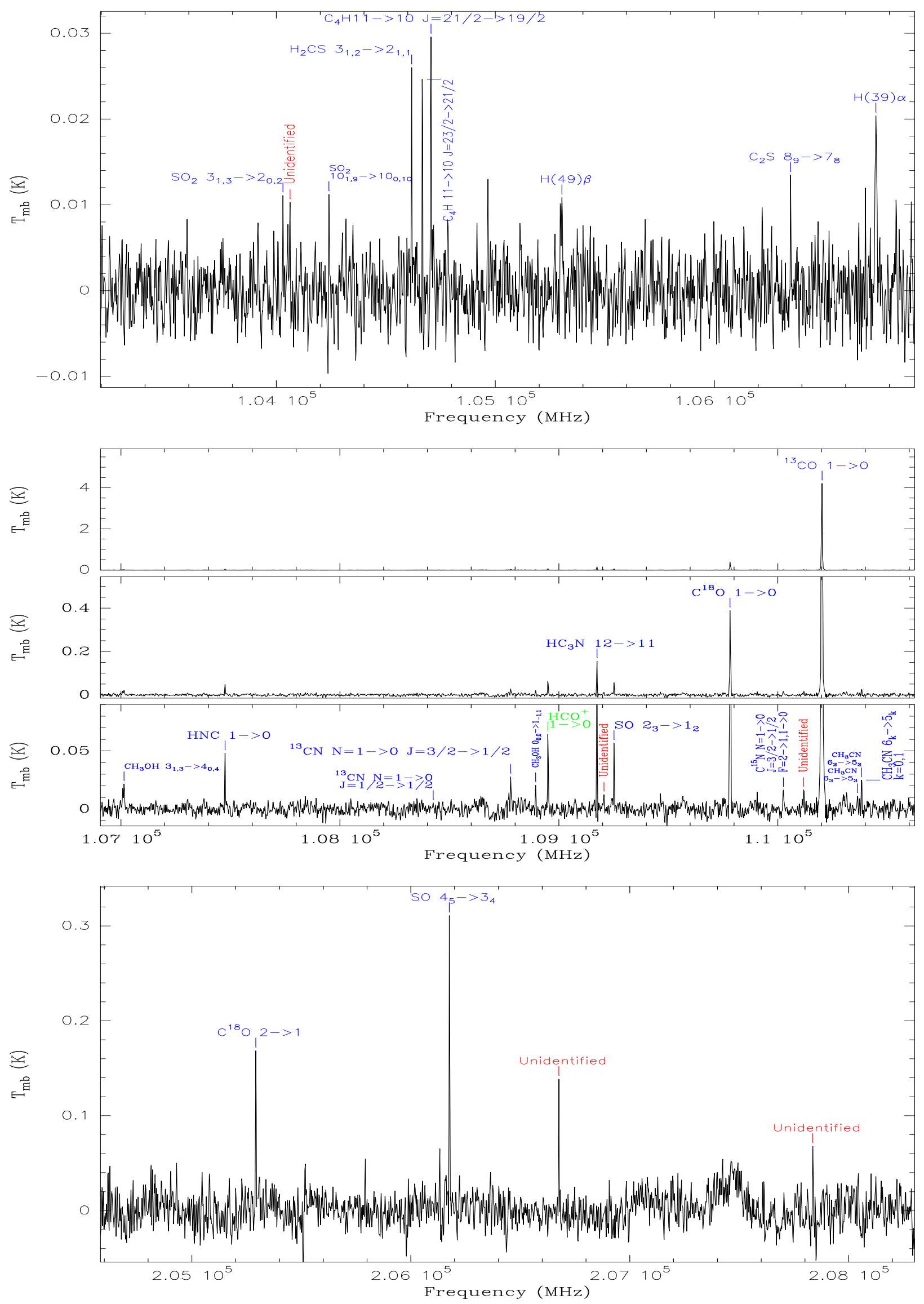

Fig. A.3. continued. 
D. Ginard et al.: Spectral line survey of the ultracompact HII region Mon R2

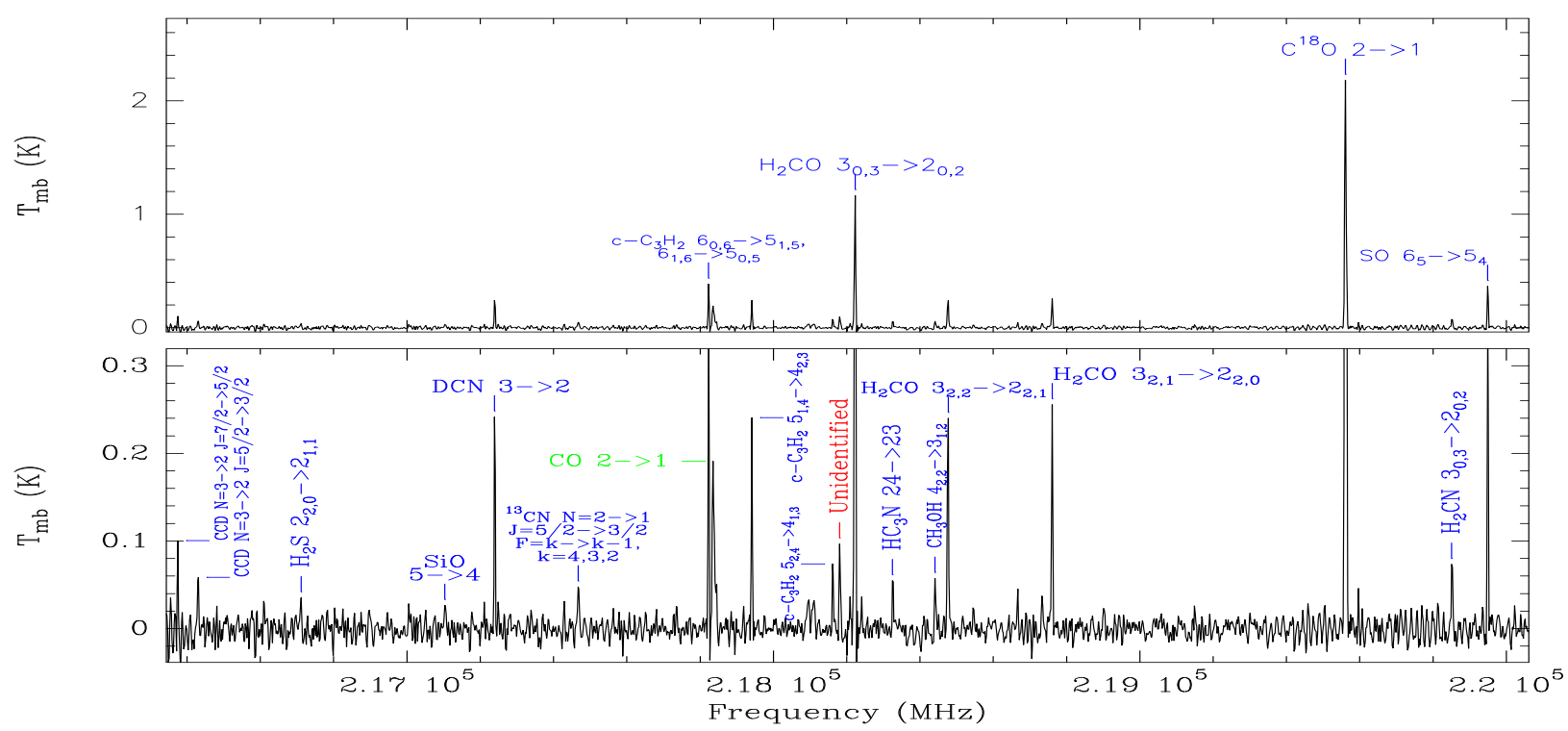

Fig. A.3. continued. 


\section{Appendix B: Rotational diagrams}
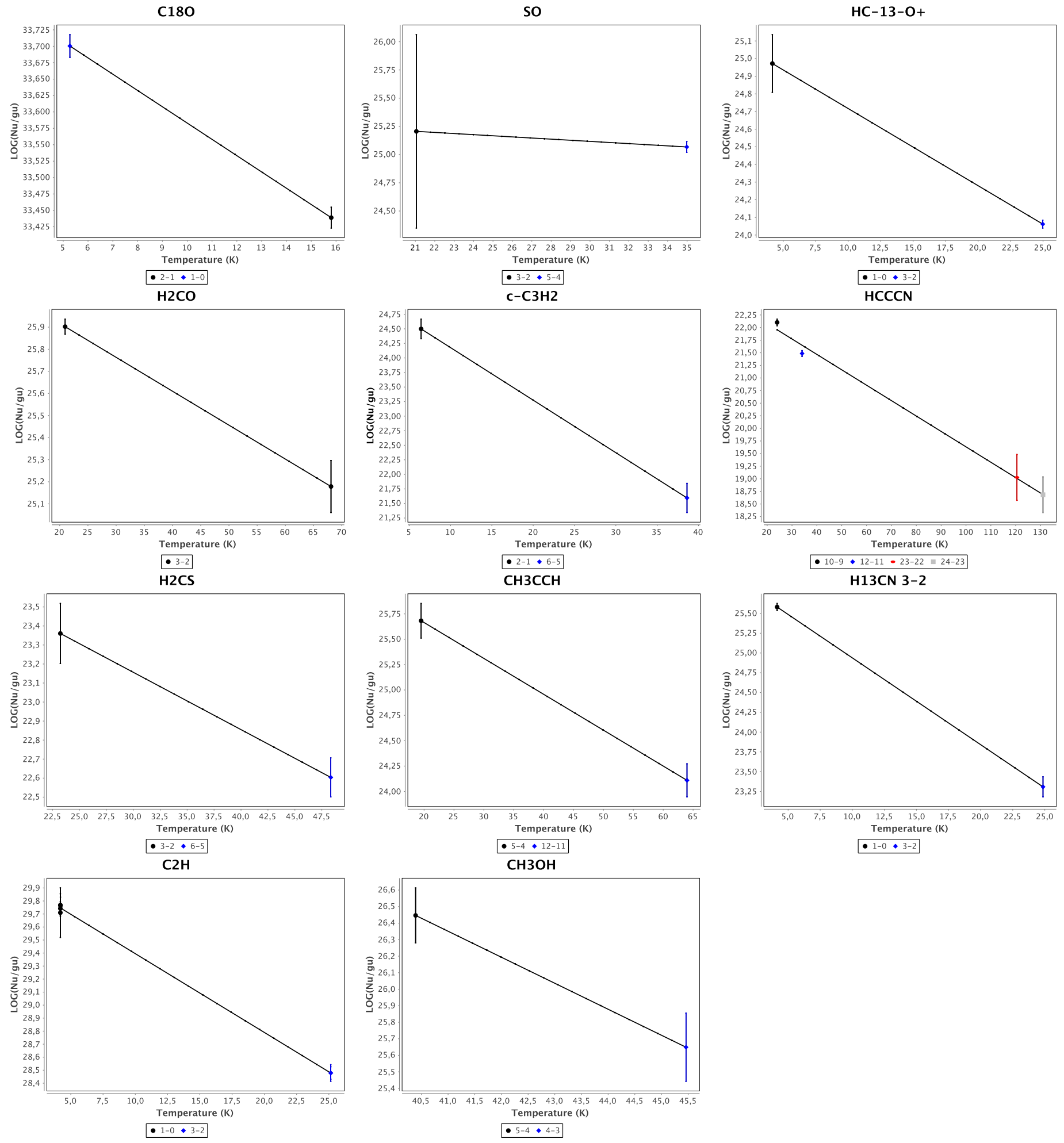

Fig. B.1. Rotational diagrams of the IF's most representative molecules (offset $\left(0^{\prime \prime}, 0^{\prime \prime}\right)$ ). 
D. Ginard et al.: Spectral line survey of the ultracompact HII region Mon R2
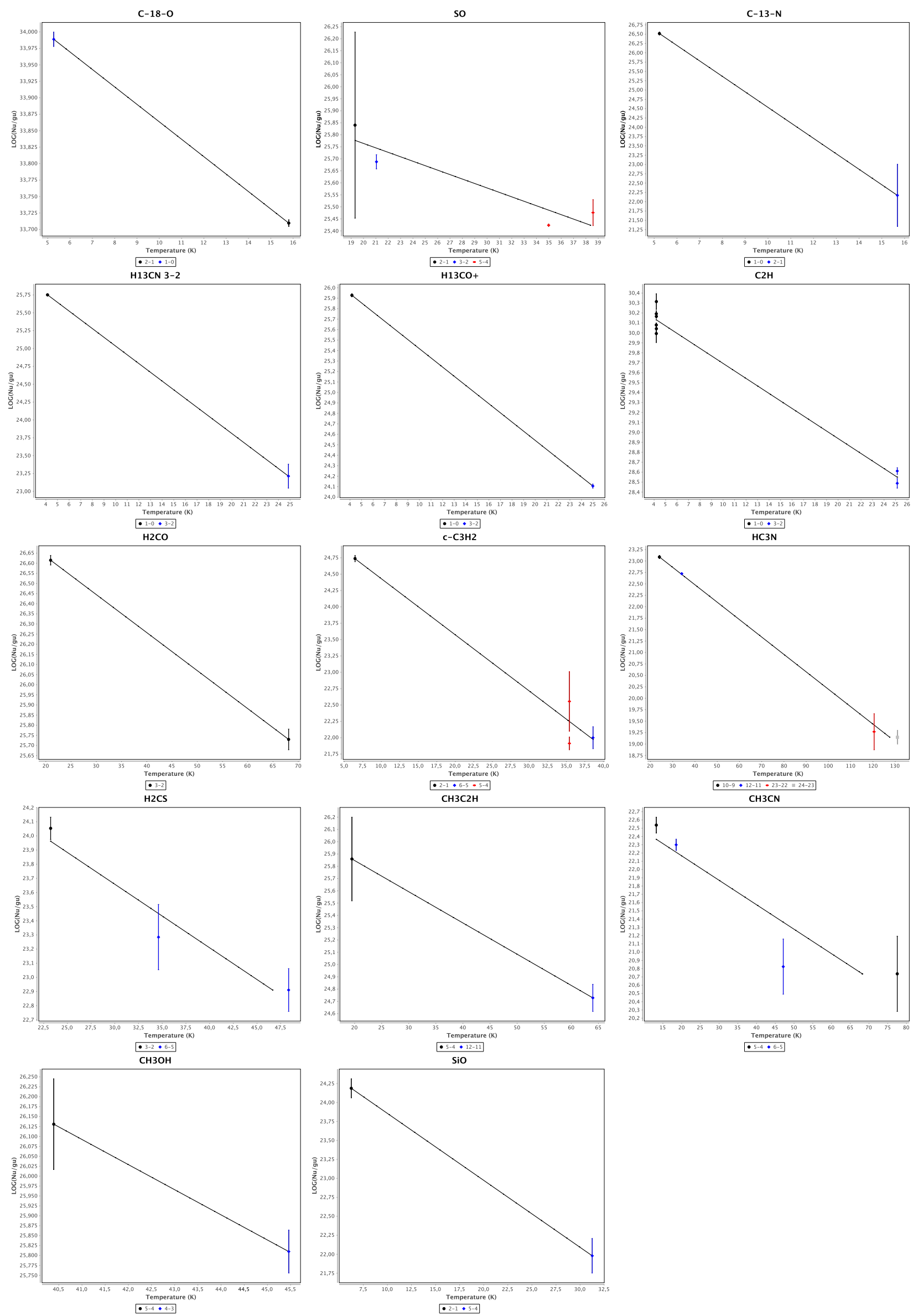

Fig. B.2. Rotational diagrams of the MP's most representative molecules (offset $\left(+15^{\prime \prime},-15^{\prime \prime}\right)$ ). 
A\&A 543, A27 (2012)
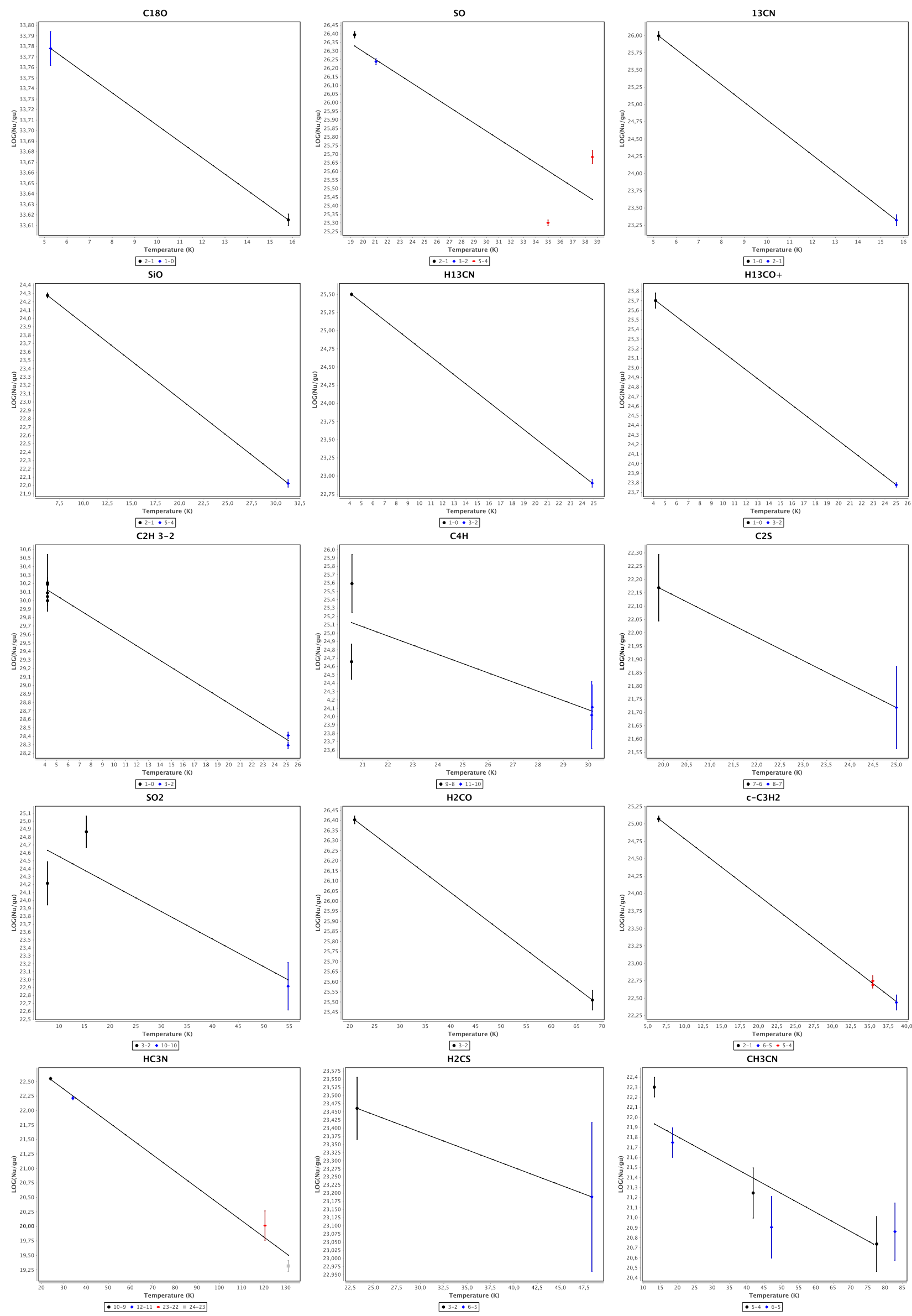

Fig. B.3. Rotational diagrams of the most representative molecules towards MP2 (offset $\left(+0^{\prime \prime},+40^{\prime \prime}\right)$ ). 
D. Ginard et al.: Spectral line survey of the ultracompact HII region Mon R2

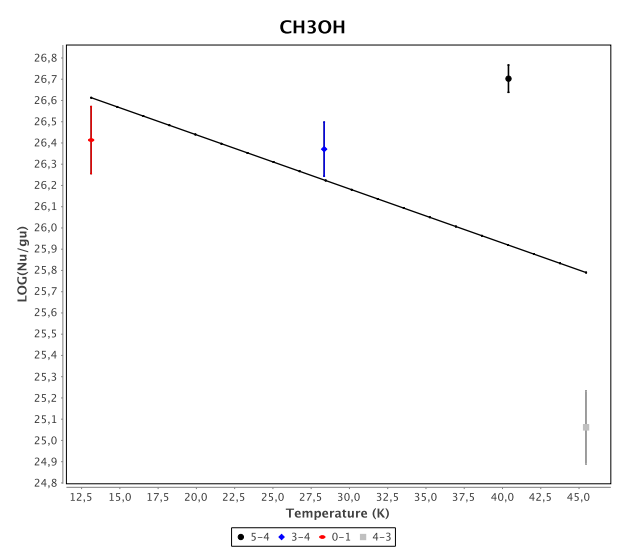

Fig. B.3. continued. 